\title{
Centrifuge Modeling of Lateral-Axial Oblique Loading on Buried Pipelines in Cohesionless Soil
}

\author{
by
}

Gabrielle Marcotte

A thesis submitted to the Faculty of Graduate and Postdoctoral Affairs in partial fulfillment of the requirements for the degree of

\author{
Master of Applied Science \\ in
}

The Department of Civil and Environmental Engineering

Carleton University

Ottawa, Ontario

(C) 2017, Gabrielle Marcotte 


\begin{abstract}
Pipelines may be subject to oblique loading conditions due to relative ground motion associated with geohazards including ground subsidence, slope movement/failure, frost heave and fault movement. Conventional guidelines for engineering stress analysis of pipe/soil interaction employ a series of orthogonal, independent springs, within structural based finite element modelling procedures, to represent soil reaction loads. This formulation does not properly account for coupled load effects during oblique pipe/soil interaction events as it is unable to account for the complex relationship between the soil and pipeline or the load effects induced by loading in multiple directions.
\end{abstract}

A series of reduced scale physical tests to investigate oblique load effects, in the lateral-axial plane, on a buried pipe in cohesionless soil were conducted using a rigid, $46 \mathrm{~mm}$ diameter pipe. The pipe was buried at two burial depths, H/D of 2 and 4, and was tested at five different angles between $0^{\circ}$ (pure axial) and $90^{\circ}$ (pure lateral). The shallow buried pipe modelled a prototype 304 $\mathrm{mm}$ diameter pipeline, and a prototype $609.5 \mathrm{~mm}$ diameter pipeline for the deeper burial depth.

Failure surfaces for the yield load compared favourably with previous physical tests and numerical simulations of oblique loading events. In addition, the mobilization distance to yield were comparable with previous reduced-scale tests but the results were more consistent with the ALA guidelines, which was attributed to the experimental procedures and use of acoustic foam to moderate spurious boundary conditions effects on the measured response. 


\section{Acknowledgements}

I would like first to like to thank Professors Shawn Kenny and Siva Sivathayalan for all of their help during this research. Their guidance and recommendations have helped me through the long research and writing process.

I also would not have been able to complete this research without the support and understanding of the staff of C-Core especially Mr. Gerry Piercy, and Mr. Karl Kuehnemund who helped me daily in the lab with set-up, testing, and advice and Mr. Karl Tuff who helped me with all of the electronics required during testing. Without the team at C-Core, their experience, and their centrifuge, this research would not have been possible.

I would also like to thank my friends and family, especially Murray and Oliver, who have encouraged me and provided emotional support during my research and the long writing process. 


\section{Table of Contents}

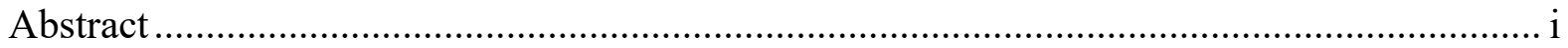

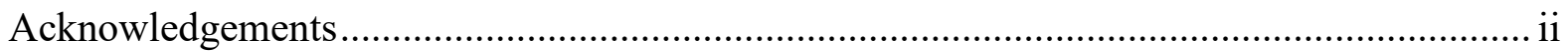

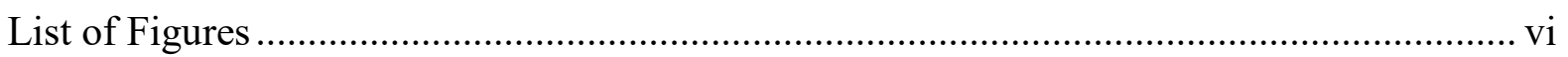

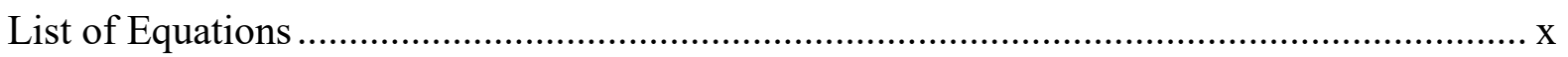

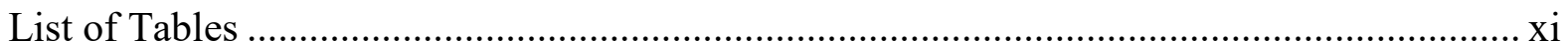

List of Abbreviations and Symbols.................................................................................. xii

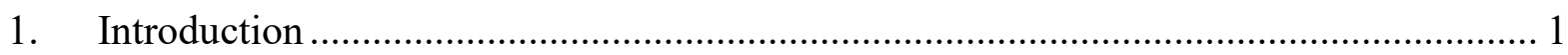

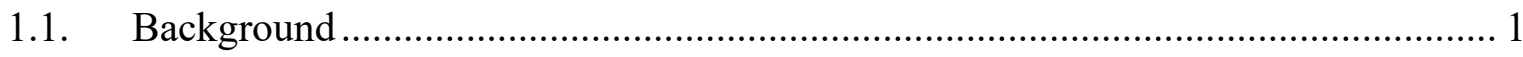

1.2. Problem Statement ........................................................................................ 2

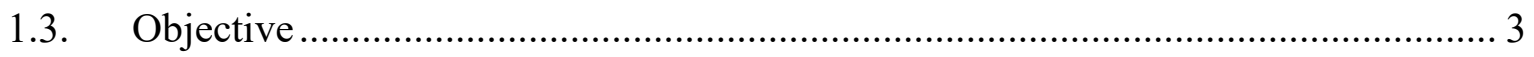

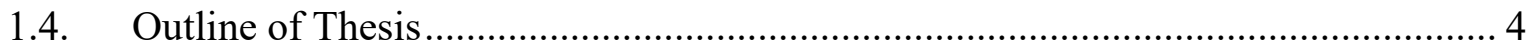

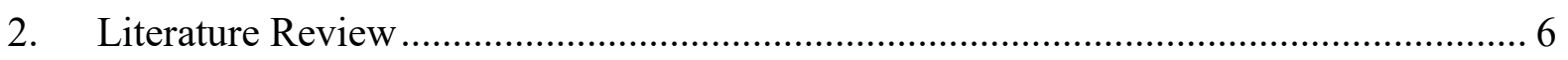

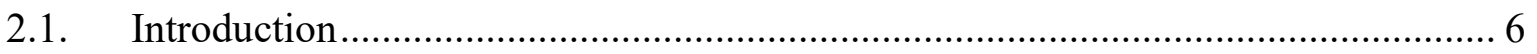

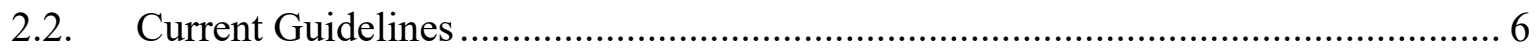

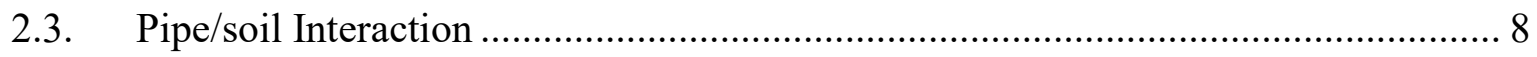

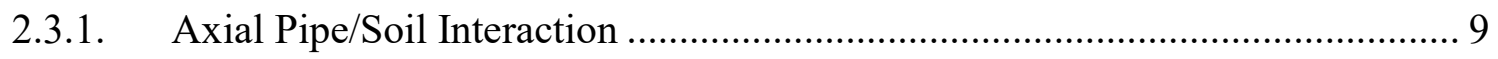

2.3.2. Lateral Pipe/Soil Interaction ..................................................................... 12

2.3.3. Vertical Pipe/Soil Interaction ...................................................................... 14

2.3.4. Axial-Lateral Pipe/Soil Interaction................................................................. 16 
2.4. Centrifuge Modeling Background .................................................................. 18

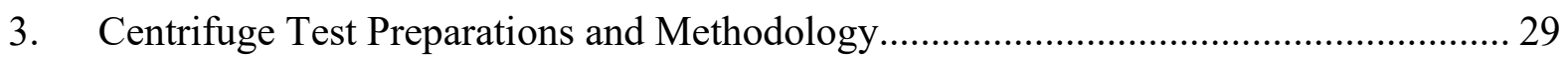

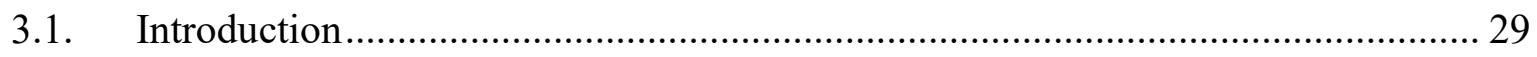

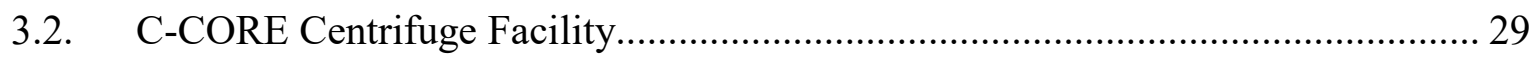

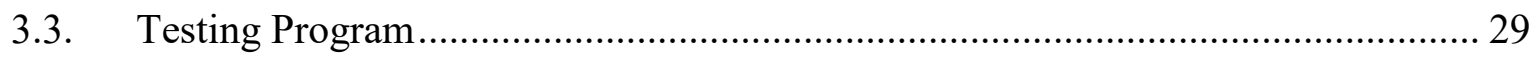

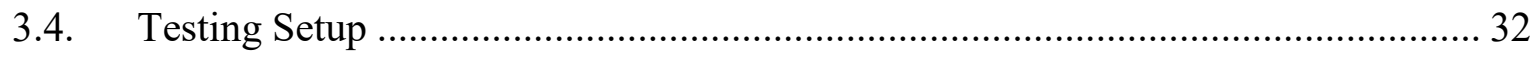

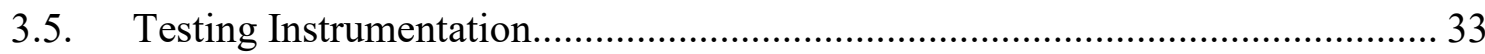

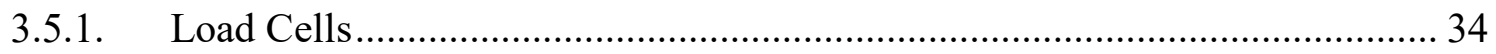

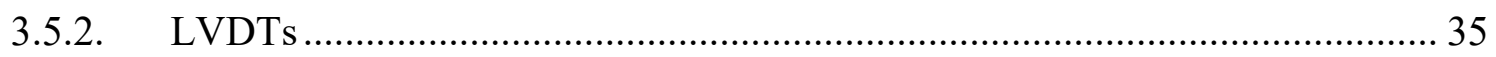

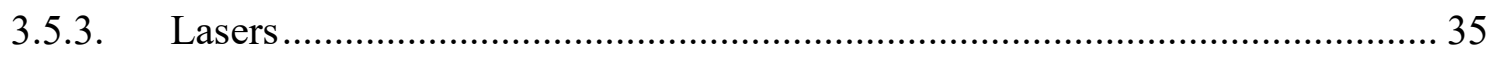

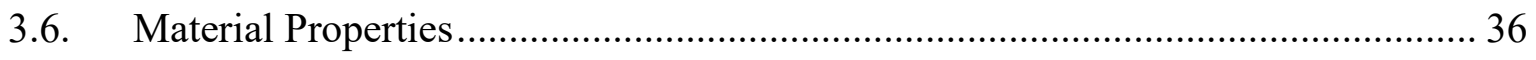

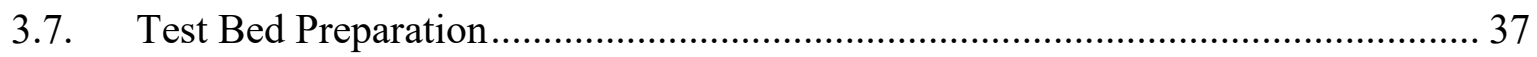

3.7.1. Cone Penetration Tests ................................................................................. 38

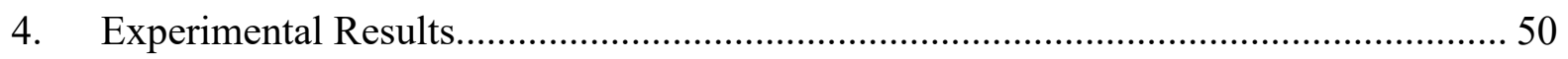

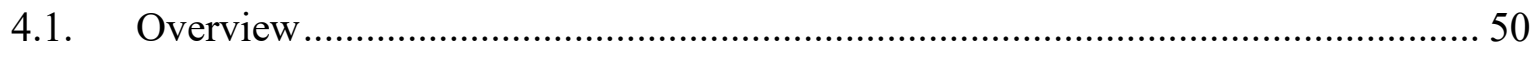

4.2. Pipe Mobilization....................................................................................... 52

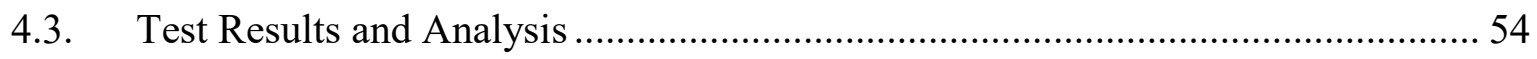

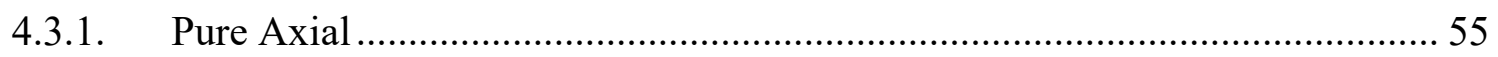

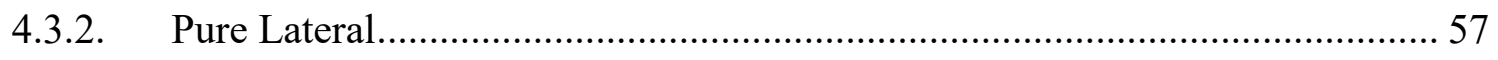

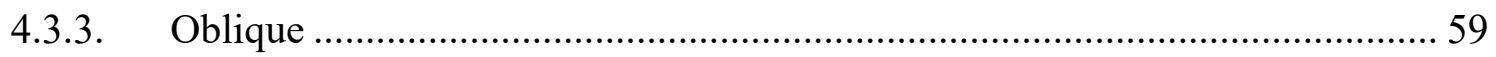


4.3.4. Uplift.

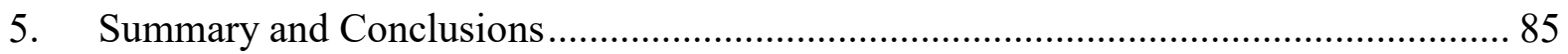

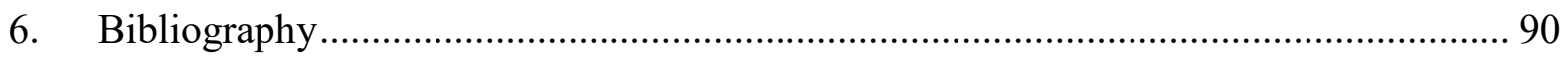

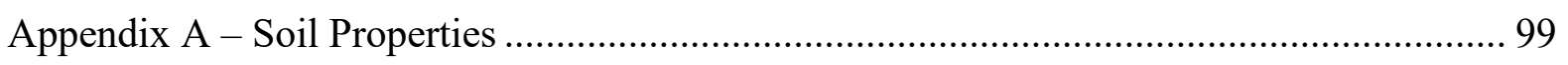

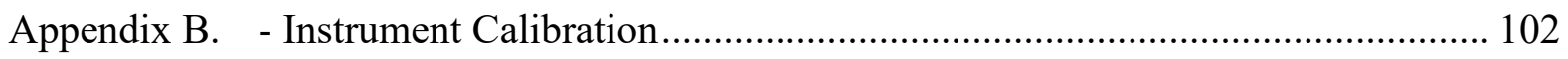

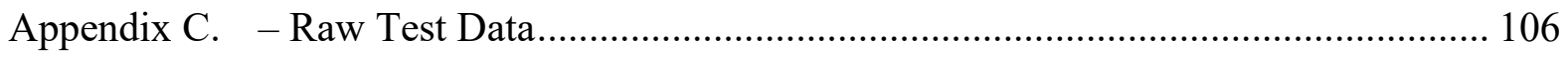

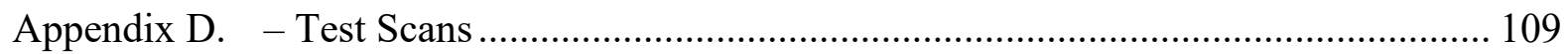

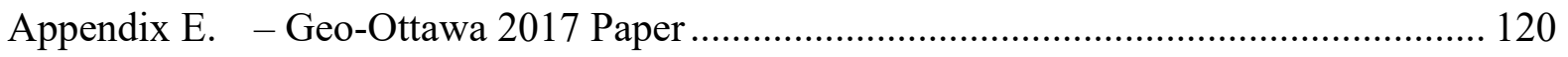




\section{List of Figures}

Figure 2-1 - Current Pipeline Model Approach (from Kenny and Jukes, 2015)

Figure 2-2 - Common measurement for buried pipeline including pipe diameter (D), cover depth

(c), burial depth $(\mathrm{H})$, and embedment depth (h). 21

Figure 2-3- Lateral bearing capacity fit curve (Honegger and Nyman, 2004) 22

Figure 2-4- Lateral bearing force comparison for loose sands (a), dense sand (b), and pipe

diameters (c) (From Guo and Stolle, 2005)...... 23

Figure 2-5- Downward bearing capacity factors (Meyerhof. 1995) 24

Figure 2-6 - Uplift bearing factor for horizontal anchors in sand (Merifield and Sloan, 2006) ... 25

Figure 2-7 - Oblique pipe/soil interaction in loose sand (a) lateral loads, (b) axial loads (Hsu et al. 2001) 25

Figure 2-8 - Oblique pipe/soil interaction in dense sand (a) lateral loads, (b) axial loads (Hsu et al. 2001) 26

Figure 2-9 Lateral-Axial oblique loading failure envelope for non-cohesive soil with heavy pipe configuration at an embedment ratio $\mathrm{H} / \mathrm{D}=2$ and interface friction factor of 0.5 (from Kenny and Jukes, 20015) 27

Figure 2-10 Lateral- axial oblique loading failure envelope for cohesive soil (from Kenny and Jukes, 2015) 28

Figure 3-1 - Schematic diagram of shallow and deep pipe embedment depth 41

Figure 3-2- Pipe Set-up within Strongbox (Debnath, 2016). 41

Figure 3-3- Pipe assembly (1) including biaxial load cell $(2,3)$, stanchions $(4,5)$, dog bone (6), and back bracket (7). 
Figure 3-4- Major elements of the centrifuge test apparatus ('payload') including dog bone (6), ball race (7, 8), LVDT (9), guiding plate (10), motorized carriage (11), laser (12), and cone (13). 42

Figure 3-5 - Pipe assembly (1) in strongbox after bedding layer including back bracket (7), acoustic foam (14), and laser target (15) ..................................................................... 43

Figure 3-6- Load cell configuration, based on Stroud (from Debnath, 2016) ............................. 43

Figure 3-7- Load cell dimensions and schematic used for lateral load (from Daiyan, 2011)....... 44

Figure 3-8- Load cell calibration apparatus used for lateral and axial loading ............................ 44

Figure 3-9- Crushable Acoustic Foam after Test 8, 20, $\mathrm{H} / \mathrm{D}=4 \mathrm{D}$.............................................. 45

Figure 3-10- Sieve analysis results for sand used in testing ...................................................... 45

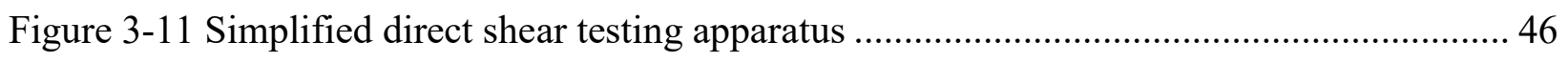

Figure 3-12- Cone penetration tests results for shallow burial depth tests $(\mathrm{H} / \mathrm{D}=2)$................... 47

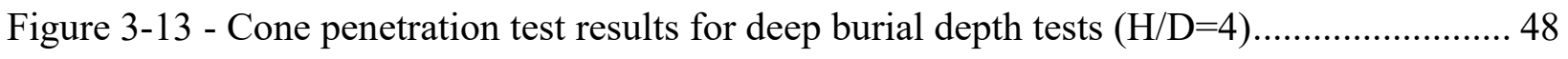

Figure 3-14- CPT test results normalized to an acceleration of 1 g............................................... 49

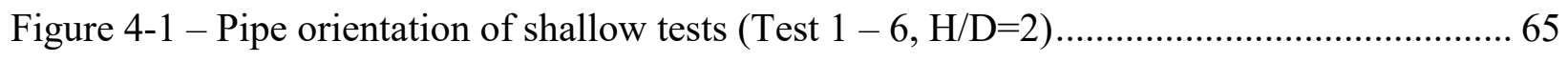

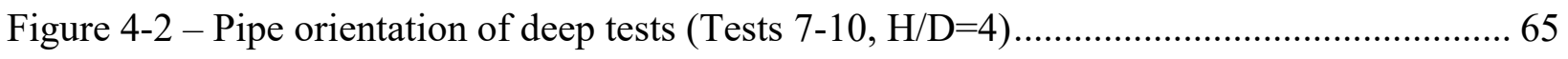

Figure 4-3 - Bending of the double dog-bone set-up before and after Test $10\left(\mathrm{H} / \mathrm{D}=4,30^{\circ}\right) \ldots . .66$

Figure 4-4 - Load cell A after model pipe was pulled out from between stanchions (Test 9, 90,

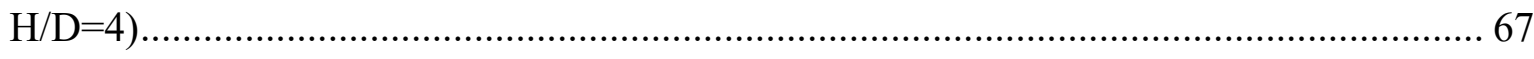

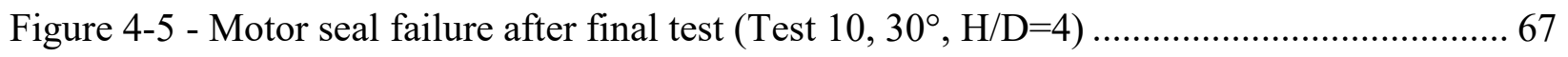

Figure 4-6 - Laser displacement as measured on the dog bone and actuator as a function of true

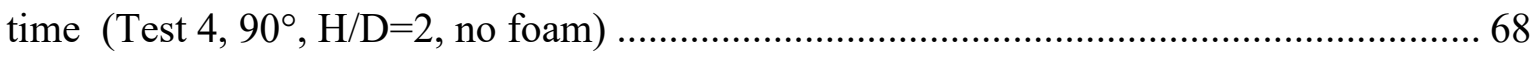


Figure 4-7 - Laser displacement as measured on the dog bone and actuator as a function of true

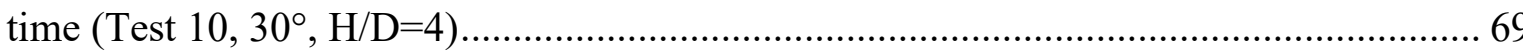

Figure 4-8 - Schematic of idealized pipeline lag during mobilization ........................................ 70

Figure 4-9 - Lateral Loads (normalized) as a function of corrected pipe movement (shallow tests)

Figure 4-10 - Normalize axial loads as a function of corrected pipe movement (deep tests)....... 72 Figure 4-11 - Schematic illustration of peak load determination ( Pike et al. 2011, from Debnath, 2016) 73

Figure 4-12 - Results of pure axial tests as a function of pipe diameter (Test $2-\mathrm{H} / \mathrm{D}=2$, Test 7$\mathrm{H} / \mathrm{D}=4)$ 74

Figure 4-13 - Comparison of axial test results to existing data (variation to Kenny et al., 2015)75 Figure 4-14 - Results of the pure lateral tests as a function of pipe mobilization (Test 2- H/D=2 -no foam, Test $3-\mathrm{H} / \mathrm{D}=2-$ foam, Test $9-\mathrm{H} / \mathrm{D}=4)$ 76

Figure 4-15 - Comparison of lateral test results in loose sands (variation on Kenny et al., 2015)77 Figure 4-16 - Normalized axial load as a function of pipe displacement for oblique tests $\left(50^{\circ}\right.$ $\left.\mathrm{H} / \mathrm{D}=2,70^{\circ}-\mathrm{H} / \mathrm{D}=2,20^{\circ}-\mathrm{H} / \mathrm{D}=4,30^{\circ}-\mathrm{H} / \mathrm{D}=4\right)$ 78

Figure 4-17 - Normalized lateral load as a function of the true pipe displacement for oblique

$$
\text { tests }\left(50^{\circ}-\mathrm{H} / \mathrm{D}=2,70^{\circ}-\mathrm{H} / \mathrm{D}=2,20^{\circ}-\mathrm{H} / \mathrm{D}=4,30^{\circ}-\mathrm{H} / \mathrm{D}=4\right)
$$

Figure 4-18 - Comparison of axial and lateral load results (variation on Kenny et al., 2015) ..... 80

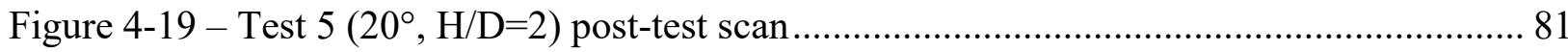

Figure 4-20 - Normalized lateral load as a function of pipe displacement (Test 6, 70, $\mathrm{H} / \mathrm{D}=2$ ) 82

Figure 4-21 - Normalized axial loads as a function of pipe displacement (Test $6,70^{\circ}, \mathrm{H} / \mathrm{D}=2$ ) 82 
Figure 4-22 - Uplift displacement of leading and trailing edge of dogbone (Test 4, 90, $\mathrm{H} / \mathrm{D}=2$ ) 83

Figure 4-23 - Soil Settlement as a function of time for Test 3, 5, 6, 7, 8, 9, and 10................ 84

Figure A-1 - Shear test results of silica sand used in test.......................................99

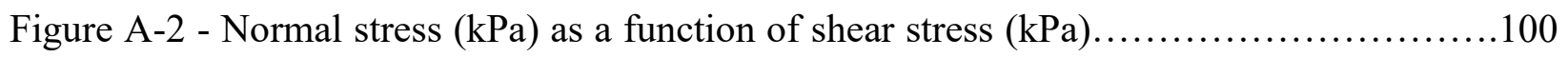

Figure B-1 - LVDT 3031 calibration............................................ 104

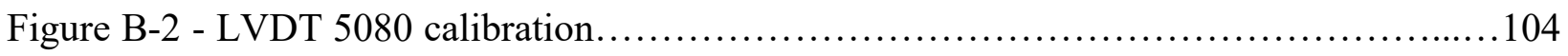

Figure C-1 -Unprocessed lateral load $(\mathrm{N})$ as a function of true pipe displacement $(\mathrm{mm})$ for all

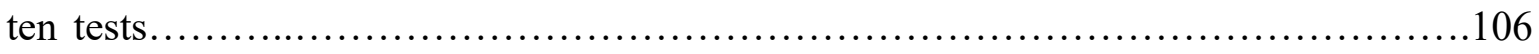

Figure C-2 - Unprocessed axial load $(\mathrm{N})$ as a function of true pipe displacement $(\mathrm{mm})$ for all ten tests.................................................................. 107

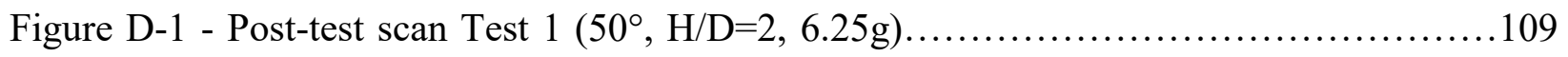

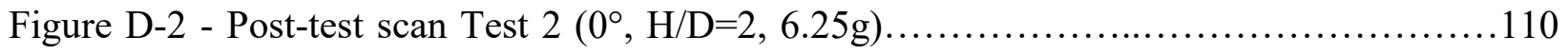

Figure D-3 - Post-test scan Test $3\left(90^{\circ}, \mathrm{H} / \mathrm{D}=2\right.$, no foam, 6.25g) without dogbone and with dogbone................................................................ 111

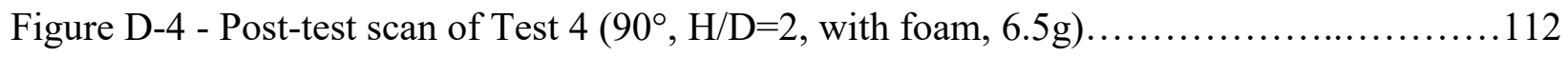

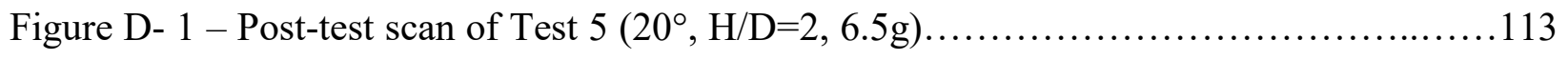

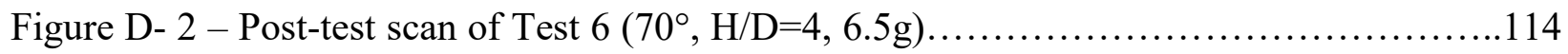

Figure D- 7 - Pre-test (right) and post-test (left) scans for Test $7\left(0^{\circ}, \mathrm{H} / \mathrm{D}=4,13.25 \mathrm{~g}\right) \ldots \ldots \ldots 115$

Figure D- 8 - Pre-test (right) and Post-test (left) scans of Test $8\left(20^{\circ}, \mathrm{H} / \mathrm{D}=4,13.25 \mathrm{~g}\right) \ldots \ldots \ldots 116$

Figure D- 9 - Pre-test (right) and Post-test (left) scans of test $9\left(90^{\circ}, \mathrm{H} / \mathrm{D}=4,13.25 \mathrm{~g}\right) \ldots \ldots \ldots 117$

Figure D- 10 - Pre-test (right) and Post-test scan of test $10\left(30^{\circ}, \mathrm{H} / \mathrm{D}=4,13.25 \mathrm{~g}\right) \ldots \ldots \ldots \ldots . .118$ 


\section{List of Equations}

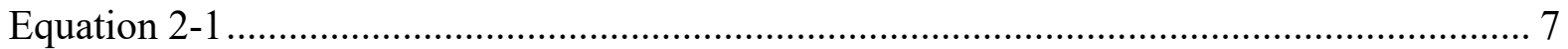

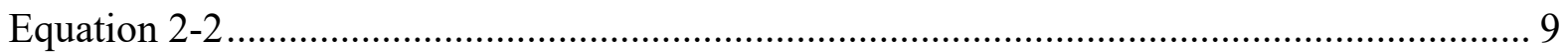

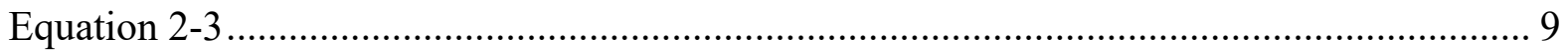

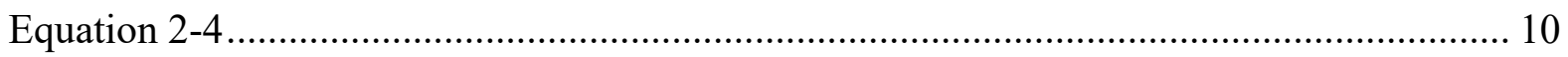

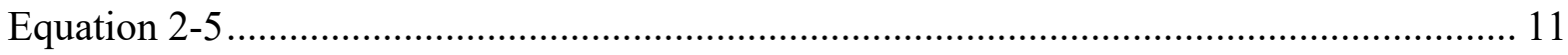

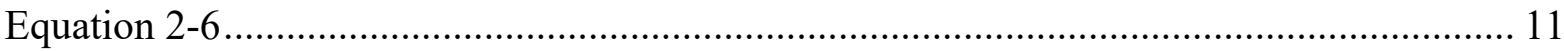

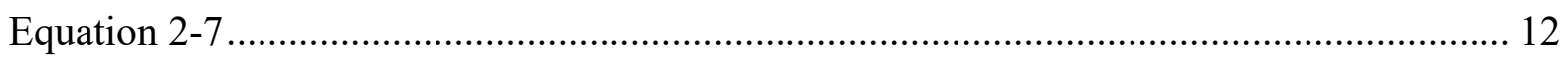

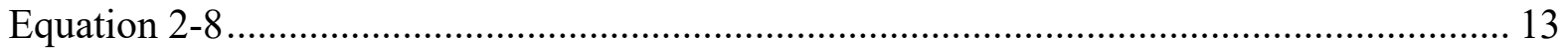

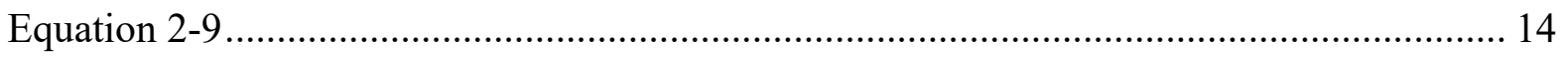

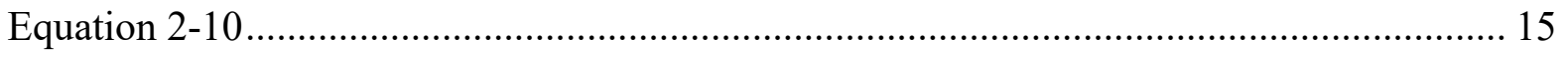

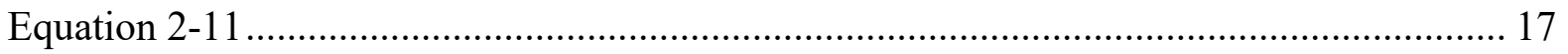

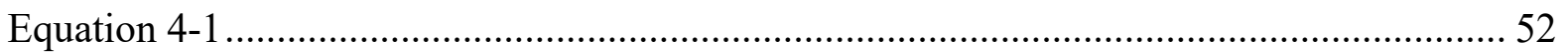

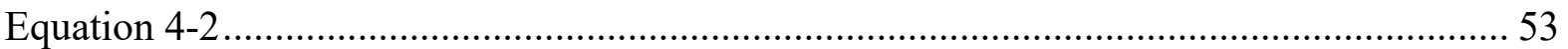

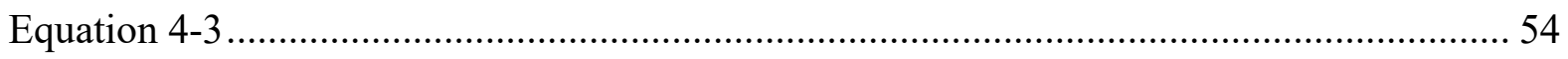




\section{List of Tables}

Table 2-1- Friction factor based on pipe coating, (ALA, 2005) ………………………......... 20

Table 2-2- Common Scaling Relationships (from Taylor, 1995) ........................................... 20

Table 3-1 - Centrifuge strongbox and pipe model parameters ............................................... 40

Table 3-2 - Mobilization Angle and Density of Tests ......................................................... 40

Table 4-1 - Peak lateral load results and corresponding mobilization .................................... 64

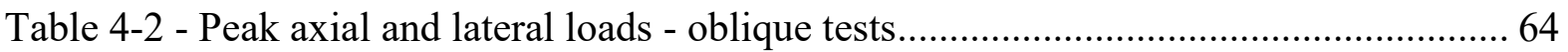

Table 


\section{List of Abbreviations and Symbols}

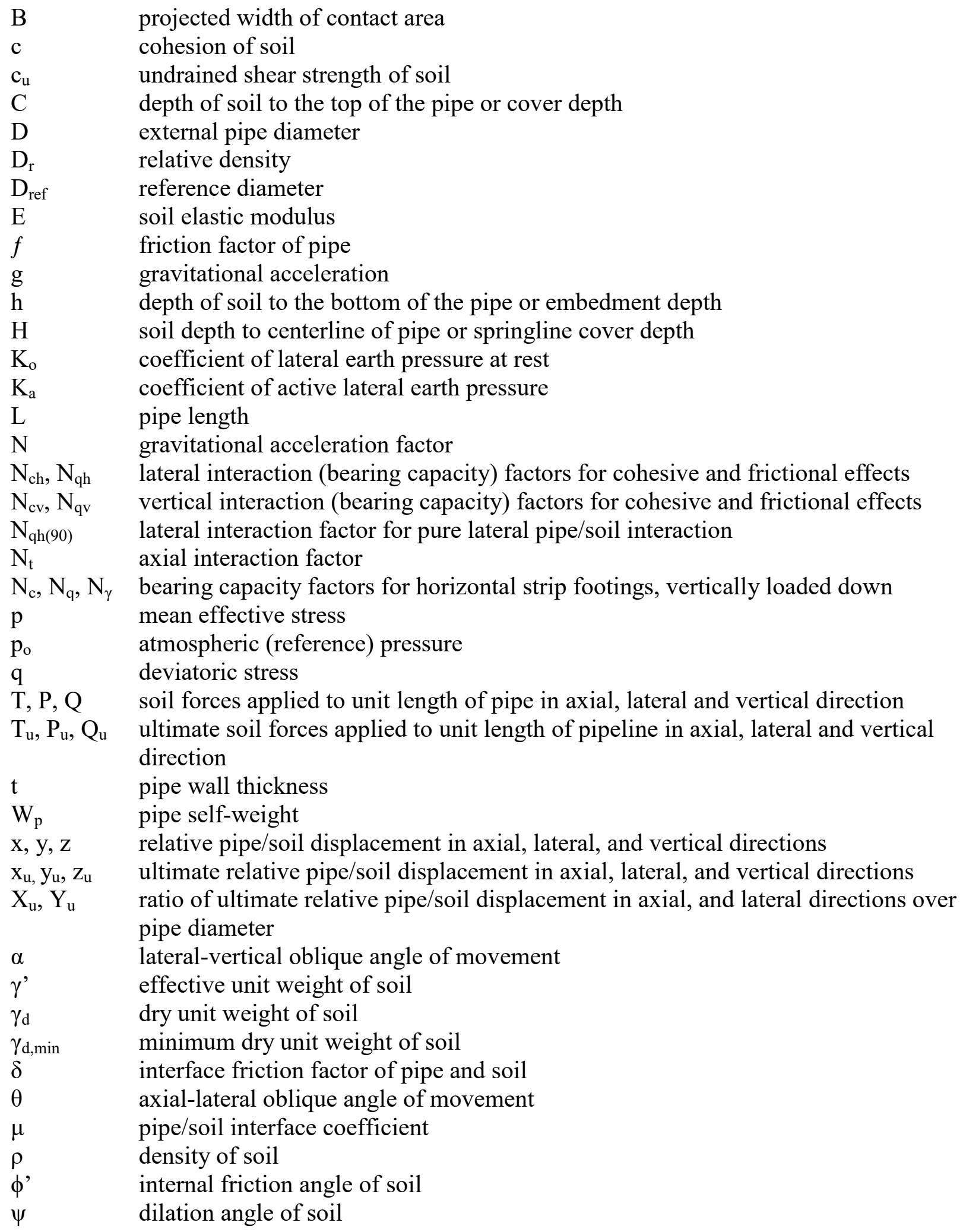




\section{Introduction}

\subsection{Background}

Pipelines are one of the most effective methods to transport liquids and gases over long distances (NRCan, 2014). Across Canada, there is an estimated 852,000 km of energy transmission pipelines. To minimize the effect of loads and potential damage caused by external influences, from natural (e.g. wind, snow) and anthropogenic (e.g. third-party interference) events, the majority of pipelines are buried.

Buried pipelines, however, can be subjected to large deformations and loads due to geohazards (e.g. subsidence, liquefaction, unstable slopes, and freeze/thaw settlement) that can damage the pipeline. Damaged pipelines may not be able to meet the operational and serviceability requirements as mandated by codes and standards (e.g. Canadian Standard Z662) or company specific thresholds (e.g. business or service risk).

Current engineering practices (e.g. ALA, 2005) used to analyze pipe/soil interaction events are based on idealized structural models that have inherent bias and uncertainty. A better understanding of the complex relationship between the pipeline and the surrounding soil needs to be achieved. This improved understanding is required to help ensure that design guidelines and maintenance requirements are economical and effective while taking safety into account. Additional research will allow for higher confidence levels in the estimated lifespans for new and ageing pipelines and will benefit all stakeholders including consultants, operators, regulators and the public. 


\subsection{Problem Statement}

Current design guidelines (e.g. ALA, 2005) are used as the technical basis to develop structural based numerical modelling procedures simulating pipe/soil interaction events. The models can then be used to analyze the soil loads imposed on the buried pipeline during differential ground movement events as well as the pipeline stress and deformation experienced during the event.

The traditional modeling approach is generally based on a Winkler-type beam/spring foundation model with several underlying assumptions. The pipeline is idealized as a structural element based on Euler or Timoshenko beam theory with additional variables to account for the effects of internal pressure and thermal expansion. The continuum soil response is modelled using a discrete series of distributed spring elements along the pipeline's longitudinal axis. For three-dimensional analysis, three springs are placed along three mutually perpendicular axes relative to the pipe cross-section. For this research, the three axes are stated as axial (i.e. longitudinal), lateral (e.g. transverse horizontal), and vertical directions (e.g. transverse vertical). Each soil spring element is uncoupled and acts independently. Generally, bilinear or hyperbolic functions are used to determine the relationship between the soil yield load and the yield displacement.

Previous studies have been conducted to determine if these assumptions are accurate and to determine the soil yield load, mobilization distance to yield, and the soil failure mechanisms during soil-pipeline displacement events (e.g. Hsu, 2001; Phillips et al, 2004; Debnath et al. 2016; Daiyan et al. 2010, 2011). These studies include theoretical studies, numerical studies, and full-scale and reduce scaled experiments. It has been confirmed in these studies that although uncoupled soil springs are easier to model, they do not always provide accurate results when 
compared with full-scale or reduced-scale physical models and numerical continuum simulation models are compared. The impact of pipeline weight, the interface conditions, burial depths, and soil properties can also affect the results of the pipe/soil interaction models.

Completing additional physical models to confirm the scaling laws and soil behaviour can reduce the limitations and uncertainty of the existing models. Due to the cost and time required to complete full-scale model tests, this thesis will use reduced-scale centrifuge tests to confirm the previously stated assumptions.

\subsection{Objective}

The main objective of this thesis is to improve the knowledge on soil load coupling effects during pipe/soil interaction events for a rigid pipe translating within the axial-lateral plane through loose cohesionless soil.

The main outcome of these tests is a new dataset for oblique axial-lateral pipe/soil interaction events that can be compared with and augment existing datasets. Based on the dataset the yield load, mobilization distance to yield, oblique yield load-displacement failure envelope and failure mechanisms can be compared with previous studies that included reduced scale centrifuge modelling, full-scale modelling, and numerical simulation. The data can be used to compare results from other physical tests, as well as the calibration and verification of improved structural based numerical modelling procedures addressing oblique load coupling effects on buried pipelines. This integrated knowledge base can be used to inform current engineering practice and may be used to advance engineering guidelines and best practice for structural based finite element modelling of oblique pipe/soil interaction events. 


\subsection{Outline of Thesis}

This thesis is separated into six chapters and five Appendices.

Chapter 1 provides an introduction to the thesis including background, problem statement and research objectives.

Chapter 2 presents the literature review that covers the existing guidelines and previous research including physical models, numerical models and mathematical models. This section will also discuss previous pipe/soil interaction research and the principals of centrifuge modelling.

Chapter 3 discusses the centrifuge modelling conducted for this thesis. This will include the test setup, apparatus, soil properties, testing instrumentation, and pipe properties.

Chapter 4 shows the experimental test results for the axial, lateral, and oblique tests. The results are compared with existing literature, and guidelines. Shallow and deep burial tests were completed and will be presented within this chapter. The accuracy of the scaling laws is also discussed within this chapter.

Chapter 5 summarizes the research and provides recommendations for the next steps in this field of research. Conclusions from this research are also provided in this chapter.

Appendix A provides the sieve analysis results of the soil used in testing.

Appendix B presents the calibration results of the monitoring instruments used during testing including load cells, LVDTS, and lasers.

Appendix C presents the graphs of the raw data from the centrifuge models.

Appendix D presents copies of the pre- and post-test scans of a selection of tests 
Appendix E presents a copy of the paper published in the proceedings of the $70^{\text {th }}$ Canadian Geotechnical conference (GeoOttawa2017), and orally presented at the conference. 


\section{Literature Review}

\subsection{Introduction}

Any large ground movement event, for example, a landslide, earthquake, subsidence or other geohazard event, which occurs near a buried pipeline, will cause increased loading around the pipeline as the pipeline resists the movements. To help determine the extent of the loads acting on the pipeline and the behaviour of the soil surrounding the pipeline, full scale, numerical, and reduced scaled research has been completed. This knowledge base has been used to develop current engineering design guidelines for the analysis of buried pipeline response to geotechnical loads.

This chapter will discuss the current engineering guidelines, previous research including physical models, numerical models and mathematical models, the previous pipe/soil interaction research, and the principles of centrifuge modelling. The literature discussed will focus on dry, cohesionless soil (sand) since that was the bedding material used in the physical model tests conducted in this study.

\subsection{Current Guidelines}

Many geotechnical problems involve modelling the interaction between soil and a rigid structure. To model these types of problems accurately, including piles, caissons, and pipelines, the structure and soil behaviour must be inter-connected which may increase the difficulty and time required for the modelling. The design guidelines and modelling recommendations that are currently used attempt to balance the accuracy provided by theoretical studies and the simplicity required to be used on an on-going basis by the private sector. 
The current pipeline design guidelines including the American Lifeline Alliance (ALA) guidelines (2005) and those proposed by Honegger and Nyman (2001) are based on the assumption that the pipeline can be modelled as a structural beam element while the soil can be modelled as three discrete springs as shown in Figure 2-1. The three springs are all treated as independent and are placed perpendicular to each other (i.e. axial, lateral, and vertical) to represent the resistance of the soil on the beam or pipeline. This model is based on the Winkler (1867) approach for a rigid beam on an elastic foundation. In this model the load-displacement relationship for the springs are represented as follows:

Eq. $2-1$

$$
T=f(x), P=g(y), \quad Q=h(z)
$$

where $\mathrm{T}, \mathrm{P}$, and $\mathrm{Q}$ represent the forces applied along the length of the pipe $(\mathrm{N} / \mathrm{m})$, and $\mathrm{x}, \mathrm{y}$, and $\mathrm{z}$ are the relative displacements between the pipe and soil in the longitudinal, lateral and vertical directions $(\mathrm{m})$. The force-displacement relationship between the soil-springs and the pipeline are known to be nonlinear based on previous research on piles and other structures (e.g. plates, anchors, pipes) (Kenny et al., 2015). The ALA guidelines (2005) recommend using bilinear models, which are simpler to use, or hyperbolic functions. Additional research has been conducted to refine the load-displacement relationship for buried pipelines but also for piles, anchor plates, and other large foundations including additional theoretical, physical tests and finite element models.

The traditional Winkler (1867) model treats each spring as an independent unit, that is, any loading in a single direction does not translate to loading in the other two directions. This type of assumption does not allow for the replication of all the shearing modes within the soil and may 
create an oversimplified model, especially if the loading is occurring along more than one plane. To help counteract this shortcoming, several multiple-parameters models have been proposed including the Pasternak/Loof method, the Reisner's simplified continuum model and modified Reisner's model (Horvath, 2002, and Horvath, et al. 2011). These models allow for "spring coupling", which means the springs are not treated as independent and loading in one direction will affect the soil spring along a separate plane. This spring coupling allows for more accurate modelling of the shearing of the soil around the pipeline, but the applications are normally confined to two axes being coupled for simplicity and ease of use (e.g. Guo, 2005; Hodder and Cassidy, 2010; Kenny and Jukes, 2015).

\subsection{Pipe/Soil Interaction}

Pipe modelling interaction models are traditionally categorized based the direction of loading and mobilization. Initial research was focused on loading in a single direction (axial, lateral, or vertical), which can be easily modelled by the Winkler and coupled Winkler models. Regardless of the type of loading, four major dimensions are used to characterize buried pipelines. The four dimensions, as shown in Figure 2-2, are:

D: External pipe diameter

C: Depth of soil to the top of the pipeline or cover depth

$\mathrm{H}$ : Soil depth to the centre of the pipeline or springline burial depth

h: Depth of soil to the bottom of the pipe or embedment depth. 
Another parameter that must be taken into account regardless of loading methodology is the friction factor that is dependent on the pipeline coating and internal friction angle of the soil. The interface friction angle can be defined by the following equation:

Eq. $2-2$

$$
\delta=f \emptyset^{\prime}
$$

where $\phi^{\prime}$ is the internal friction angle of the soil and $f$ is the friction factor based on the pipe coating.

Friction factors typically vary from 0.5 to 1.0 depending on the smoothness and characteristics of the pipe coatings and are shown in Table 2-1. For example, a concrete pipe or a pipeline that has been buried for many years and oxidized would have a friction factor of 1 , as the shear failure of the soil would occur near the pipe surface (O’Rourke, 1989).

\subsubsection{Axial Pipe/Soil Interaction}

To calculate the ultimate axial load on a buried pipeline, the following equation has been proposed: (ALA, 2005; Honnegger and Nyman, 2004; PRCI, 2004)

Eq. 2-3

$$
T_{u}=\pi D H \gamma \frac{1+K_{o}}{2} \tan \delta
$$

where,

$\mathrm{T}_{\mathrm{u}}$ : ultimate axial soil load on the pipe per unit length

D: pipe diameter 
$\mathrm{H}$ : springline burial depth

$\gamma$ : effective unit weight of soil

$\mathrm{K}_{\mathrm{o}}$ : coefficient of earth pressure at rest

$\delta$ : interface angle of friction between the pipe and the soil.

The relative displacement or mobilization distance required to achieve the ultimate axial load varies between 3 and $5 \mathrm{~mm}$ depending on the density of the sand and the internal friction angle of the soil. This equation assumes that the pipeline is at rest and does not take into account any lateral or vertical loads along the pipeline. If the pipeline is also in motion, the equation will underestimate the axial loads when compared to physical test results (Kennedy et al. 1977).

The two major variables that can affect the ultimate axial load are the interface angle of friction, $\delta$, which has been explained, and the coefficient of earth pressure at rest, $\mathrm{K}_{0}$. An equation for the coefficient of lateral earth pressure has not been proposed by the current guidelines (ALA, 2005) but the following relationships can be used for loose sands and normally consolidated clay (Jacky, 1944):

Eq. 2-4

$$
K_{o}=1-\sin \phi^{\prime}
$$

where $\phi$ ' is the effective friction angle of the soil. 
For dense over-consolidated sands, the following equation can be used (Sherif et al., 1984):

Eq. $2-5$

$$
K_{o}=\left(1-\sin \phi^{\prime}\right)+5.5\left(\frac{\gamma_{d}}{\gamma_{d \min }}-1\right)
$$

where $\gamma_{\mathrm{d}}$ is the dry unit weight, and $\gamma_{\mathrm{dmin}}$ is the minimum dry unit weight of sand. These equations are variations of the equations recommended by the Canadian Foundation Engineering Manual (2006) for pile retaining wall design.

Experimental testing on piles (e.g. Jardine and Overy, 1996; Lam et, al, 2009) and on buried pipelines (e.g. Karimian, 2006; Wijewickreme et al., 2009) has confirmed that the proposed equations do not take into account the dilation of sand during shearing. Eq. 2-4 and Eq. 2-5 also assume that the stress distribution along the pipeline is uniform.

For physical modelling, the pipe self-weight is another factor that must be taken into account, but that has not been included in Eq. 2-3. Schaminee et al. (1990) has proposed the following variation on the previous equation:

Eq. 2-6

$$
T_{u}=0.25\left\{\gamma^{\prime} H+2 K_{a} \gamma^{\prime}\left(H-\frac{D}{2}\right)+\gamma^{\prime} H+\frac{W_{p}}{D}\right\} \mu \pi D
$$

where $\mathrm{Wp}$ is the pipe self-weight, and $\mathrm{Ka}$ is the active lateral pressure coefficient. 


\subsubsection{Lateral Pipe/Soil Interaction}

Lateral pipe/soil interaction occurs where there is a relative horizontal displacement of the soil or the pipeline. Early research into the lateral resistance of the soil was conducted by completing experimental or numerical studies on vertical plates moving horizontally through the soil or by studying retaining walls and shallow pipelines (e.g. Mckenzie, 1955; Rowe and Davis 1982).

Current guidelines propose the following equation to calculate the peak lateral loads (Honnegar, Nyman, 2004; ALA, 2005):

Eq. 2-7

$$
P_{u}=\gamma^{\prime} H D N_{q h}+N_{c h} c D
$$

where:

$\mathrm{N}_{\mathrm{qh}}$ : lateral bearing capacity factor for frictional effects

$\mathrm{N}_{\mathrm{ch}}$ : Lateral bearing capacity for cohesive effects ( 0 in cohesionless soil)

This equation takes into account soil friction and cohesion. For this research, cohesionless soil was used therefore $\mathrm{N}_{\mathrm{ch}}$ is zero. Hansen (1961) proposed a fitted curve for determining $\mathrm{N}_{\mathrm{qh}}$ which is shown in Figure 2-3. 
The relative displacement at the ultimate load is proposed as:

Eq. 2-8

$$
y_{u}=0.04\left(H+\frac{D}{2}\right)
$$

The displacement distance should not exceed 0.1 to $0.15 \mathrm{D}$ regardless of pipe diameter or spring line burial depth. These equations provide a higher ultimate lateral load than those proposed by the studies conducted with vertical plates (e.g. Taurtmann, 1983; Ovesen, 1964; and Rowe and Davis, 1982).

Guo and Stolle (2005) compared the results of experimental studies on lateral pipe/soil interaction and vertical anchor plates in sand. By comparing the predicted maximum soil forces shown in Figure 2-4 (a) and (b), it was shown that the peak lateral load was sensitive to 'scale effects' caused by the pipe diameter and model scale. This scale effect is most notable at a lower pipe diameter $(\mathrm{D}<273 \mathrm{~mm})$ especially when there was minimal cover depth above the pipe. As part of their study, a finite element model was also completed. The finite element model was able to normalize and show that the results were similar if the scale effects and burial depth $(\mathrm{H})$ were taken into account. The graph showing these results is shown in Figure 2-4 (c). It was theorized that the grain size may affect the slip surface and soil failure type during a reduced scaled tests (Guo and Stolle, 2005). 


\subsubsection{Vertical Pipe/Soil Interaction}

Vertical pipe/soil models must be separated into upward and downward models, as the failure mechanisms and ultimate loads/displacements are different depending on the direction the pipe is loaded.

The downward resistance of the soil against pipe movement can be estimated by using the bearing capacity equation of cylindrical strip foundations. The ultimate displacement is assumed to be approximately $0.1 \mathrm{D}$ for granular soils based on the ALA guidelines or $1.0 \mathrm{D}$ to $1.5 \mathrm{D}$ if Calvetti et al. (2004) numerical models are used. The ultimate displacement calculations still require refinement as the ultimate displacements calculated using numerical methods and guidelines do not match. Previous reduce scaled models conducted by Daiyan (2013) found a peak vertical displacement of close to $1 \mathrm{D}$, which is much higher than the displacements proposed by the guidelines. The equation to calculate the ultimate downward load is as follows (ALA, 2005):

Eq. 2-9

$$
Q_{u l t}=c N_{c} B+\gamma^{\prime} H N_{q} D+\frac{1}{2} \gamma B^{2} N_{\gamma}
$$

Where:

$\mathrm{N}_{\mathrm{c}}, \mathrm{N}_{\mathrm{q}}, \mathrm{N}_{\gamma}$ : Bearing capacity factors for horizontal strip footings, vertically loading (Figure 2-5)

c: soil cohesion

$\gamma$ : total unit weight of soil 
$\gamma^{\prime}$ : effective unit weight of soil

B: projected width of contact area with soil. For pipelines, the diameter of the pipe can be used.

For pipe/soil models in the upward direction, the experimental data and the numerical data do not match and the uplift displacement varied from $0.5 \% \mathrm{H}$ to $5 \% \mathrm{H}$. The experimental results of Trautmann (1983) and the numerical results provided by Rowe and Davis (1982) were all lower than the loads predicted by Merrifeld and Sloan (2006), which is shown in Figure 2-6. The variation in results may be caused by errors due to pipe weight, diameter, soil properties (including grain size, soil dilation and strength), and ratcheting (Kenny and Jukes, 2015). Ratcheting is caused by soil filling the void below the pipe during cyclical loading. Once the pipe is unloaded, the pipe is unable to return to its initial position, which causes the uplift displacement from each loading cycle to build on itself.

Trautmann and O'Rourke (1983) have proposed the following force-displacement relation for large-scale tests in dry, uniform sand:

Eq. 2-10

$$
Q=\frac{Z}{A^{\prime \prime}+B^{\prime \prime} z}
$$

where,

$\mathrm{A}^{\prime \prime}=0.07 \mathrm{z}_{\mathrm{u}} / \mathrm{Q}_{\mathrm{u}}$ and $\mathrm{B}^{\prime \prime}=0.93 / \mathrm{Q}_{\mathrm{u}}$.

Qu: ultimate uplift resistance

$\mathrm{z}_{\mathrm{u}}$ : ultimate displacement at which $\mathrm{Q}_{\mathrm{u}}$ is reached 
Trautmann (1983) also concluded that shallow and deep failure mechanisms are based on the sand density of the bedding structure. For loose sand, which was used for this research, the failure mechanism transitioned from shallow failure to deep failure at a burial depth to pipeline diameter ratio of approximately 4 .

\subsubsection{Axial-Lateral Pipe/Soil Interaction}

The current guidelines do not have an accepted methodology to model pipe/soil interaction for oblique loading events, apart from vertical-lateral loading, and the associated coupled soil shear loading response. A coupled spring response is the recommended approach for multidirectional loaded models as the Winkler model does not allow for soil response in more than one direction. Studies have been conducted to help determine accurate coupled spring models that are simple to use. These include full-scale experiments (Hsu et al., 2001), numerical and finite models (Hsu et al, 2001; Phillips et al., Daiyan, 2010) and reduced scale models (e.g. Phillips et al, 2004; C-Core, 2008; Debnath et al. 2016; Daiyan et al. 2010, 2011).

Hsu et al. (2001) conducted full-scale laboratory tests in the horizontal plane for shallow buried pipes of three diameters in both loose and dense sands. Ten tests were conducted for various angles between $0^{\circ}$ (pure axial) and $90^{\circ}$ (pure lateral). The results of the full-scale tests are shown in Figure 2-7 for loose sand and Figure 2-8 for dense sands. C-Core (2008), Phillips et al. (2004), Daiyan et al. (2010, 2011) and Debnath (2016) all observed higher ultimate loads than those measured in full-scale tests.

Phillips et al. (2004) conducted reduced scaled physical experiments and finite element analysis for lateral-axially loaded pipes in cohesive soil. Based on that research, it was proposed that for small oblique angles, the failure occurs by sliding along the pipe soil interface, which is 
similar to failure that occurs during pure axial loading. At larger angles, the soil failure mechanism is predominately caused by shear and bearing failure. A lateral axial yield envelope equation based on numerical and reduced-scale models for in cohesive soils has been determined to be:

Eq. $2-11$

$$
N_{q h \theta}^{2}+3 N_{t \theta}^{2}=N_{q h 90}^{2}
$$

where

$\mathrm{N}_{\mathrm{qh} 90}$ : the interaction factor for pure lateral loading

$\mathrm{N}_{\mathrm{qh} \theta}=\mathrm{F}_{\mathrm{x}} / \mathrm{c}_{\mathrm{u}} \mathrm{DL}: \mathrm{F}_{\mathrm{x}}$ is the maximum lateral force on pipe

$\mathrm{N}_{\mathrm{t} \theta}=\mathrm{F}_{\mathrm{z}} / \mathrm{c}_{\mathrm{u}} \mathrm{DL}: \mathrm{F}_{\mathrm{z}}$ is the maximum axial force on pipe

The failure envelope is based on the results shown in Figure 2-9. Daiyan $(2010,2011)$ and Debanth (2015) conducted similar tests with cohesionless soil and determined that a similar failure envelope was applicable, as shown in Eq. 2-1. The failure envelope for cohesionless soils is dependent on the friction angle of the soil, embedment ratio $(\mathrm{H} / \mathrm{D})$, and friction factors of the pipe material, as shown in Figure 2-10.

The finite element models and reduced scale model results have not been consistent especially at low attack angles (Kenny and Jukes, 2015). It is hypothesized that the variation in the results may have been caused by the pipe weight and end conditions of the model pipe during testing. The soil behaviour, including the mounding caused by pipe uplift and voids at the trailing edge of the pipe has also not been accurately modelled by computer models and may be 
affected by the testing methodology used for the reduced scale tests. The reduced scale tests conducted by Debnath (2015) used a lighter model pipe, which provided results that were a closer match to the computer models.

The results of the full-scale tests conducted by Hsu (2001 and 2006) did not show any scaling effects when compared to finite element analysis (FEA) models especially in the pipe diameter range of 150 to $610 \mathrm{~mm}$ (Kenny et al., 2015), shown in Figure 2-10. The failure envelope developed using the full-scale results show a much steeper soil failure envelope when compared to the FEA and reduced-scale models. The test results are separated based on the pipe dimensions including diameter and burial depth and the soil properties. Since the FEA models completed by Daiyan (2013) and the full-scale results completed by Hsu (2001 and 2006) do not match, the cause of the variations must be confirmed. It is assumed that the scaling effects and boundary condition assumptions may be the cause of the discrepancies. Additional tests with different soil properties and pipe diameters are required to refine the computer models and confirm the testing methodologies used for the physical tests.

\subsection{Centrifuge Modeling Background}

Physical modelling is a tool used to test many complex geotechnical problems, including soil/structure interaction problems. Physical models can be used to verify assumptions made during both theoretical and analytical testing, calibrate finite-element models, and provide an opportunity to manipulate and visualize tests in a way that is not possible in numerical and analytical tests. Centrifuge modelling is one of the more cost-effective and efficient modelling techniques, especially when compared to full-scale tests. 
Centrifuge tests allow for quick modelling of large stress-strain events as the centrifuge increases the gravitational acceleration (g) by a factor of ' $\mathrm{N}$ '. The stress and strain forces acting on the prototype do not change as the acceleration is increased but the size of the prototype required can be reduced by a factor of $1 / \mathrm{N}$ and the time required to attain a specified strain can all be reduced by the same factor (Abdoun, 2011, Ng, 2014).

The scaling laws used for centrifuge testing have been determined using dimensional analysis or governing equations. The scaling relationships used for this research are shown in Table 2-2. The scaling relationships were determined by Taylor (1995) and have been confirmed by other research (Garnier et al. 2007, Ng, 2014). 
Table 2-1- Friction factor based on pipe coating, (ALA, 2005)

\begin{tabular}{|l|c|}
\hline Pipe Coating & $\boldsymbol{f}$ \\
\hline Concrete & 1.0 \\
\hline Coal Tar & 0.9 \\
\hline Rough Steel & 0.8 \\
\hline Smooth Steel & 0.7 \\
\hline Fusion Bonded Epoxy & 0.6 \\
\hline Polyethylene & 0.6 \\
\hline
\end{tabular}

Table 2-2- Common Scaling Relationships (from Taylor, 1995)

\begin{tabular}{|l|c|}
\hline Parameter & $\begin{array}{r}\text { Scale Factor (Prototype: Model) } \\
\text { at Ng }\end{array}$ \\
\hline Length & $1: 1 / \mathrm{N}$ \\
\hline Stress & $1: 1$ \\
\hline Strain & $1: 1$ \\
\hline Density & $1: 1$ \\
\hline Unit Weight & $1: \mathrm{N}$ \\
\hline Force & $1: 1 / \mathrm{N}^{2}$ \\
\hline Time (dynamic) & $1: 1 / \mathrm{N}$ \\
\hline
\end{tabular}



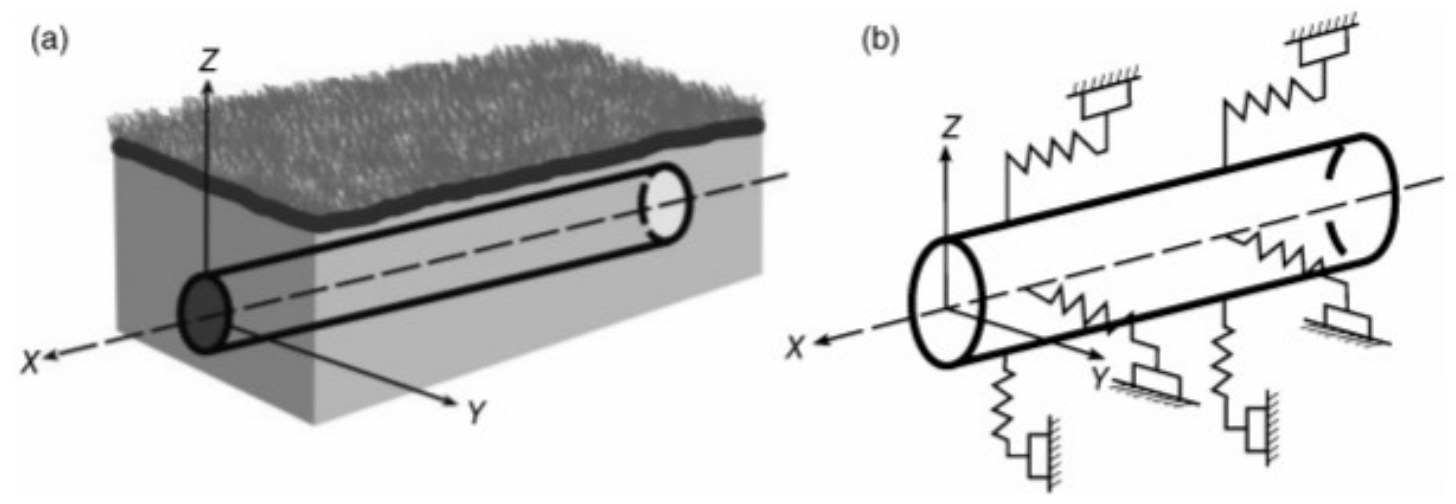
a) Pipeline Schematic
b) Idealized Pipeline Model

Figure 2-1 - Current Pipeline Model Approach (from Kenny and Jukes, 2015)

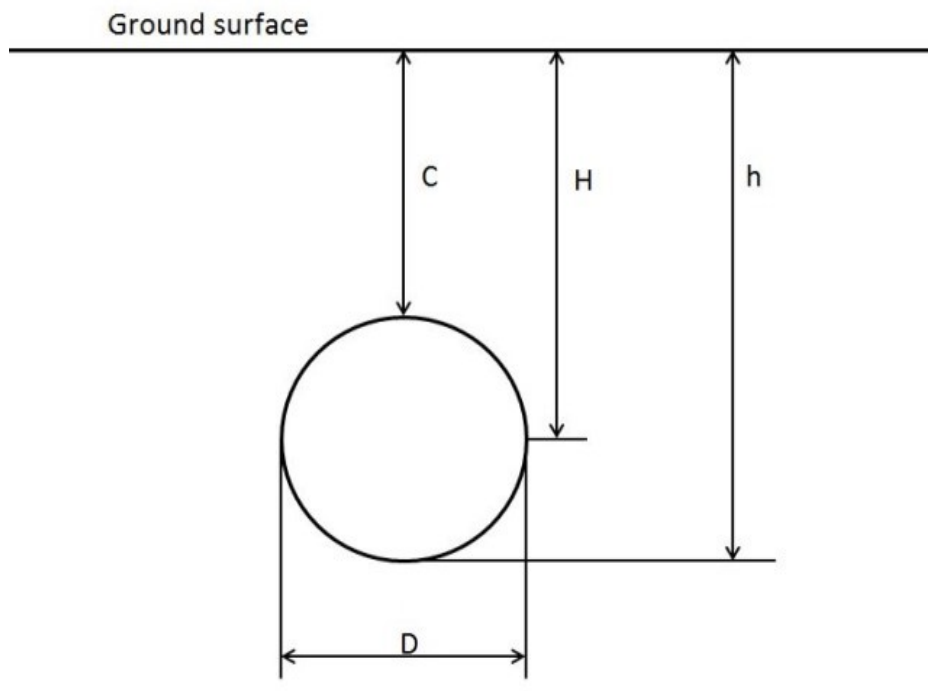

Figure 2-2 - Common measurement for buried pipeline including pipe diameter (D), cover depth (c), burial depth $(\mathrm{H})$, and embedment depth (h). 


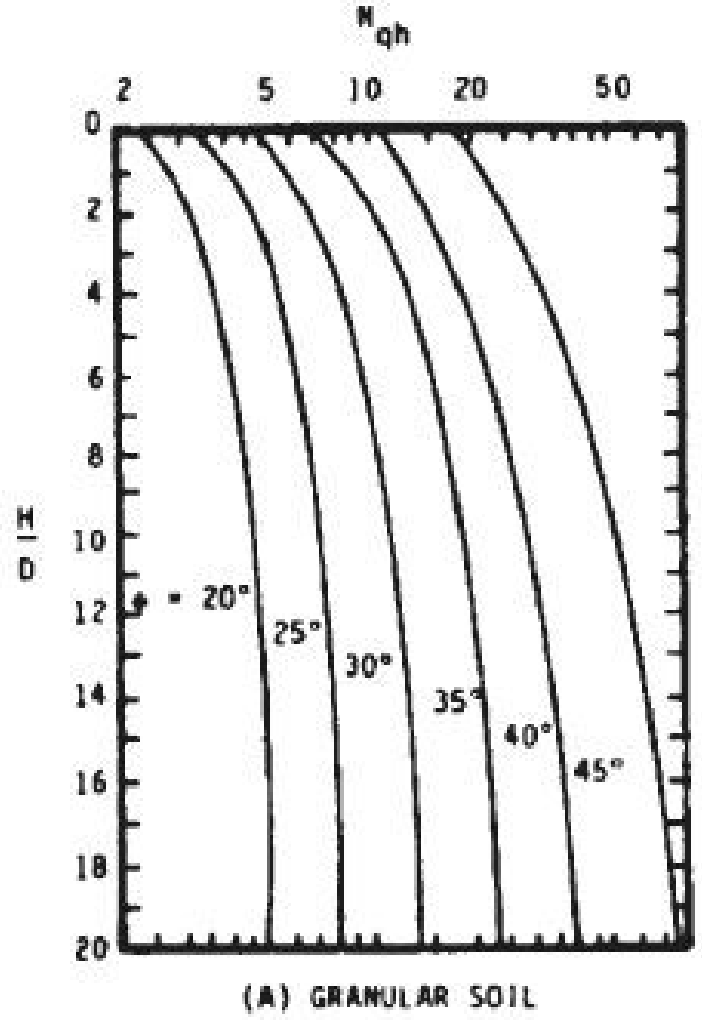

Figure 2-3- Lateral bearing capacity fit curve (Honegger and Nyman, 2004) 


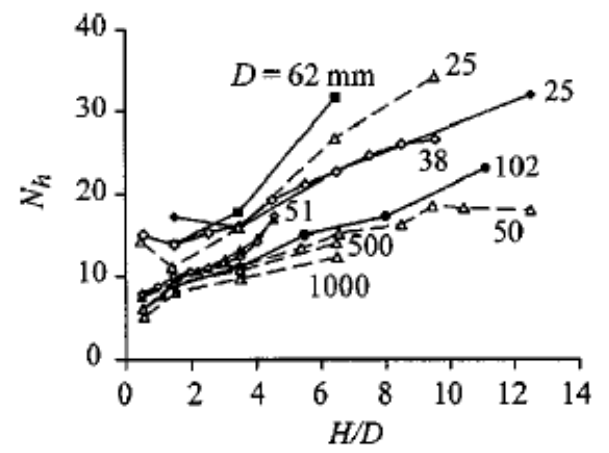

- Akinmusuru, $\phi=35^{\circ}, \mathrm{D}=38 \mathrm{~mm}$

$\leftarrow$ Audibert, $\phi=40^{\circ}, \mathrm{D}=25 \mathrm{~mm}$

- - Audibert, $\phi=40^{\circ}$, D $-62 \mathrm{~mm}$

$\leadsto-$ Murray \& Geddes, $\phi=43.6^{\circ}$, D $=50.8 \mathrm{~mm}$

- Neely, et al, $\phi=39^{\circ}, \mathrm{D}=51 \mathrm{~mm}$

$\rightarrow$ Trautmann, $\phi=44^{\circ}, D=102 \mathrm{~mm}$

$\checkmark-$ Dickin \& Leung, $\phi=41.46^{\circ}$, $\mathrm{D}=25 \cdot 1000 \mathrm{~mm}$

a) Dense sand $\left(\phi^{\prime}>35^{\circ}\right)$
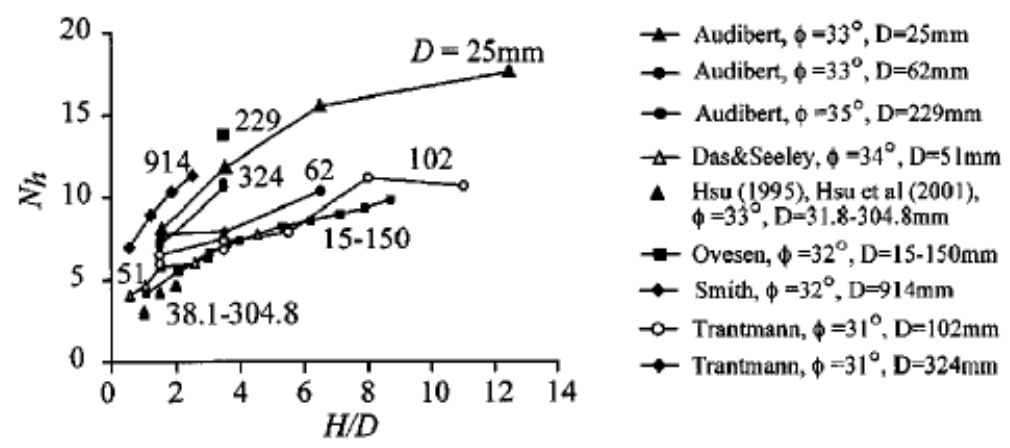

b) Loose sand $\left(\phi^{\prime}<35^{\circ}\right)$

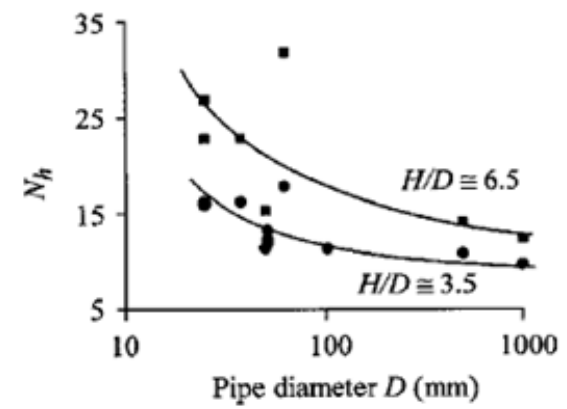

c) Effect of pipe diameter

Figure 2-4- Lateral bearing force comparison for loose sands (a), dense sand (b), and pipe diameters (c) (From Guo and Stolle, 2005) 


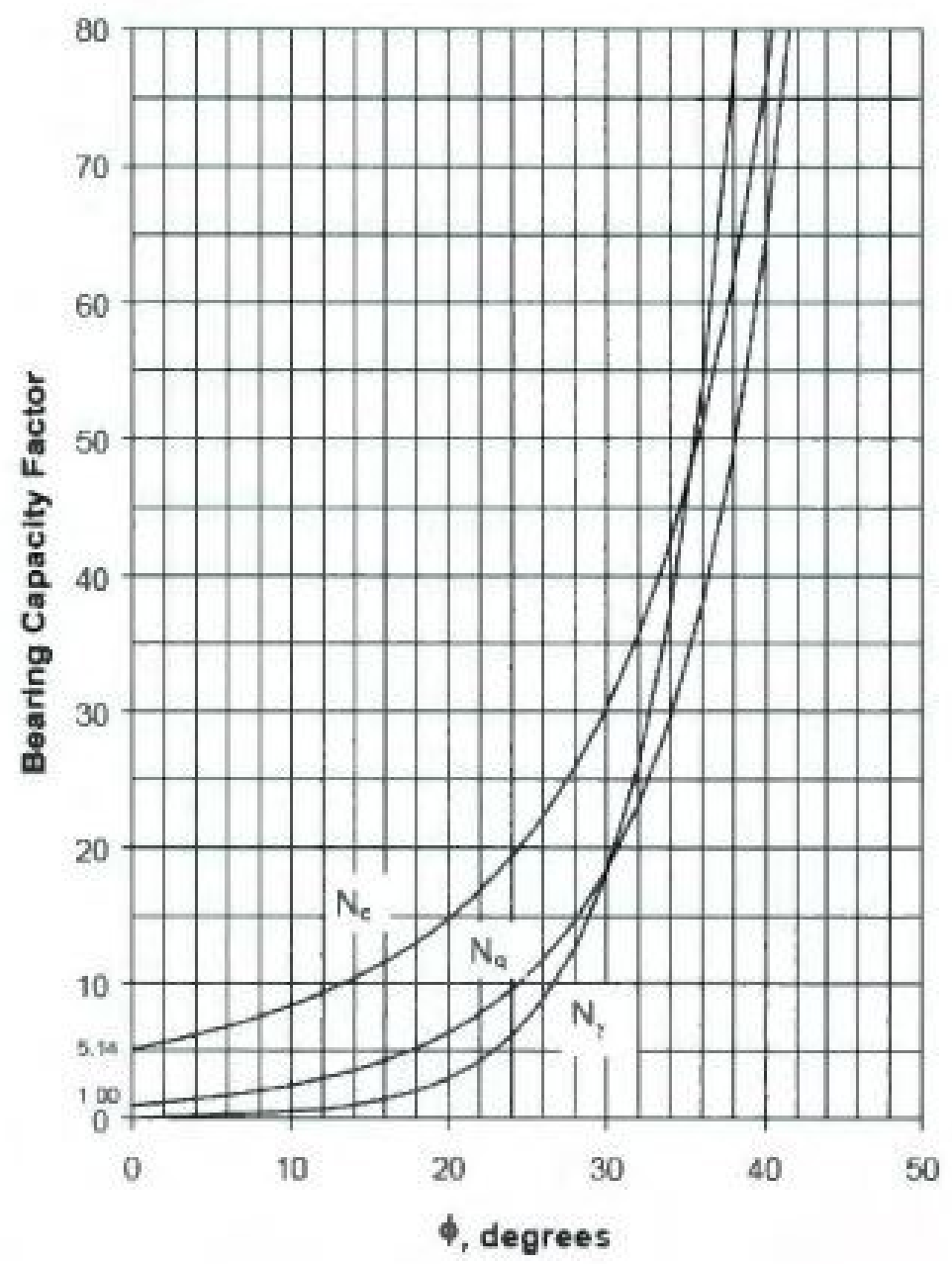

Figure 2-5- Downward bearing capacity factors (Meyerhof. 1995) 


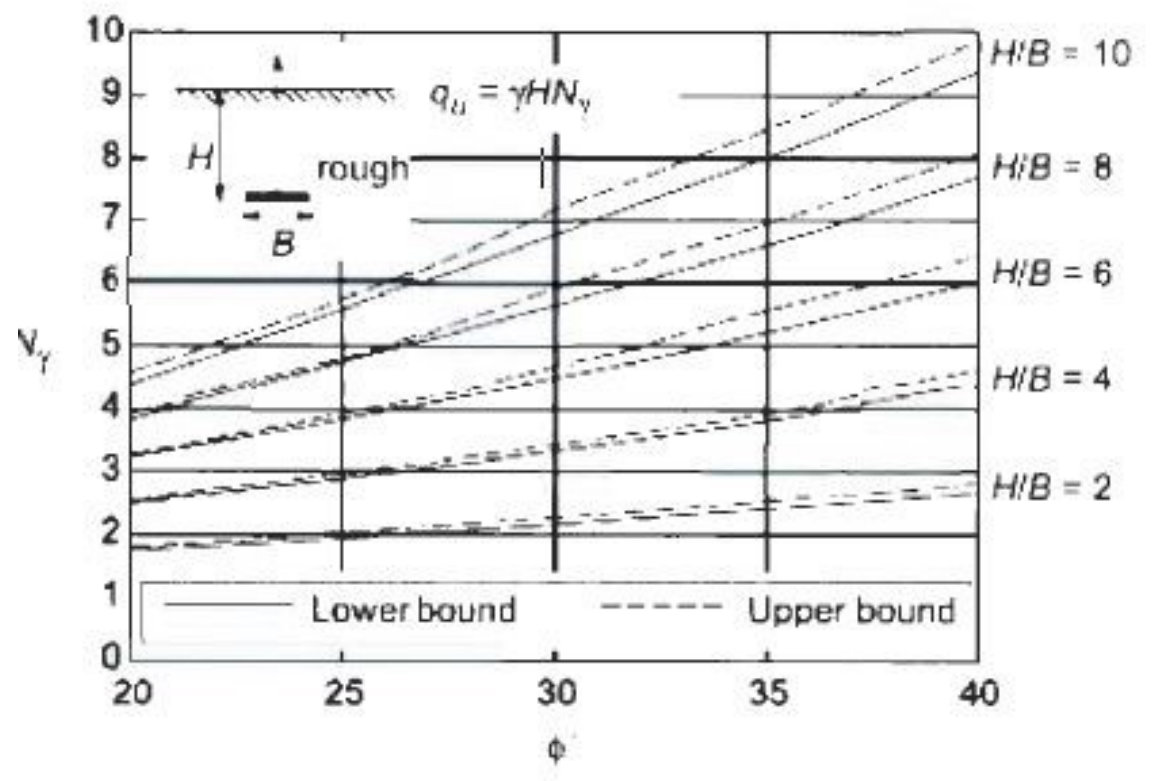

Figure 2-6 - Uplift bearing factor for horizontal anchors in sand (Merifield and Sloan, 2006)
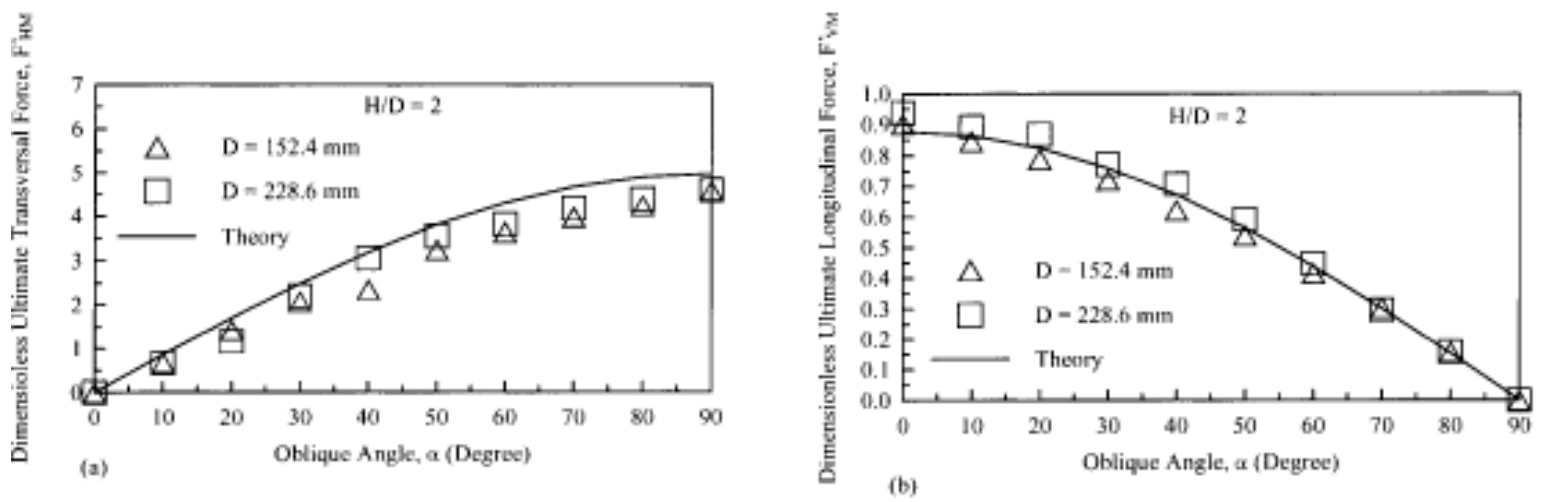

Figure 2-7 - Oblique pipe/soil interaction in loose sand (a) lateral loads, (b) axial loads (Hsu et al. 2001) 

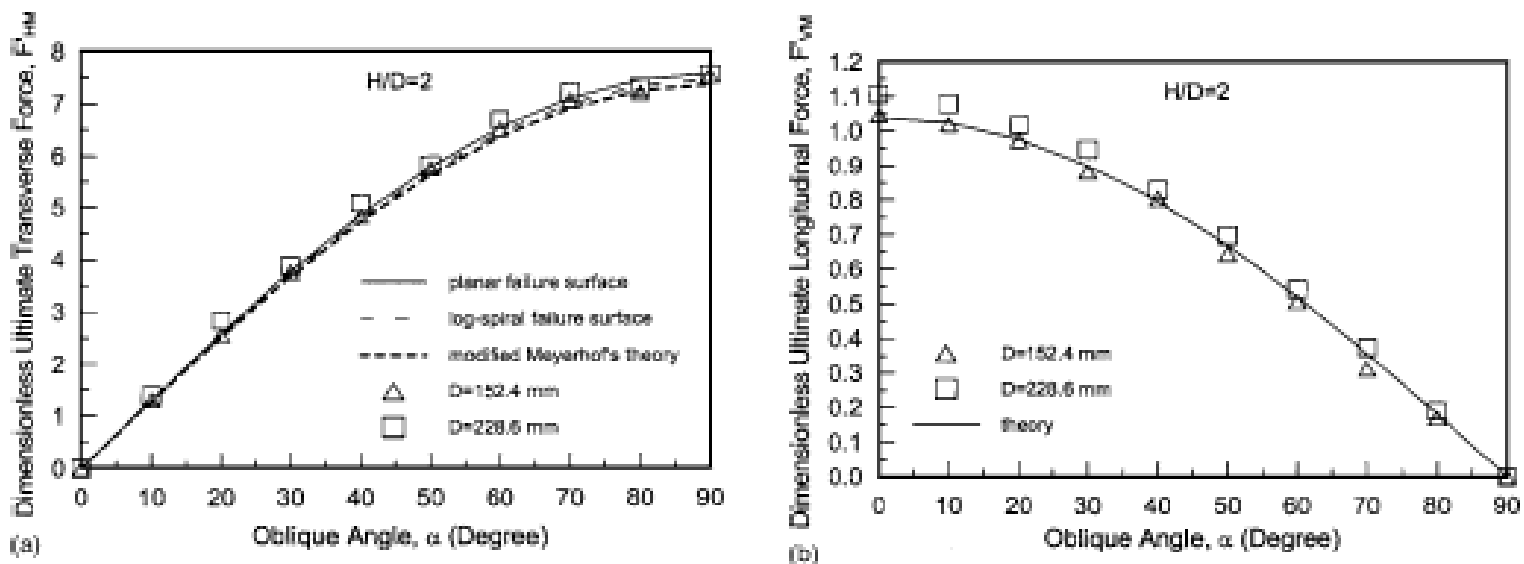

Figure 2-8 - Oblique pipe/soil interaction in dense sand (a) lateral loads, (b) axial loads (Hsu et al. 2001) 


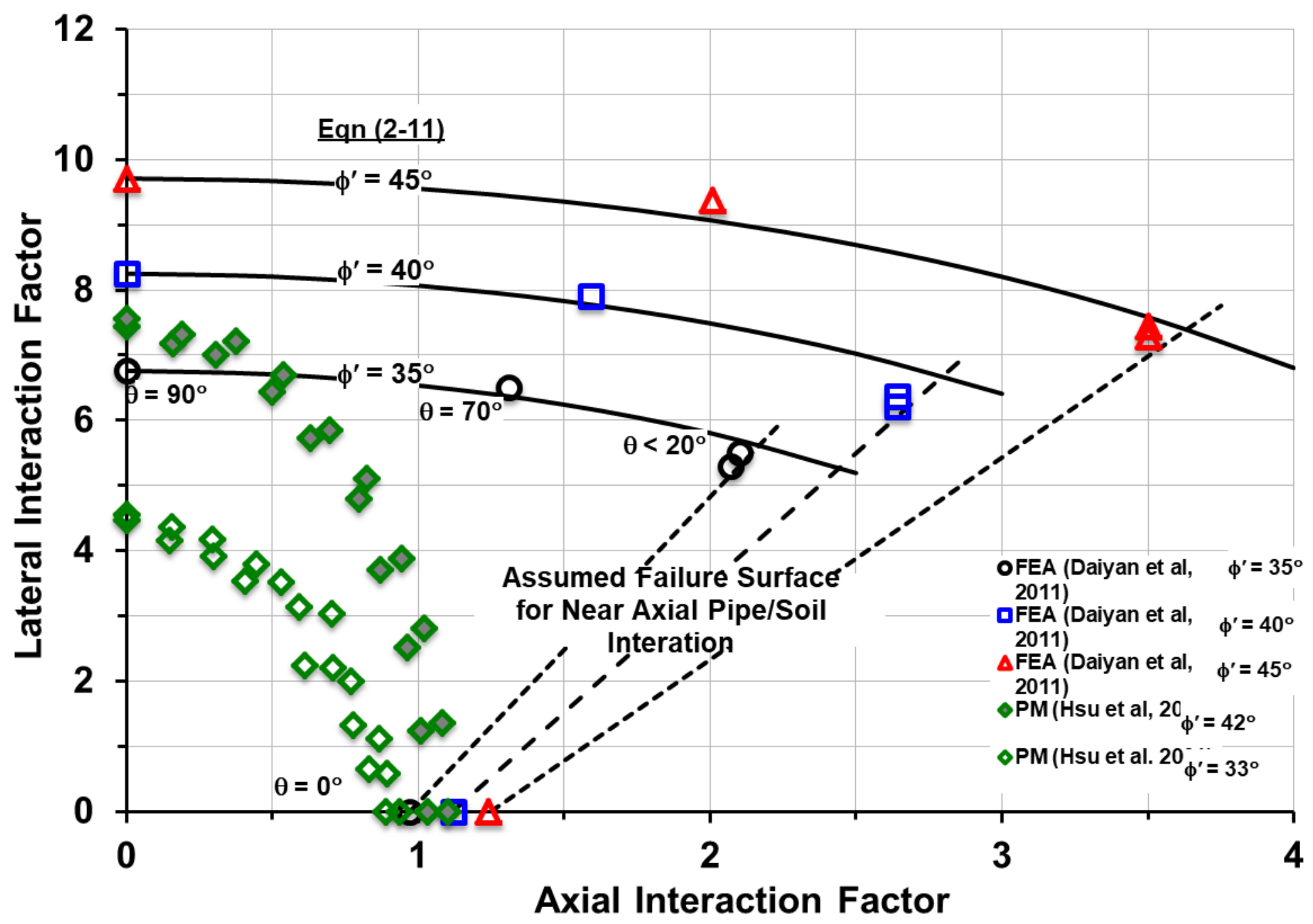

Figure 2-9 Lateral-Axial oblique loading failure envelope for non-cohesive soil with heavy pipe configuration at an embedment ratio $H / D=2$ and interface friction factor of 0.5 (from Kenny and Jukes, 20015) 


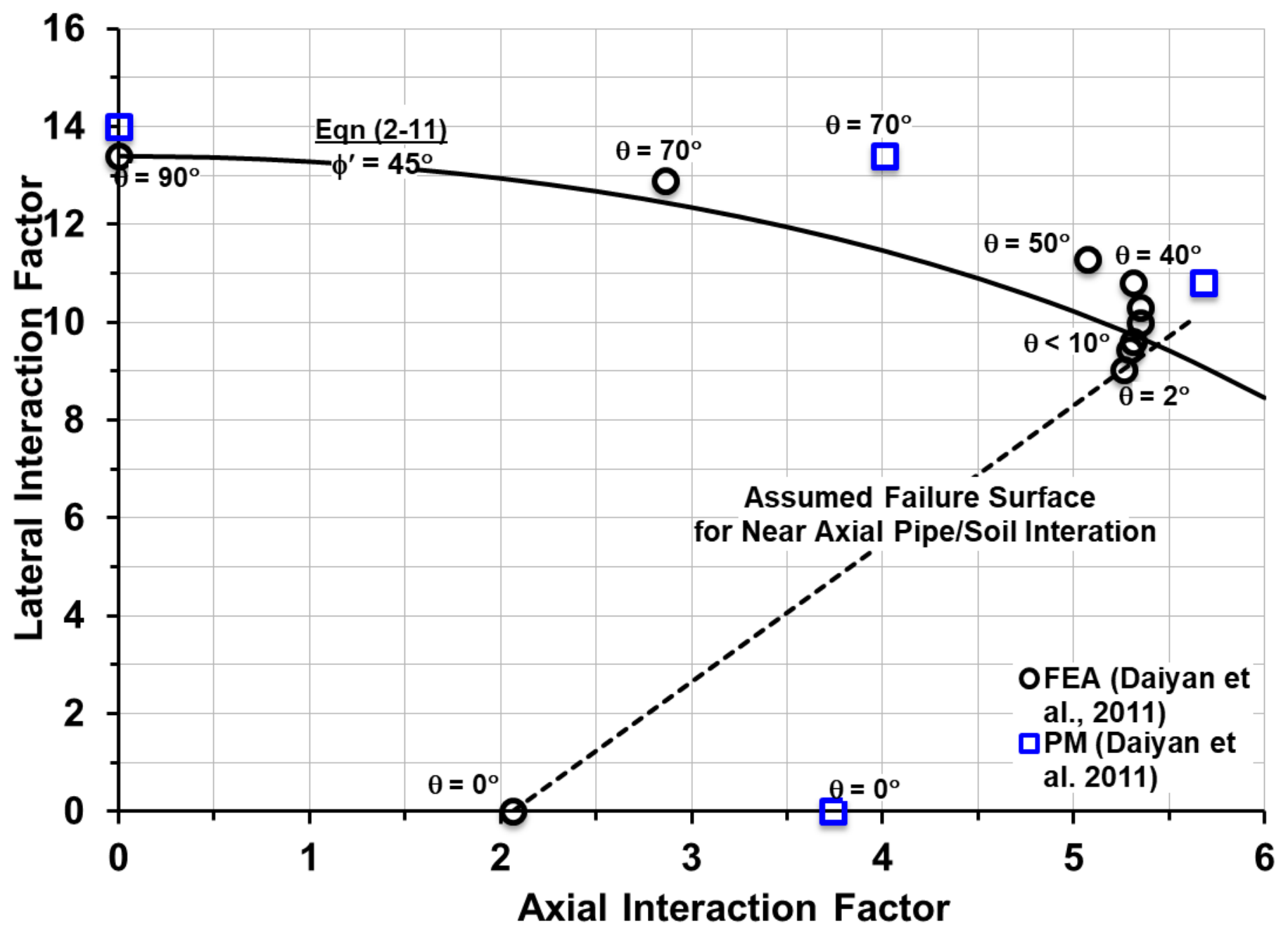

Figure 2-10 Lateral- axial oblique loading failure envelope for cohesive soil (from Kenny and Jukes, 2015) 


\section{Centrifuge Test Preparations and Methodology}

\subsection{Introduction}

Due to the cost-effectiveness of reduced-scale tests compared to full-scale tests, centrifuge testing was used for this research. This chapter will discuss the facility, test preparation and methodology used for the completion of this research.

\subsection{C-CORE Centrifuge Facility}

The C-CORE Centrifuge Facility in St. John's, Newfoundland was used to complete the research. The centrifuge machine has a radius of $5.5 \mathrm{~m}$ and a payload capability of $200 \mathrm{G}$. The centrifuge also has the capability to model cold weather scenarios with the use of refrigeration, and earthquake loading with the use of an Actidyn earthquake simulator. The centrifuge can also model scenarios involving water and wave loading by adding water to the payload.

All of the samples were prepared in the adjoining soil preparation laboratory, which included a sand raining room and workspace. C-CORE and Memorial University machined all of the parts used during testing on site including the centrifuge strongbox, stanchions, and load cells used for testing.

\subsection{Testing Program}

A series of ten reduced-scale tests were completed in dry loose silica sand. The parameters for these tests, including acceleration, burial depths, and testing angles were based on the previous research completed at the facility by Daiyan (2013), Debnath (2015), Kenny (2015), and Phillips (2004). The testing angles were chosen based on results of the finite element models completed by Daiyan (2013) which were conducted using similar angles. Dry sand was used to 
simplify the results as pore water pressure, buoyancy of the pipeline, and cohesion of the soil would not need to be taken into account during data processing. Daiyan (2013) and Debnath (2015) also used similar soil parameters. The same strongbox and pipe were used for all ten tests. The measurements of the strongbox and pipeline can be found in Table 3-1. The results of these tests will be discussed in Chapter 4 .

Six tests were completed at a shallow burial depth of $2 \mathrm{D}$ at the pipe springline with a gravitational acceleration of $6.25 \mathrm{~g}$. The model pipeline diameter was $48 \mathrm{~mm}$, which equates to a prototype (i.e. full scale) $304 \mathrm{~mm}$ pipe diameter. The shallow pipe was modelled at the following angles: $0^{\circ}$ (pure axial), $20^{\circ}, 50^{\circ}, 70^{\circ}$, and $90^{\circ}$ (pure lateral) within the horizontal lateral-axial plane. Five of the tests $\left(0^{\circ}, 20^{\circ}, 50^{\circ}, 70^{\circ}\right.$, and $\left.90^{\circ}\right)$ were completed with crushable acoustic foam in front of the stanchions. To assess the influence of end bearing effects, one shallow lateral test $\left(90^{\circ}\right)$ was completed without crushable acoustic foam in front of the leading stanchion. The load cell during the $70^{\circ}$ test failed since the cables connecting the load cells were damaged. The damage occurred at a true mobilization distance of approximately $15 \mathrm{~mm}$. The load cells cables were reattached, and the calibration matrices were re-confirmed. It was determined that recalibration of the load cells was not required as the calibration matrix matched when a sample load was applied. The calibration process will be discussed in Section 3.5.1.

Four tests were completed at springline burial depth of $4 \mathrm{D}$ and acceleration of $13.25 \mathrm{~g}$. The deeper burial depth condition modelled a prototype $609.5 \mathrm{~mm}$ diameter pipeline with loading angles of $0^{\circ}, 20^{\circ}, 30^{\circ}$ and $90^{\circ}$ degrees. Crushable acoustic foam was placed in front of the stanchions for all four of the tests. Neither Daiyan (2013) nor Debnath (2015) had completed tests at this depth. The deeper burial depth allowed for a higher confining pressure on the pipe 
and the data obtained will be used at a later date to confirm the scaling factors and finite element analysis previously proposed. This is the deepest that the pipe can be buried using the existing strong box if a bedding layer of $2 \mathrm{D}$ is to remain. During the final test at $30^{\circ}$, the load cells failed, and the full mobilization distance was not attained. Figure 3-1 shows the burial depths of both shallow and depth tests in relation to the strongbox.

For nine out of ten tests, a $50 \mathrm{~mm}$ by $50 \mathrm{~mm}$ piece of crushable acoustic foam was placed in front of the stanchions. The foam was placed to cover the entire length of the stanchion to the dog bone, $135 \mathrm{~mm}$ for the shallow tests and $200 \mathrm{~mm}$ for the deep tests, and was placed after the initial bedding layer. During testing, the stanchions moved into the foam to minimize the effects of the stanchions moving through the sand.

The pipe was loaded and unloaded several times during testing. The cyclical loading allows for verification and calibration of any inputted soil properties during numerical modeling by providing information on the elastic behaviour of the soil (Daiyan, 2013). During each test, the pipe was pulled forward for approximately 0.3 pipe diameters $(0.3 \mathrm{D})$ and then returned to its start position. The pipe was then moved to $0.6 \mathrm{D}$, returned to $0.3 \mathrm{D}$ and then mobilized to its full mobilization length. For the shallow tests, the pipe was mobilized a total of 1.0 to 1.2 pipe diameters. For the deep tests, the pipe was mobilized to a total of approximately 2.2D. The total displacement distance was determined by comparing the results of the previous research of Daiyan (2013) and Debnath (2015) and the ALA guidelines. The ultimate yield displacement proposed in the ALA (2005) guidelines is 0.1D for cohesionless soils and 0.2D for cohesive soils (Kenny and Jukes, 2015). Previously completed reduced-scale tests using dry sand determined an ultimate yield displacement closer to 1D to 1.1D. With the increased confining pressure on the pipe during the deep tests, it was assumed that an increase in the overall displacement of the pipe 
would be required since the ultimate yield displacement was expected to be higher. The total mobilization distance was measured using the motorized carriage and confirmed with the laser measurements from the guiding plate and the dog bone.

\subsection{Testing Setup}

The testing apparatus and instrumentation used for this series of reduced scaled models were similar to those used by Debnath (2015) and Daiyan (2013). As shown in Figure 3-2, the pipe assembly, shown in Figure 3-3, was mounted on a guiding plate within the strong box. The guiding plate was attached to an actuator, which moved the pipe through the sand at a constant speed of $2.5 \mathrm{~mm} / \mathrm{min}$. The entire assembly was attached to support beams to ensure stability during testing.

As shown in Figure 3-3 and Figure 3-4, the pipe assembly included a 46mm diameter hollow pipe (1) with two bi-axial load cells $(2,3)$ which were used to measure the axial and lateral loads during the tests. The pipe was pulled through the prepared soil bed by vertical stanchions $(4,5)$ and braced horizontally by a 'dog bone' piece (6). For the last two tests, which were completed at a deeper burial depth and therefore subjected to a higher load, two dog bones were used to help stiffen the assembly and to keep the stanchions in place. The two dog bone assembly (6) is shown in Figure 3-4.

As shown in Figure 3-4, each stanchion was placed through an opening in the ball race $(7,8)$. The ball race acts as a sleeve for the stanchions and allows for vertical movement of the pipe assembly. The ball races are then attached to a guiding plate, which is attached to the motorized carriage, which is used to pull the pipe through the soil at an approximate speed of $2.5 \mathrm{~mm} / \mathrm{min}$. 
As shown in Figure 3-5, two pieces of crushable acoustic foam were placed in front of the stanchions according to the direction of motion of the pipe, to limit the effect of the stanchions during pipeline mobilization. The stanchions moved into the foam during testing.

During the preparation of the soil bed, the centrepiece of the dog bone was removed, and the back bracket (7) was used to hold the pipe in place and at the correct angle. This was to ensure that the dog bone did not affect the density of the sand above the pipe during the sand raining process. Once the soil bed preparation was completed, the centrepiece of the dog bone was screwed into place, and the back bracket was removed for testing. The back bracket was screwed to the bottom of the strongbox at the correct angle during the dry fit process.

For this research, the pipe was not restrained vertically. No additional external vertical loads were added during this research.

\subsection{Testing Instrumentation}

Shown in the Figure 3-3, Figure 3-4, and Figure 3-5, the instrumentation used to monitor the behaviour of the soil and of the pipeline included a linear variable displacement transducer (LVDT) at each end of the dog bone (9) to monitor the vertical displacement of the pipe assembly, an LVDT in the corner of the soil bed to determine the settlement of the soil due to the acceleration of the payload, a laser to measure the horizontal displacement of the motor carriage (12), and a laser to measure the horizontal displacement of the pipe assembly (15). A cone (13)

for a cone penetration test was also completed once the prepared sample reached the required acceleration for the test. All of the instrumentation was calibrated before the beginning of testing. The results of the calibrations are shown in Appendix B. 


\subsubsection{Load Cells}

Two biaxial load cells were used during testing. The design and operation of the load cells were based on Stroud (1971). As shown in Figure 3-6 and Figure 3-7, the load cells included four longitudinal strain gauges placed on the webbing pieces (axial) and two horizontal strain gauges (lateral) placed on the horizontal webs. The load was transferred to the load cell through a ball bearing placed between the load cell and the pipe. This type of connection was chosen since no moment could be transferred to the load cell during testing.

Due to the orientation of the strain gauges, and the reduced size of the load cells, cross-talk between the lateral and axial strain gauges had been noted during previous tests (Daiyan, 2011, and Debnath, 2013). To ensure that the load cell readings were calibrated correctly to account for the crosstalk, the calibration methodology included incrementally loading and unloading each load cell in the axial, lateral, and combined directions. For the lateral calibrations, each load cell was tested at a lever arm length of $35 \mathrm{~mm}$ and $45 \mathrm{~mm}$, which is shown as ' $\mathrm{L}$ ' in Figure 3-7. A pulley system was used to make the lateral loading easier. Each load cell was loaded up to 102 $\mathrm{kg}$ in $10 \mathrm{~kg}$ increments at the following orientations: pure axial (down), pure lateral $\mathrm{L}=35 \mathrm{~mm}$ (right), pure lateral $\mathrm{L}=45 \mathrm{~mm}$ (right), pure lateral $\mathrm{L}=35 \mathrm{~mm}$ (left) and pure lateral $\mathrm{L}=45 \mathrm{~mm}$ (left). This allowed for the calculation of a coupled calibration matrix for each load cell in both lateral loading directions, which could be used to correct for crosstalk of the gauges (Maddocks, 1981).

A final test using the calibration apparatus, shown in Figure 3-8, was completed where the load cell was loaded both axially and laterally at a given lever arm length. For the final calibration test, the load cell was loaded incrementally up to $51 \mathrm{~kg}$ in the axial and lateral direction. This final calibration test was conducted to confirm that the correct calibration matrix 
was being used and after the load cell cables were reattached after Test $6\left(70^{\circ}, \mathrm{H} / \mathrm{D}=2\right)$. The load cells were labelled to ensure that the correct matrix was used for each test.

\subsubsection{LVDTs}

The three LVDTs were calibrated using a calibration device and procedure established by C-CORE. The calibration device locked the LVDT in place and allowed translation of the pin where the voltage output could be related to a specified displacement through a linear calibration equation.

An LVDT was placed on each dogbone piece to measure the vertical displacement of the pipe during testing. A third LVDT was also placed in the far corner of the strong box away from the pipe assembly. The third LVDT was used to measure the settlement of the sand layer during the acceleration of the payload.

\subsubsection{Lasers}

Two lasers were calibrated using a series of length bars with a known length. One laser target was placed on the motor to measure the horizontal displacement of the entire pipe assembly. One laser target was also placed on one of the dog bone pieces to measure the horizontal displacement of the assembly near the sand surface. This was done to allow for a correction of the horizontal displacements based on the possible rotation of the pipe assembly. 


\subsection{Material Properties}

The strongbox and pipe assembly were all machined and assembled at the C-CORE facility. A smooth SCH 80s steel pipe with a diameter of $46 \mathrm{~mm}$ was used for the pipe section which relates to a friction factor of 0.7 (ALA, 2005). Previous tests conducted by Daiyan (2013) used a $41 \mathrm{~mm}$ diameter pipe which was heavier (Debnath, 2015). A slightly larger, lighter pipe was used in subsequent research to minimize any downward movement of the pipe during the acceleration of the payload during testing.

Acoustic foam, shown in Figure 3-9, was chosen as the crushable foam in front of the stanchions due to its elastic behaviour. The foam was re-used between tests once the foam reverted to its original shape. Painters tape was used to hold the foam in place. Based on material data sheets of similar foam, the tensile strength of the foam varies from $50 \mathrm{kPa}$ to $80 \mathrm{kPa}$ (Zhang, 2007). In previous studies conducted by Daiyan (2013), a firmer pink expanded polystyrene (EPS) was used to help mitigate the effects of the stanchions and no foam was used in the reduced scale tests conducted by Debnath (2015). The ultimate loads noted in Daiyan's (2013) research were higher than expected while Debnath's (2015) research provided lower than expected values. The foam used during this research was chosen to provide less resistance than the EPS while still mitigating the effects of the stanchions. More details on the results of these tests are shown in Chapter 4.

A loose fine-grained silica sand was used as the bedding material for the testing. Three sieve analysis tests were conducted on three samples of the sand used during testing to confirm the soil classification. The results of all three tests were similar and are shown in Figure 3-10. The $\mathrm{D}_{50}$ of the soil is $0.21 \mathrm{~mm}$. The sand was re-used between each test which introduced deleterious material such as paint flecks to the sand. The differences in the results of sieve analysis 2 may 
have been caused by deleterious material and does not affect the characterization of the soil. Similar sand was used for the previous research conducted by Debnath (2015) and Daiyan (2013).

A series of five simple shear tests, shown in Figure 3-11, were conducted on the sand at the Carleton University soil laboratory. The simple shear tests were conducted using drained conditions and followed the ASTM standard procedure (ASTM, 2011). The tests were conducted using normal stresses of $26 \mathrm{kPa}$ to $125 \mathrm{kPa}$ which are similar to the loads that acted on the sand during centrifuge testing. These test resulted in an average peak friction angle of $29^{\circ}$. The results of these tests are shown in Appendix A.

\subsection{Test Bed Preparation}

For all ten of the completed tests, the sand was rained into the strongbox in three layers using sand raining conditions based on the sand raining procedure provided by C-CORE. The sand was rained into the strong box at a constant speed of $7 \mathrm{~cm} / \mathrm{s}$. The sand raining heights were determined by conducting three sand raining trials with sample containers at various heights during each test. Based on the sand raining trials, the distance between the hopper and current sand layer was approximately $53 \mathrm{~cm}$ for each layer. The top of the sand was vacuumed between each layer to ensure that each layer remained as flat as possible to help ensure a uniform density over the area of the strong box. The density of the samples varied from $1450 \mathrm{~kg} / \mathrm{m}^{3}$ to 1483

$\mathrm{kg} / \mathrm{m}^{3}$. The average density was $1468 \mathrm{~kg} / \mathrm{m}^{3}$ with a standard deviation of 10 . The density for each test is shown in Table 3-2.

A bedding layer of $100 \mathrm{~mm}(2.4 \mathrm{D})$ was used for each test to ensure the bottom of the strong box did not affect the results of the test. The initial and final location of the pipe was also never 
closer than $2.5 \mathrm{D}$ to ensure that the sides of the strong box did not affect the test results. The pipe has been modelled as though it were in a continuous layer of homogeneous soil.

\subsubsection{Cone Penetration Tests}

Cone Penetration Tests (CPTs) were conducted on each sample once the payload reached the desired acceleration and before the pipeline mobilization began. An additional CPT was conducted after Test $9\left(90^{\circ}, \mathrm{H} / \mathrm{D}=4\right)$ when the centrifuge was at rest. The CPTs were conducted to confirm that a similar density was maintained between each test.

To conduct the CPT, an instrumented cone was pushed into the sand at a rate of $2 \mathrm{~mm} / \mathrm{s}$. The tip resistance or cone load, and tip displacement were measured. The results of the CPTs are shown in Figure 3-12 for the shallow tests, and in Figure 3-13 for the deep tests. For the shallow tests (Tests 1 through 6), the tip was pushed $175 \mathrm{~mm}$ into the sample. The tip was stopped within the initial bedding layer, $60 \mathrm{~mm}$ above the bottom of the box, to ensure that the tip or load cells within the cone were not damaged. For the deep tests (Tests 7 through 10), the tip was pushed $225 \mathrm{~mm}$ into the sample or $82 \mathrm{~mm}$ above the bottom of the box.

The true density of the samples cannot be determined using the CPT data, but the CPT data between tests can be compared to ensure test repeatability. The cone was set up in the same location and was pushed in at the same speed during each test. The hard surfaces within the testing apparatus, including the bottom of the strong box, the pipe, created interference in the readings. To ensure accuracy in the tip resistance reading in comparison to the actual density of a cohesionless sample, it is recommended that the cone is stopped a minimum of ten cone diameters away from any hard surface (Bolton et al., 1999). The geometry of the testing 
apparatus, including the strongbox, sand depth, and the pipe location, did not allow for this buffer zone to be maintained during the CPTs.

To allow for easier comparison of the CPT data sets, the data was scaled based using a factor of $1: \mathrm{N}$ (Taylor, 1999). The results of the combined CPT tests are shown in Figure 3-14. The shallow CPTs show more variation than the deep CPTs, which may be caused by soil density variation through the initial sand raining process as they were the first tests completed. As the test program continued, the variation in soil density between testbeds was reduced. The slopes of the CPT data sets demonstrate that a similar density was attained for each test regardless of the slight slope variations. The densities were also confirmed with standard density calculations based on the weight and volume of the payload. The densities are listed in Table 3-2. 
Table 3-1 - Centrifuge strongbox and pipe model parameters

\begin{tabular}{|l|c|c|}
\hline \multirow{2}{*}{ Parameter } & \multicolumn{2}{|c|}{ Value } \\
\cline { 2 - 3 } & $\begin{array}{c}\text { Shallow } \\
\text { Tests }\end{array}$ & $\begin{array}{c}\text { Deep } \\
\text { Tests }\end{array}$ \\
\hline Acceleration field, g & 6.25 & 13.25 \\
\hline Pipe diameter (mm) & \multicolumn{2}{|c|}{46} \\
\hline Centrifuge strong box (mm x mm x mm) & \multicolumn{2}{|c|}{$1180 \times 940 \times 400$} \\
\hline Pipe length to diameter ratio, L/D (\#) & \multicolumn{2}{|c|}{4} \\
\hline Pipe burial depth at springline to diameter ratio, H/D (\#) & 304 & 609.5 \\
\hline Modeled pipeline diameter (mm) & \multicolumn{2}{|c|}{533} \\
\hline Pipe length with sensors (mm) & \multicolumn{3}{|c|}{} \\
\hline
\end{tabular}

Table 3-2 - Mobilization Angle and Density of Tests

\begin{tabular}{|c|c|c|c|c|}
\hline Test ID & $\begin{array}{c}\text { Acceleration } \\
\text { Field }\end{array}$ & Burial Depth & $\begin{array}{c}\text { Angle of } \\
\text { Movement }\end{array}$ & Density $\mathbf{( k g / \mathbf { m } ^ { 3 } )}$ \\
\hline 1 & 6.25 & 2D & $50^{\circ}$ & 1475 \\
\hline 2 & 6.25 & 2D & $0^{\circ}$ & 1453 \\
\hline 3 & 6.25 & 2D & $\begin{array}{c}90^{\circ}(\text { no } \\
\text { foam) }\end{array}$ & 1460 \\
\hline 4 & 6.25 & $2 \mathrm{D}$ & $\begin{array}{c}90^{\circ} \\
\text { (foam) }\end{array}$ & 1468 \\
\hline 5 & 6.25 & 2D & $20^{\circ}$ & 1450 \\
\hline 6 & 13.25 & 4D & $70^{\circ}$ & 1475 \\
\hline 7 & 13.25 & 4D & $0^{\circ}$ & 1483 \\
\hline 8 & 13.25 & 4D & $20^{\circ}$ & 1465 \\
\hline 9 & 13.25 & 4D & $90^{\circ}$ & 1470 \\
\hline $9-$ Post & 1 & N/A & N/A & 1470 \\
\hline 10 & 13.25 & 4/D & $30^{\circ}$ & 1475 \\
\hline
\end{tabular}




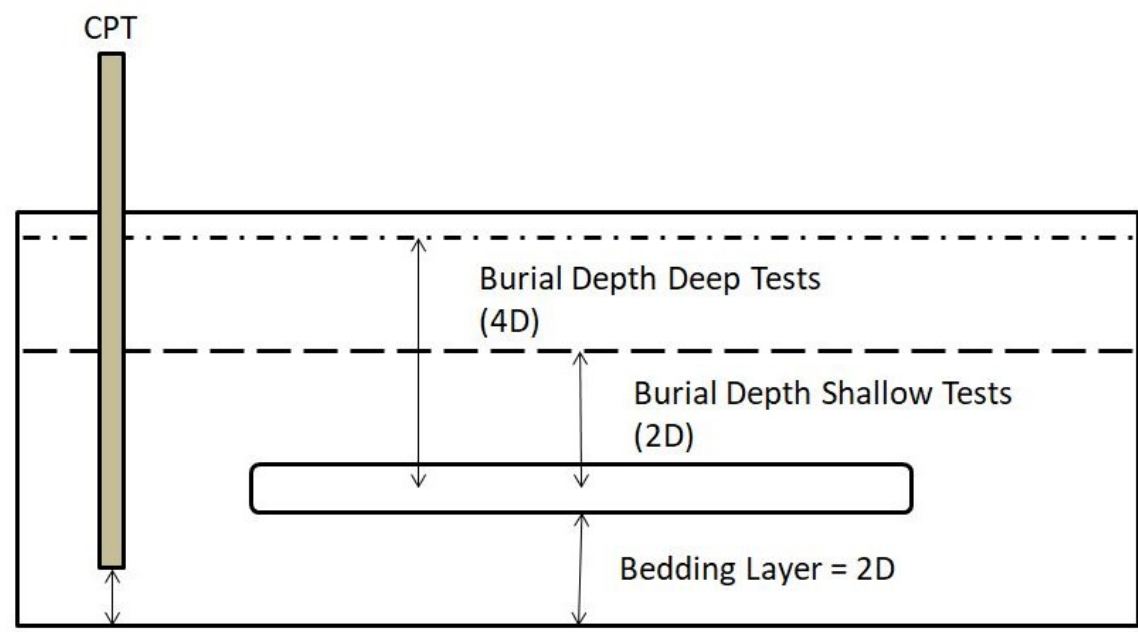

CPT Test stopped 1 to 2D from bottom of the box

Figure 3-1 - Schematic diagram of shallow and deep pipe embedment depth

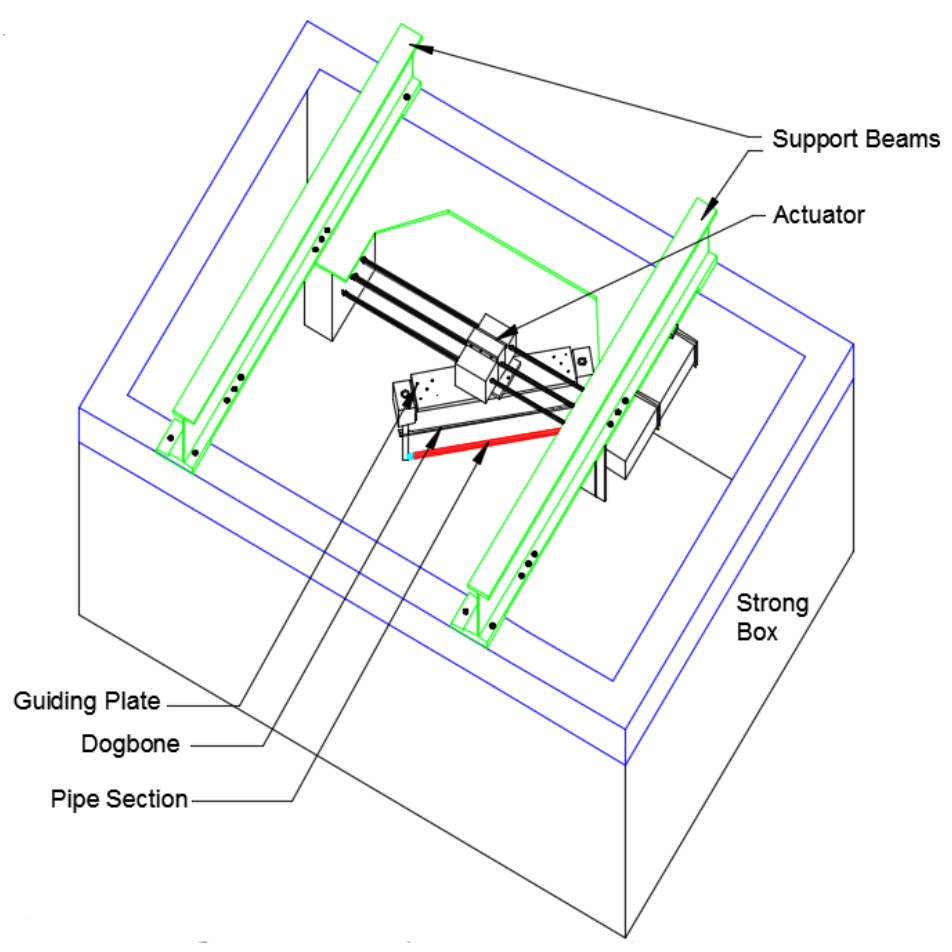

Figure 3-2- Pipe Set-up within Strongbox (Debnath, 2016) 


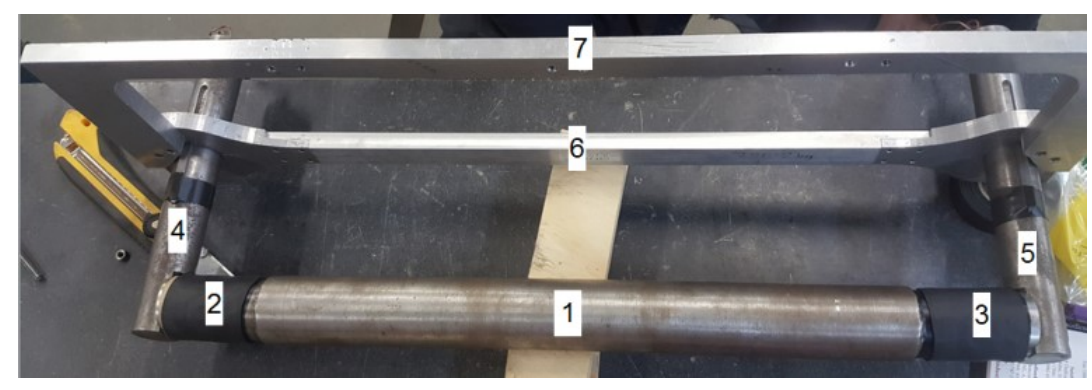

Figure 3-3- Pipe assembly (1) including biaxial load cell $(2,3)$, stanchions $(4,5)$, dog bone (6), and back bracket (7).

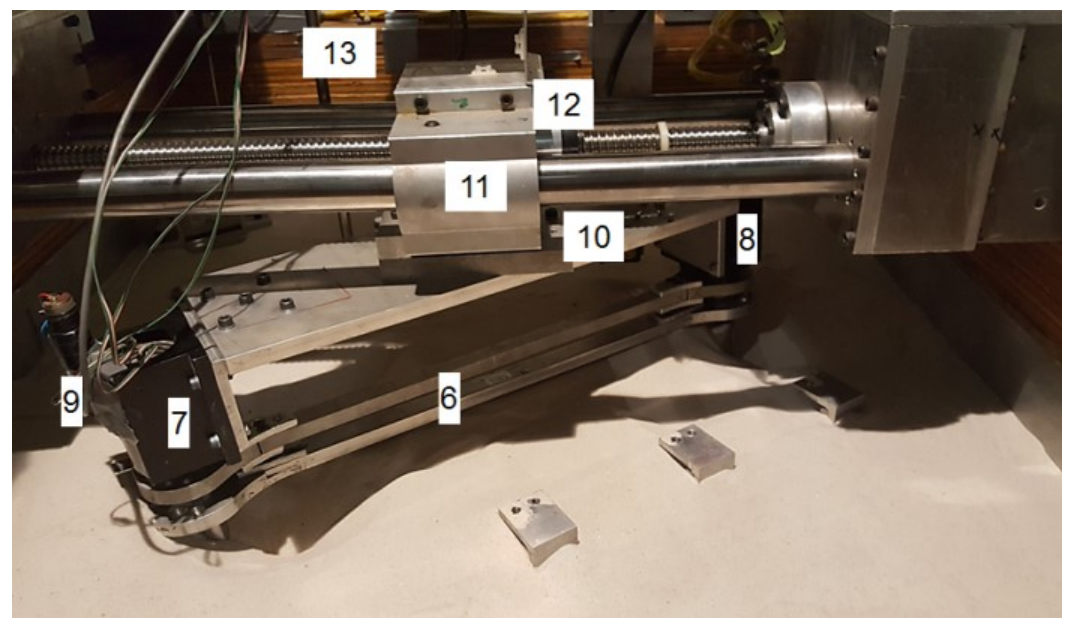

Figure 3-4- Major elements of the centrifuge test apparatus ('payload') including dog bone (6), ball race (7, 8), LVDT (9), guiding plate (10), motorized carriage (11), laser (12), and cone (13). 


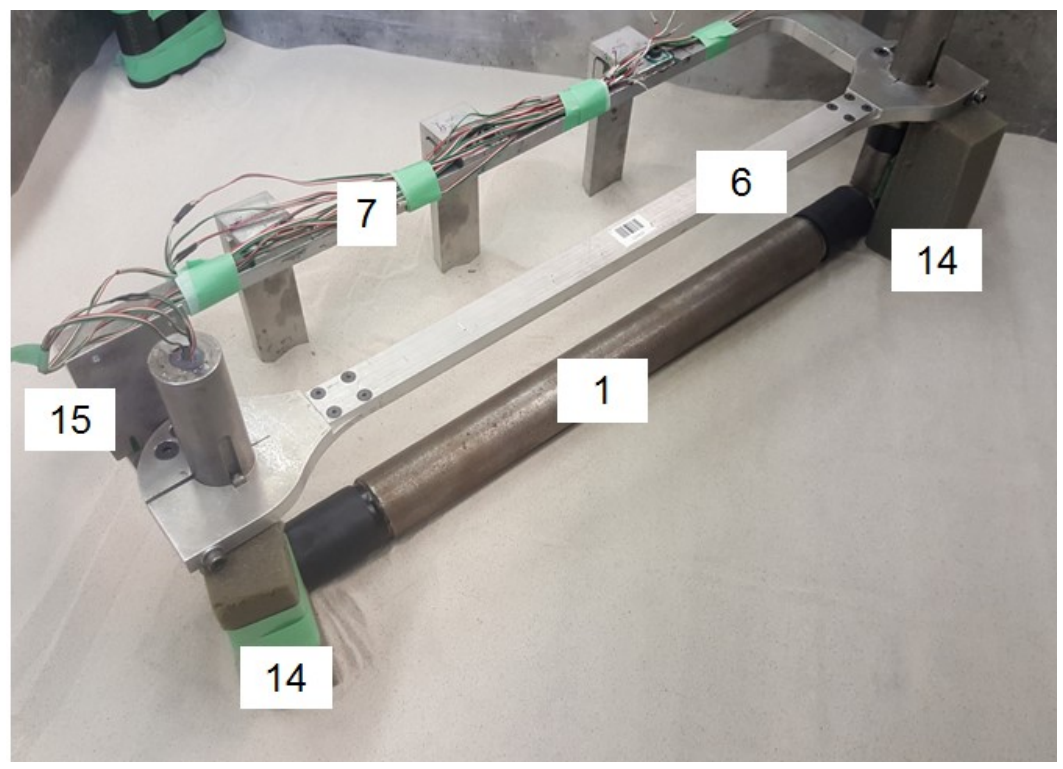

Figure 3-5 - Pipe assembly (1) in strongbox after bedding layer including back bracket (7), acoustic foam (14), and laser target (15).

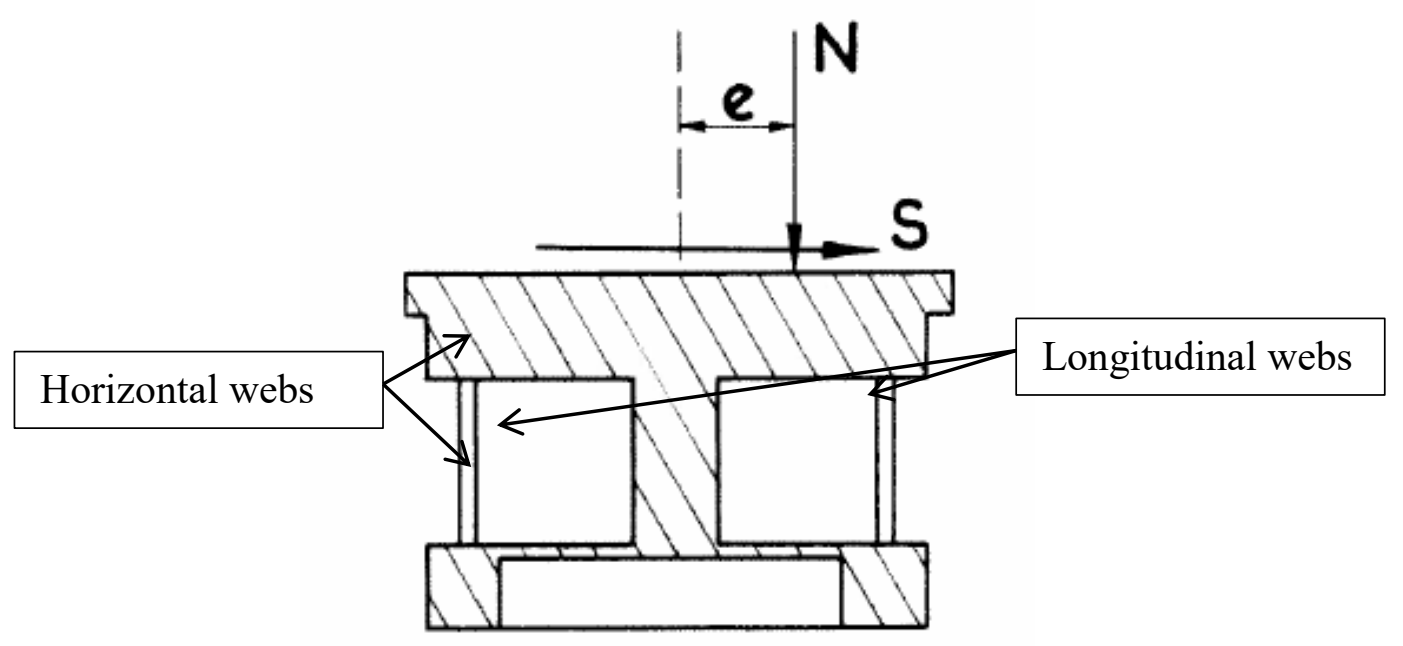

Figure 3-6- Load cell configuration, based on Stroud (from Debnath, 2016) 


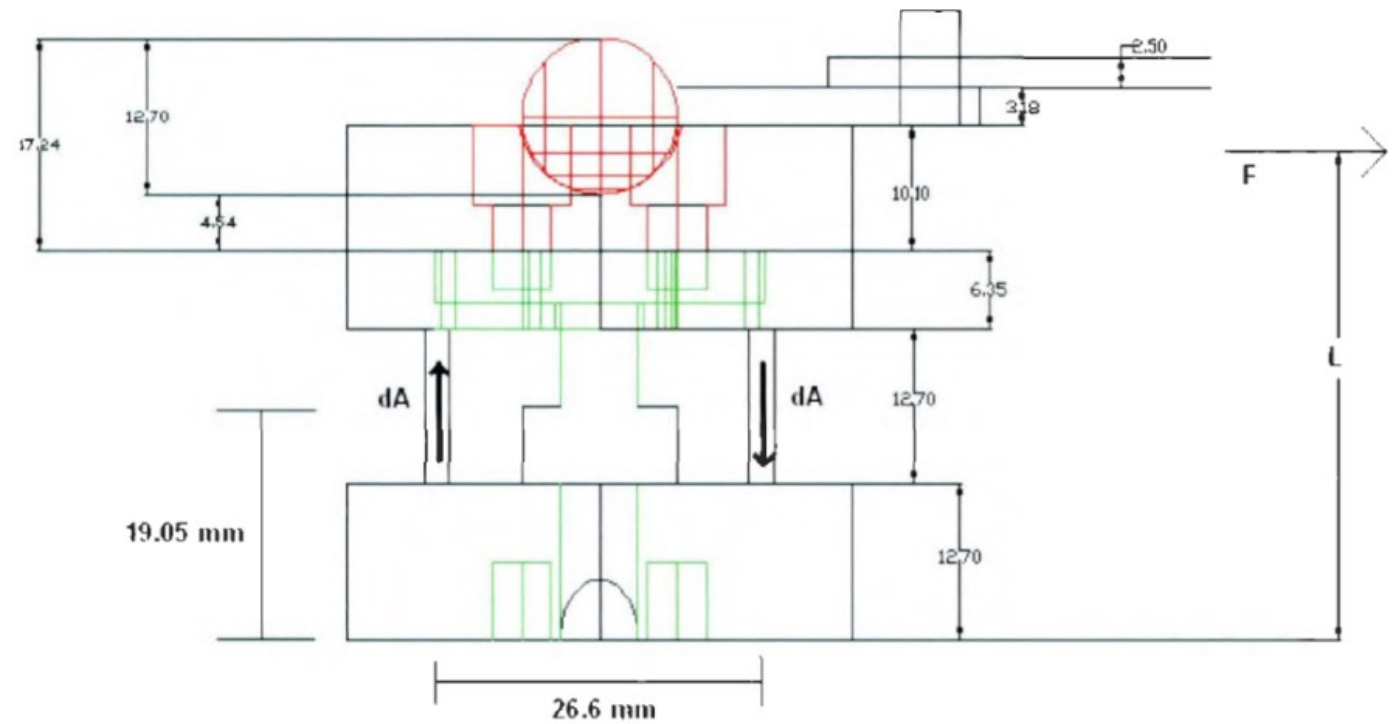

Figure 3-7- Load cell dimensions and schematic used for lateral load (from Daiyan, 2011)

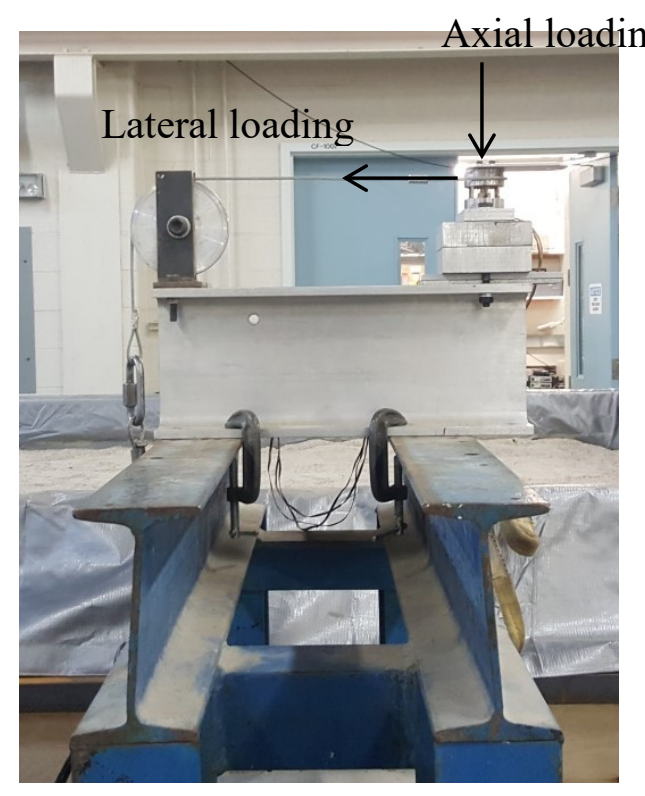

Figure 3-8- Load cell calibration apparatus used for lateral and axial loading 


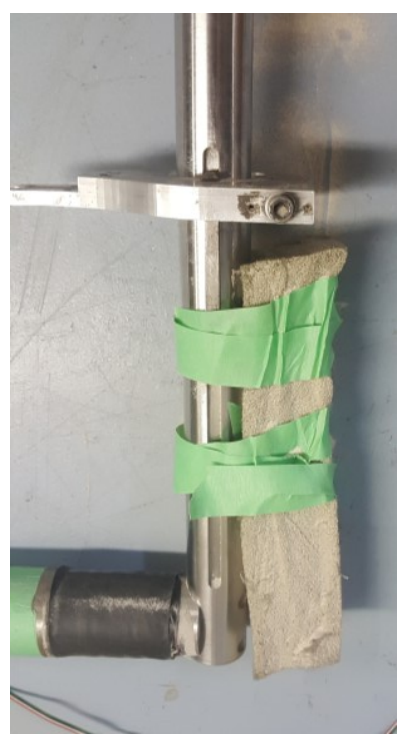

Figure 3-9- Crushable Acoustic Foam after Test 8, 20, $\mathrm{H} / \mathrm{D}=4 \mathrm{D}$

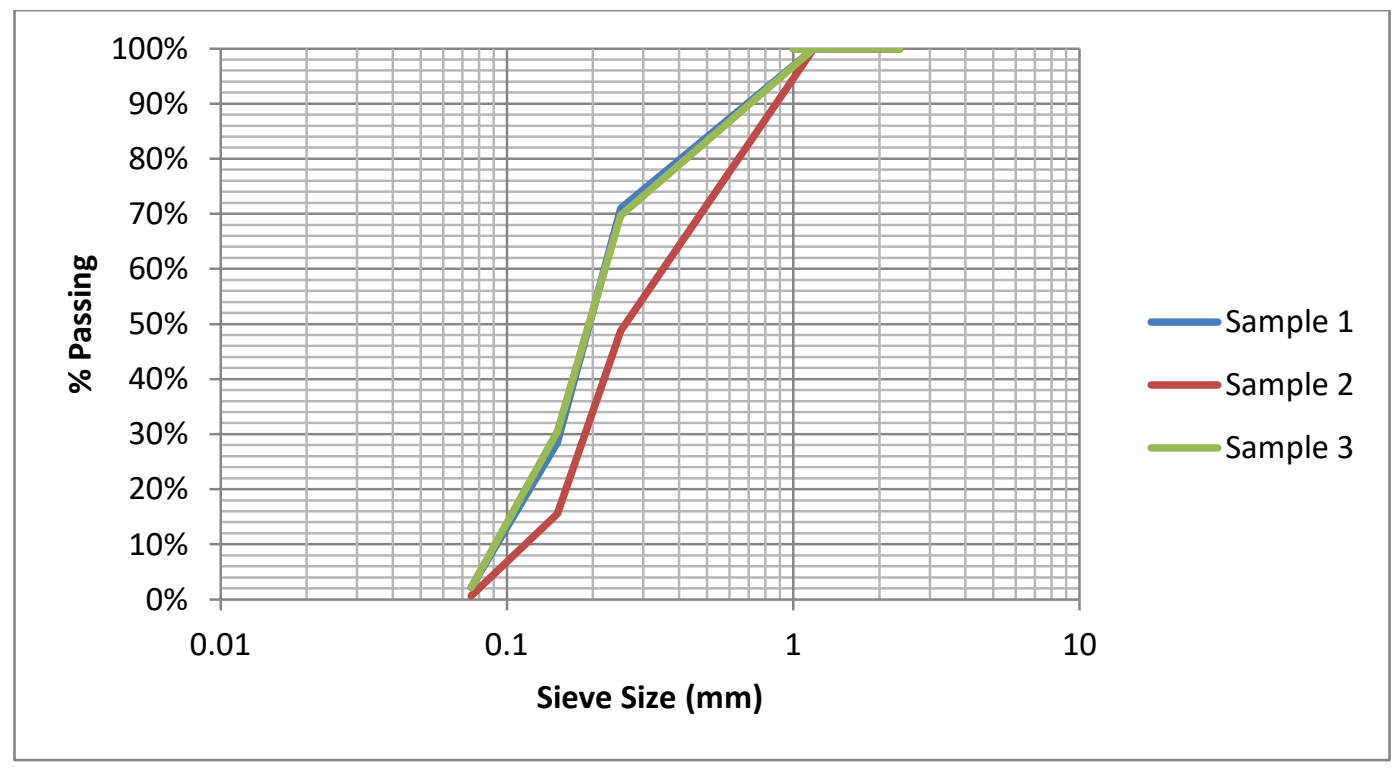

Figure 3-10- Sieve analysis results for sand used in testing 


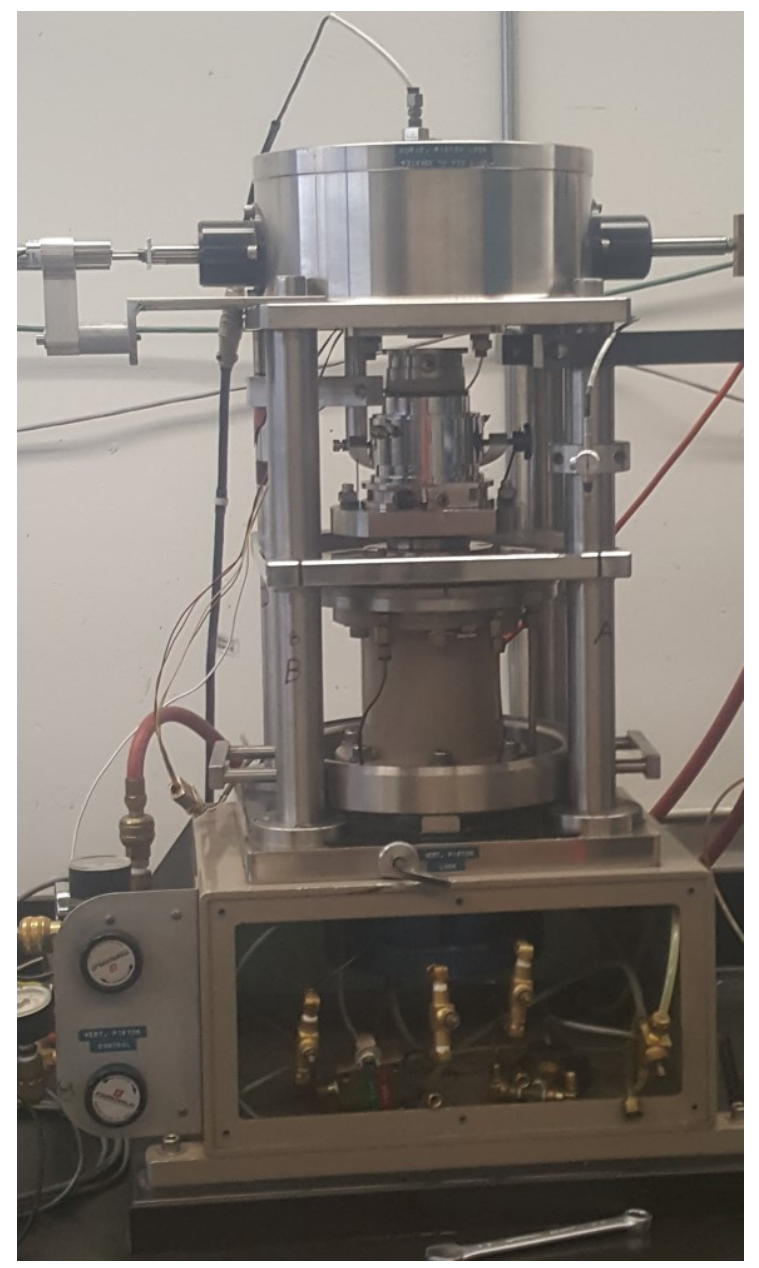

Figure 3-11 Simplified direct shear testing apparatus 


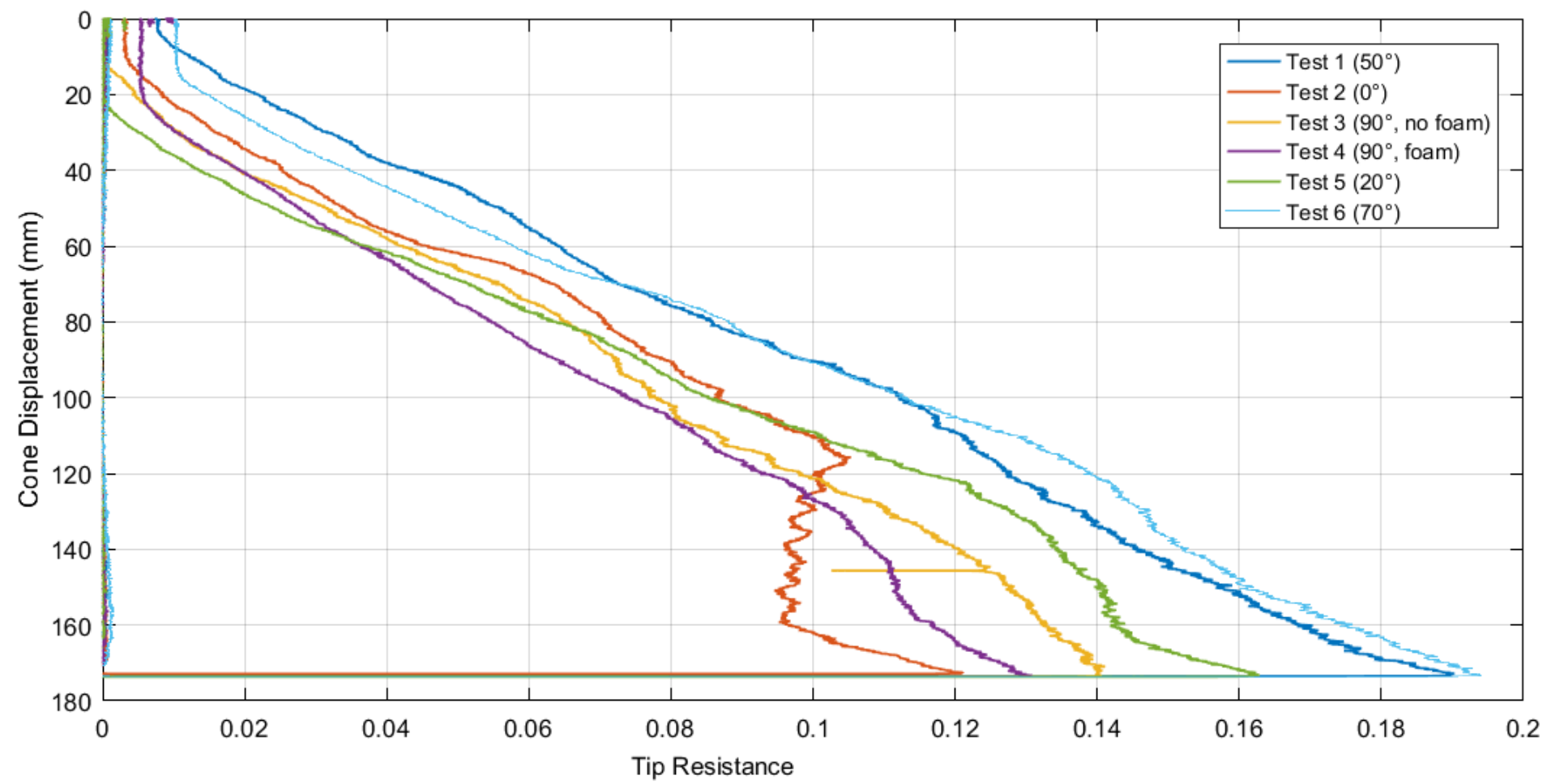

Figure 3-12- Cone penetration tests results for shallow burial depth tests $(H / D=2)$ 


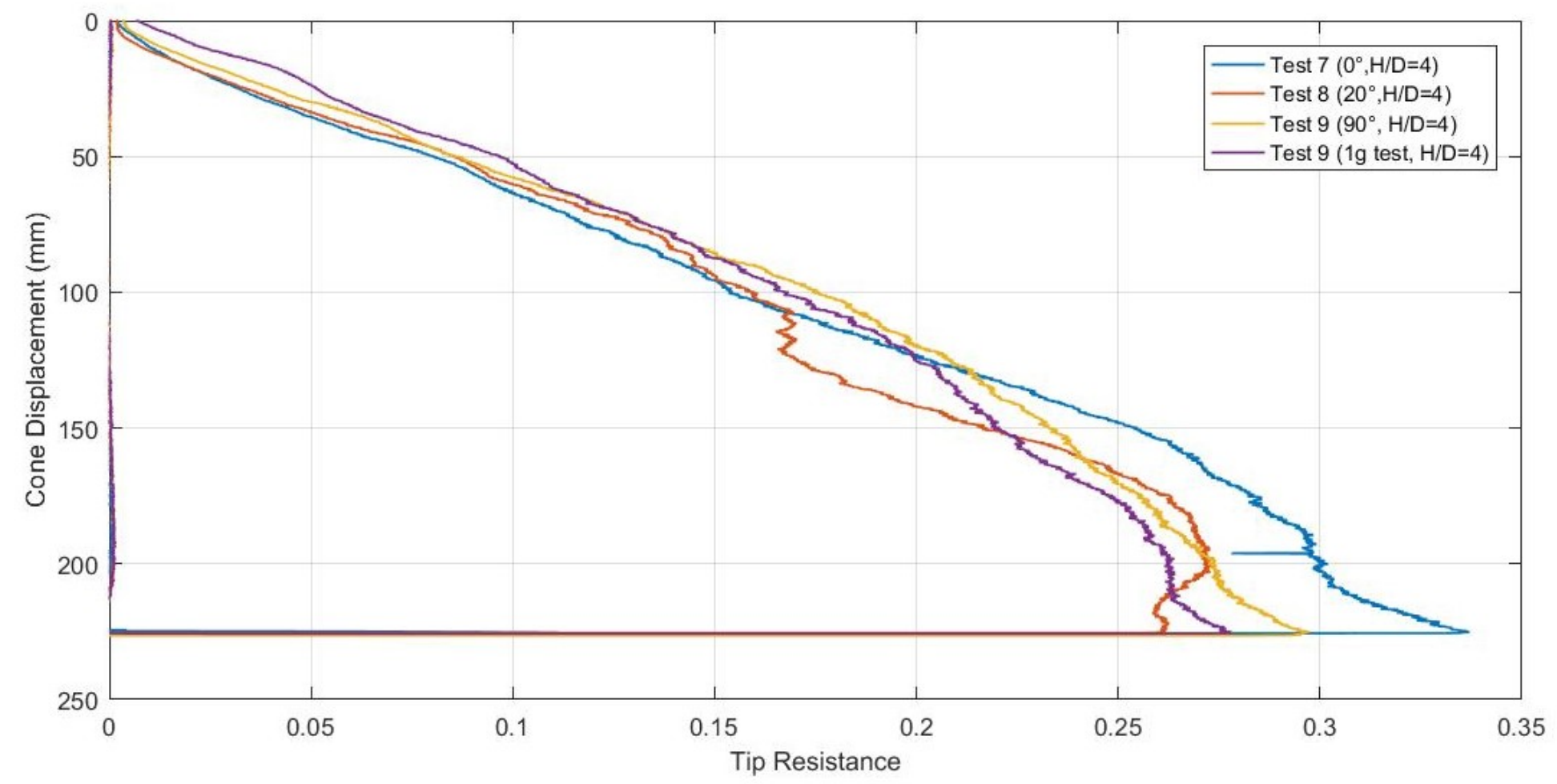

Figure 3-13 - Cone penetration test results for deep burial depth tests $(H / D=4)$ 


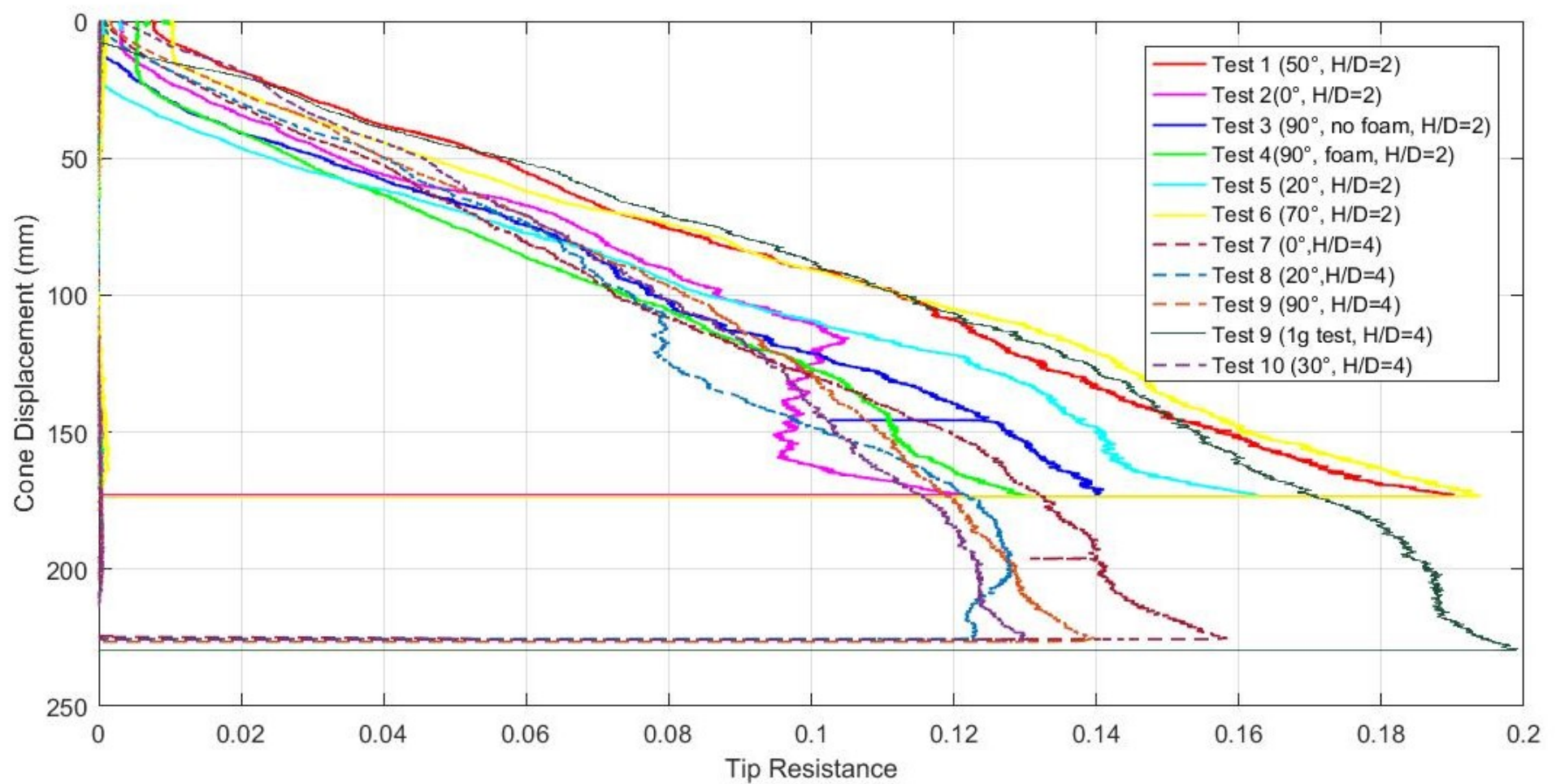

Figure 3-14- CPT test results normalized to an acceleration of $1 \mathrm{~g}$ 


\section{Experimental Results}

\subsection{Overview}

A series of ten reduced scale centrifuge tests were completed at the C-CORE facility. The raw data was collected and analyzed using MATLAB and Excel. This chapter will present the results of these tests and compare the results to previous research.

A series of six tests were completed at a spring line burial depth of 2D and were considered the shallow tests. As shown in Figure 4-1, the tests were completed at the following angles: $0^{\circ}$, $20^{\circ}, 50^{\circ}, 70^{\circ}, 90^{\circ}$, and $90^{\circ}$. One of the $90^{\circ}$ tests was completed without the acoustic foam to allow for a comparison of the loading results. During the final shallow test at $70^{\circ}$, Test 6 , the sensor cables came loose during the test and caused faulty readings starting at a true mobilization of approximately $15 \mathrm{~mm}$. The load cells were not damaged during Test $6\left(\mathrm{H} / \mathrm{D}=2 ; 70^{\circ}\right.$ attack angle). The raw data from all of the shallow tests can be found in Appendix B.

A series of five tests were completed at a spring line burial depth of 4D and were considered the deep tests. As shown in Figure 4-2, the tests were completed at the following angles: $0^{\circ}, 20^{\circ}$, $30^{\circ}$, and $90^{\circ}$. During testing, the increased loads due to the deeper burial depth during all four tests caused additional bending of the dog bone pieces and may have affected the results. After the first deep test, a second dog bone was added to stiffen the setup and to help minimize the bending. However, bending was still visually noted during testing, as shown in Figure 4-3.

During Test $9\left(90^{\circ}\right)$, the force of the stanchions pulling the model pipe was higher than the resistance provided by the load cells and dog bone pushing inward to the pipe. The load cell reading dropped to zero load at a displacement distance of approximately $2 \mathrm{D}$, which indicated 
that the pipe was pushed out from between the two stanchions. The pipe was pushed out with enough force to cause the ball bearing to etch into the front of the load cell during test failure, shown in Figure 4-4. During Test $10\left(\mathrm{H} / \mathrm{D}=4 ; 30^{\circ}\right.$ attack angle), the seal on the actuator failed at a mobilization of approximately 2.1D, shown in Figure 4-5. No additional tests could be conducted after the seal failed. The loads measured during the deep tests were approximately $25 \%$ higher than expected. Based on the equations proposed by ALA (2005), Honegger and Nyman (2001), and PRCI (2004), the expected loads were approximately $1.5 \mathrm{kN} / \mathrm{m}$ while the highest loads measured were $2 \mathrm{kN} / \mathrm{m}$ These higher than expected loads may have been caused by several factors including the increased resistance and weight caused by the amount of overburden sand, bending of the stanchions, and the rotation of the pipe assembly, which is discussed below. The raw data from all four deep tests is included in Appendix B. 


\subsection{Pipe Mobilization}

As discussed in Chapter 3, the mobilization distances were measured using two lasers. One of the lasers was mounted on the actuator and the second was mounted on the dogbone. As shown in Figure 4-6 and Figure 4-7, the laser mounted on actuator showed a larger overall displacement than the laser mounted on the dogbone. The true displacement of the pipe cannot be measured directly using the current the testing set up as the sand covers the pipe. The pipe is unable to move as quickly as the motor since the sand creates additional resistance for the pipe to overcome. The pipe lag, as shown in Figure 4-8, causes a larger measured mobilization at the top of the stanchion as the pipe assembly rotates during testing. Daiyan (2013) recommended the following displacement correction equation, which was used to correct the pipe displacements for this research as it helps to correct for the pipe lag:

Eq. 4-1

$$
d_{\text {pipe }}=d_{\text {actuator }}-1.5\left(d_{\text {actuator }}-d_{\text {dogbone }}\right)
$$

The difference in displacement between the two lasers varied from 7 to $9 \mathrm{~mm}$ (0.11D) during the shallow tests. During the shallow tests, the pipe was mobilized a true corrected distance of 35 to $51 \mathrm{~mm}$ or 0.7 to $1.1 \mathrm{D}$ for each respective test. During the unloading of the pipe assembly, the difference in displacement noted between the two lasers was negligible.

During the deep tests, the difference in displacement varied from 11 to $18 \mathrm{~mm}$, and the pipe was mobilized 60 to $101.2 \mathrm{~mm}$. This corresponds to approximately 1.3 to $2.2 \mathrm{D}$ if Eq. $4-1$ is used. During each unloading cycle, the difference between the displacement measurements increased from $0 \mathrm{~mm}$ to $5-8 \mathrm{~mm}$ to $11-18 \mathrm{~mm}$. This is due to the increased lag caused by the rotation of the pipe assembly. This is similar to the ratcheting effect explained in Section 2.3. The increased lag 
during the deep tests requires a refinement of equation 4-1 as the equation was determined using the resistance caused by an H/D ratio of 2 . It is expected that the equation would be closer to:

Eq. $4-2$

$$
d_{\text {pipe }}=d_{\text {actuator }}-2.5\left(d_{\text {actuator }}-d_{\text {dogbone }}\right)
$$

This equation would require an in-air test similar to the one conducted to determine the original equation to confirm if it is accurate. This equation has been based deflection calculations which found that the max deflection would be approximately 0.2D. The deflection calculations assumed that the stanchion behaved like a cantilever beam fixed at the actuator.

To help confirm the finite element models based on this series of tests, which may be completed by another researcher, the pipe assembly was loaded and then unloaded several times. This cyclical loading will allow for better verification of the input soil properties by providing information on the elastic behaviour of the soil (Daiyan, 2013). Information on the mobilization distances is presented in Section 3.3. 


\subsection{Test Results and Analysis}

During testing, the actual lateral and axial loads were measured using load cells placed on either side of the pipe, and the displacements were measured using lasers. To facilitate the comparison of data, all of the load results were normalized using the following equation:

Eq. $4-3$

$$
P_{t}=\frac{P_{u}}{\gamma D H L}
$$

where the normalized load $\left(\mathrm{P}_{t}\right)$ was defined as the real force per unit length $\left(\mathrm{P}_{\mathrm{u}} / \mathrm{L}\right)$ divided by the unit weight of the soil $(\gamma)$, the spring line burial depth $(H)$, and the pipe diameter (D). The corrected mobilization distance was divided by the pipe diameter to provide a normalized horizontal mobilization that could be easily compared to previous research (Kenny et al., 2015).

The results of the tests have been plotted as normalized load, y-axis, versus the corrected displacement, $\mathrm{x}$-axis. The primary information shown on the graphs are the peak load, and the mobilization displacements to reach the peak load, also known as the ultimate yield displacement. Based on previous research the ultimate yield displacement proposed by the ALA (2005) is $0.1 \mathrm{D}$ for cohesionless soils and $0.2 \mathrm{D}$ for cohesive soils while previous reduced-scale model experiments have shown an ultimate yield displacement is closer to 1D (Kenny and Jukes, 2015). It should be noted that the results from Test $6\left(70^{\circ}, H / D=2 D\right)$ have not been included in the analysis due to the failure of the cable leads. The normalized lateral load compared to the corrected displacement for the shallow tests are shown in Figure 4-9, and the normalized axial load as a function of the corrected displacement is shown in Figure 4-10. 
Since loose sand was used during testing, a clearly defined peak load was not evident in the soil load-pipe displacement data (see Figure 4-9 and Figure 4-10). The lack of clearly defined peak load demonstrated a slight tangent hardening modulus with increasing displacement and that a different method to define the peak load would have to be used. To define the peak load, three methods have been proposed (Pike et al. 2011). The three methods are as follows and shown in Figure 4-11:

1 - The peak load is defined as the point of intersection of the tangents to curve at small and large displacements (Wantland et al. 1982).

2 - The peak load is defined as the point where load-displacement curve becomes a steep straight tangent based on Terzaghi's definition of local failure.

3 - The peak load is defined as the true peak load at a large displacement.

For this research, the first and second methods have been used to define the peak load and the corresponding mobilization distances, which were also used by both Daiyan et al. (2013) and Debnath et al. (2015). The variation in peak load and mobilization between these two methods can vary by up to $15 \%$ depending on the shape of the loading and displacement curve.

\subsubsection{Pure Axial}

Two axial tests, one at the shallow burial depth (Test 2, $\left.0^{\circ}, \mathrm{H} / \mathrm{D}=2\right)$ and one at the deep burial depth (Test $7,0^{\circ}, \mathrm{H} / \mathrm{D}=4$ ) were conducted as a part of this research. The normalized axial loads and displacements for these tests are shown in Figure 4-12.

The normalized peak yield value for the shallow test (Test 2), using both Method 1 and 2 was determined to be $4 \mathrm{kN}$ at a normalized yield displacement of 0.1D. As shown in Figure 4-13, the 
shallow tests showed nearly twice the peak load noted in Debnath's centrifuge test which was conducted at a higher acceleration (2015), and nearly four times the peak load noted in Hsu et al. full model tests (2001). The peak load is 5\% less than loads proposed by Schaminee et al. (1990). This peak load may not be an accurate reading as the cyclical loading and unloading may have affected the results. The normalized axial loads decreased to $-2.5 \mathrm{kN}$ or $16 \mathrm{kPa}$, each time the actuator was reversed. The slope of the unloading and loading as a function of displacement are similar which indicates that the trailing and leading edge are flipped during the cyclical loading and that the behaviour of the soil is consistent in both directions. These results are similar to the cyclical loading responses noted during the previous reduces scale tests conducted by Nasser (2013).

The mobilization distance of $0.1 \mathrm{D}$ associated with the peak axial load for the shallow test is consistent with the mobilization distance as proposed by ALA (2005). The boundary conditions, i.e. the foam selected for in front the stanchions, allowed for a displacement result closer to the expected results.

For the deep test (Test 7) the peak yield value for the deep test is either $6.2 \mathrm{kN}$ with a mobilization distance of $0.5 \mathrm{D}$, using Method 1 to determine the peak load, or $7.9 \mathrm{kN}$ with a mobilization distance of $0.6 \mathrm{D}$ if Method 2 is used. The load-displacement relationship shown in Figure 4-12 increased much more gradually than that of the shallow axial test. During the two unloading portions of the tests, the normalized loads decreased by $1 \mathrm{kN}$ and $2 \mathrm{kN}$ respectively. This is one-third of the decrease noted during the shallow tests. The additional weight and pressure of the soil above and in front of the pipe would have minimized the amount of uplift and soil deformation around the foam and stanchion. 
The peak loads shown in Figure 4-13, are approximately twice the peak loads noted during the shallow tests conducted during this research using Method 2, or the research conducted by Debnath in dense, shallow conditions (2015). These results are in line with the ALA guidelines as the peak load increased at the same rate as the increased burial depth.

The mobilization distances of $0.5 \mathrm{D}$ and $0.6 \mathrm{D}$ are both approximately ten times higher than what is expected by the ALA guidelines but are in line with the mobilization distances found during dense sand testing (Daiyan, 2013, Debnath 2015, Hsu, 2010). The true mobilization distances may be closer to the expected values since the mobilization corrections may not be accurate because of the increased lag caused by the pipe assembly rotation during the deep tests as discussed in Section 4.2. If the corrected mobilization distance equation proposed in 4.2 is used, the corrected mobilization would be $0.33 \mathrm{D}$ and $0.42 \mathrm{D}$ respectively which is closer to the ALA guidelines.

\subsubsection{Pure Lateral}

A total of three pure lateral tests were conducted as a part of this research. As shown in Figure 4-14, one of the shallow tests was completed without foam, while the second shallow test included foam on the leading side of both stanchions and both were mobilized to a distance of 0.9D. During the third test, which was conducted at a springline burial depth of 4D, the pipe mobilization was stopped at $1.2 \mathrm{D}$ since bending was visually noted in the dog bones. A true peak of $8 \mathrm{kN}$ was noted in the results. Method 2 was used to determine the peak loads for the shallow tests as no true peak was evident in the results. The peak loads are shown in Table 4-1.

Previous research including analytical models and physical modelling results have correlated the normalized lateral loads to the spring line burial depth and soil properties (e.g. Audibert \& 
Nyman, 1977; Trautman \& O'Rourke, 1985; Smith, 1962; Debnath, 2016). The soil properties used as variables include soil density and soil friction angle. For the lateral tests conducted as a part of this research, the friction angle was $29^{\circ}$, and the average soil density used was $1467 \mathrm{~kg} / \mathrm{m}^{3}$.

As shown in Figure 4-15, the results of Test 3, with foam, correspond well with the previous research especially those of Debnath (2016) and Audibert and Nyman (1977) with a friction angle of $35^{\circ}$. The result shown for Test 2, no foam, is similar to the results of Audibert and Nyman for soil with an internal friction angle of $30^{\circ}$. The variation in these results may be caused by the lack of foam in front of the stanchions during test 2 . The foam increased the measured peak load and mobilization by $27 \%$ for an identical acceleration and mobilization sequence. These results are much closer to the estimated results. The test with foam (Test 3 ) also showed more of elastic behaviour response of the soil when compared to the test without foam (Test 2). This helps confirm the importance of the foam in front of the stanchions, which was used to minimize their effects on the end boundary conditions.

The normalized loads from the deep tests are 1.5 times larger than the expected values for a burial depth of 4D. It is assumed that this variation is caused by the stanchion dragging and the additional rotation of the pipe assembly, which would have increased the observed loads. If the stanchion is assumed to be similar to a cantilevered beam, the maximum deflection would be approximately $0.2 \mathrm{D}$. A stiffer pipe assembly may provide results closer to the results expected based on ALA guidelines and help reduce the amount of pipe lag. 


\subsubsection{Oblique}

The remaining tests were conducted at $50^{\circ}$, and $20^{\circ}$ (Tests 1 , and 5) at a burial depth of $2 \mathrm{D}$ and at $20^{\circ}$ and $30^{\circ}$ (Tests 8 and 10) for a burial depth of 4D. Figure 4-16 and Figure 4-17 show the axial and lateral loads as a function of the displacement. The peak loads in the axial and lateral directions were calculated using the three methods discussed previously. Method 1 consistently showed a lower peak than the other two methods while Method 3 always showed the highest peak value. The peak values calculated using Method 1 were as much as 30\% lower than the values calculated using Method 3. For the comparison of data, Method 1 will be used as it is the closest to previous results. The peak loads for the oblique tests are shown in Table 4-2. The results of test $6\left(70^{\circ}, \mathrm{H} / \mathrm{D}=2\right)$ have been left out of the analysis but are discussed below.

As the testing angle increased, the peak lateral loads increased in both the shallow and deep tests. Also, the peak axial loads increased between the deep tests, Test $8\left(20^{\circ}\right)$ and $10\left(30^{\circ}\right)$, and decreased between the shallow tests, Test $1\left(50^{\circ}\right)$ and $5\left(20^{\circ}\right)$. These results match with the expected results as previous research have confirmed that the peak lateral loads should increase as the attack angle increases and that the lateral load increases between $0^{\circ}$ and $40^{\circ}$ and decrease between $40^{\circ}$ and $90^{\circ}$ (Daiyan, 2013).

During Test $1\left(50^{\circ}, \mathrm{H} / \mathrm{D}=2\right)$, the pipe was cyclically loaded only once. The pipe was moved forward a full pipe diameter during the loading phase, moved backwards by half a pipe diameter during the unloading phase, and moved forward to a total displacement of 1.1D. During the unloading of the pipe, the load cells registered negative loads in both the axial and lateral directions. This indicated that during the unloading, the pipe was moved far enough back that the sand mound in front of the pipe was able to slump back towards the pipe. As stated in 
Section 4.2.1, the negative loads may have affected the peak axial loads, and in the future, the pipe should not be unloaded as much to ensure the soil does not have the opportunity to slump.

Tests $5\left(20^{\circ}, \mathrm{H} / \mathrm{D}=2\right), 8\left(20^{\circ}, \mathrm{H} / \mathrm{D}=4\right)$, and $10\left(30^{\circ}, \mathrm{H} / \mathrm{D}=4\right)$ were all loaded and unloaded twice. The load-displacement graphs for all three graphs do not show a reversal of loading on the load cell, which indicates that the loading-unloading cycles are correct. The shape of the shallow test, Test $5\left(20^{\circ}, \mathrm{H} / \mathrm{D}=2\right)$, displays a more idealized load-displacement relationship for both the axial and lateral tests. The graphs for Tests $8\left(20^{\circ}, \mathrm{H} / \mathrm{D}=4\right)$, and $10\left(30^{\circ}, \mathrm{H} / \mathrm{D}=4\right)$, also resemble an idealized load-displacement relationship, but the graphs are much 'noisier', i.e. show more variation in the results. The increase resistance on the stanchions could have caused this noise during loading and unloading caused by the deeper sand. The additional resistance and rotation of the pipe assembly, shown by the lag, which has been previously discussed, and the bending of the dog bone, may have also created oscillations through the stanchions as the pipe was being dragged through the deeper sand. These oscillations show that a stiffer pipe assembly is required for future deep burial depth tests as they have affected the test results.

The results of this research for shallow burial depth tests show higher loads than previous full-scale models (Hsu et al., 2006) and lower loads than previous reduced scale (Kenny et al., $2015)$ as shown in Figure 4-18. The oblique test results for Tests $1\left(50^{\circ}, \mathrm{H} / \mathrm{D}=2\right), 5\left(20^{\circ}, \mathrm{H} / \mathrm{D}=\right.$ 2), and $10\left(30^{\circ}, \mathrm{H} / \mathrm{D}=4\right)$ all fall well within the proposed failure envelope previously proposed by Daiyan (2013). A more refined failure envelope for this series of shallow tests, which assumes that the failure mechanism changes from soil failure to pipe failure at an attack angle of $30^{\circ}$ is shown as a green dashed line on the graph. The results for Test $5\left(20^{\circ}, \mathrm{H} / \mathrm{D}=2\right)$, when compared to other results, shows a much higher lateral load than expected while the axial load is in line with previous research. In the post-test surface scan, as shown in Figure 4-19, the lateral 
portion of the mounded sand is much larger than expected. This additional mounding may be caused by soil ratcheting and caused an increase in the loads. Non-cyclical loading would have reduced the ratcheting effect but would not have allowed for the confirmation of the elastic behaviour of the soil.

The results of the deep tests $(\mathrm{H} / \mathrm{D}=4)$ are also shown in Figure 4-13, but previous research has not been completed at the same burial depth. As previously stated the loads are higher than expected especially in Test $8\left(20^{\circ}\right)$, which falls outside of the expected soil mass failure envelope and is shown as the dotted blue line on the graph. No oblique test was completed at an attack angle larger than $30^{\circ}$ but less than $90^{\circ}$.

During Test 6 at $70^{\circ}$, the load cell cables came completely detached during the test at a mobilization of approximately $0.3 \mathrm{D}$. Once the cables were detached the load reading varied from $10000 \mathrm{~N}$ to $-10000 \mathrm{~N}$. Before the cables became detached, the normalized axial and lateral loads did not follow the expected shape and are noisier than other shallow tests, as shown in Figure 4-20 and Figure 4-21. This may be due to the fact the cables were loosened at some unknown point during or before the test, and the results are not accurate. The load cells were not damaged during this test, and the calibration matrices were re-confirmed after the test. The full test results for this test are shown in Appendix B. 


\subsubsection{Uplift}

As stated in Section 3.5, three LVDTs were used to measure the vertical movement of the pipe assembly and settlement of the sand. During testing, as the pipe was pulled through the sand, the leading end of the pipe and a soil column above the pipe were pushed up causing a small sand mound in front of the pipe and a void space behind and above the pipe. Scans of the sand surface were taken after each test to show the mounding and are shown in Appendix D. As shown in the scans; the sand mounds were most noticeable in the shallow tests. The vertical displacement of the pipe is also higher in shallow tests, which is what is expected based on the sand mounds. Figure 4-22 shows the results from the two LVDTs mounted on the dog bones from Test $4\left(90^{\circ}, \mathrm{H} / \mathrm{D}=2\right)$, which shows a typical shallow test result. The uplift measured for each test was approximately $2 \mathrm{~mm}$ or $0.04 \mathrm{D}$, which is $12 \mathrm{~mm}$ when scaled to $1 \mathrm{~g}$. As shown in the in the figure, during the unloading, the leading edge of the pipe does not fall back to its original position which shows the ratcheting explained in Section 2.3.3. If the cyclical loading had not been used, the vertical uplift would have been much lower and may have been much closer to the finite element model predicted uplift (Daiyan, 2013, Kenny and Jukes, 2015).

The third LVDT was placed in the corner of the strong box to measure the settlement of the sand during the acceleration of the payload. This LVDT was placed during Tests $3\left(90^{\circ}, \mathrm{H} / \mathrm{D}=2\right)$, $5\left(20^{\circ}, \mathrm{H} / \mathrm{D}=2\right), 6\left(70^{\circ}, \mathrm{H} / \mathrm{D}=2\right), 7\left(0^{\circ}, \mathrm{H} / \mathrm{D}=4\right), 8\left(20^{\circ}, \mathrm{H} / \mathrm{D}=\right), 9\left(90^{\circ}, \mathrm{H} / \mathrm{D}=4\right)$, and $10\left(30^{\circ}\right.$, $H / D=4)$. The results are shown in Figure 4-23. The readings from this LVDT show that the settlements for the shallow tests vary from 0.38 to $0.75 \mathrm{~mm}$ true displacement which is a settlement of approximately 0.2 to $0.3 \%$ of the sands overall thickness. For the deep tests, where the acceleration was $13.25 \mathrm{G}$ instead of $6.25 \mathrm{G}$, the soil settled between 0.7 to $1.15 \mathrm{~mm}$ or 0.2 to 
$0.35 \%$ of the sand thickness. Since the localized densification of the sand due to acceleration was less than $0.5 \%$ and did not likely occur on the surficial layers, the sand is still considered loose.

By comparing the readings from the dogbone LVDTs and the soil LVDT, it was noted that the pipe settled more than the surrounding sand during acceleration. This additional initial settlement of the pipe assembly may have also skewed the results as the surrounding soil would have been disturbed by the settlement. The pipe assembly was reduced in weight between Daiyan (2013) and Debnath's (2015) research and could be further lightened to minimize the effects of the pipe's self-weight during payload acceleration. 
Table 4-1 - Peak lateral load results and corresponding mobilization

\begin{tabular}{|l|c|c|}
\hline Test ID & Peak Load & $\begin{array}{c}\text { Normalized } \\
\text { Displacement }\end{array}$ \\
\hline $2-$ no foam & 8 & $0.2 \mathrm{D}$ \\
\hline $3-$ foam & 11 & $0.3 \mathrm{D}$ \\
\hline 9 & 20 & $0.9 \mathrm{D}$ \\
\hline
\end{tabular}

Table 4-2 - Peak axial and lateral loads - oblique tests

\begin{tabular}{|c|c|c|c|c|c|c|c|}
\hline \multicolumn{2}{|c|}{ Test ID } & \multicolumn{2}{c|}{ Method 1 } & \multicolumn{2}{c|}{ Method 2 } & \multicolumn{2}{c|}{ Method 3 } \\
\hline \multirow{2}{*}{ Angle $\left(^{\circ}\right)$} & $\begin{array}{c}\text { Peak } \\
\text { Lateral } \\
\text { Load } \\
(\mathrm{kN})\end{array}$ & $\begin{array}{c}\text { Peak } \\
\text { Axial } \\
\text { Load } \\
(\mathrm{kN})\end{array}$ & $\begin{array}{c}\text { Peak } \\
\text { Lateral } \\
\text { Load } \\
(\mathrm{kN})\end{array}$ & $\begin{array}{c}\text { Peak } \\
\text { Axial } \\
\text { Load } \\
(\mathrm{kN})\end{array}$ & $\begin{array}{c}\text { Peak } \\
\text { Lateral } \\
\text { Load } \\
(\mathrm{kN})\end{array}$ & $\begin{array}{c}\text { Peak } \\
\text { Axial } \\
\text { Load } \\
(\mathrm{kN})\end{array}$ \\
\hline 1 & 50 & 7.3 & 3.2 & 8.7 & 3.8 & 9.2 & 4.4 \\
\hline 5 & 20 & 11 & 3.8 & 12.3 & 5 & 17 & 6.8 \\
\hline 8 & 20 & 7.8 & 6 & 9 & 7 & 9.8 & 8.2 \\
\hline 10 & 30 & 12.4 & 6.2 & 13.6 & 6.8 & 14.2 & 8 \\
\hline
\end{tabular}




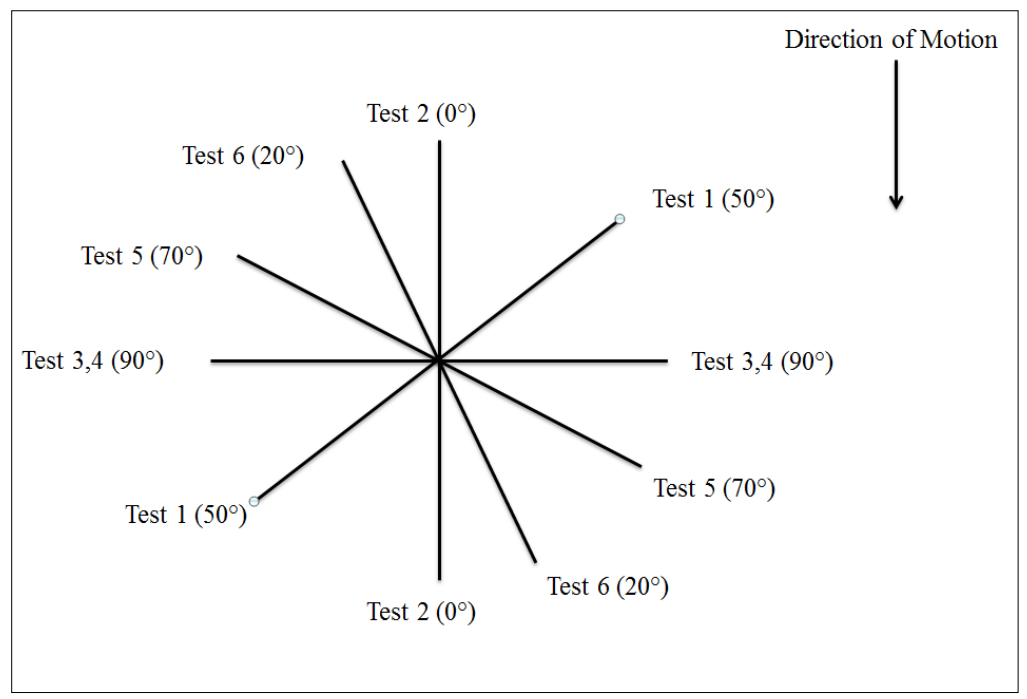

Figure 4-1 - Pipe orientation of shallow tests (Test $1-6, H / D=2)$

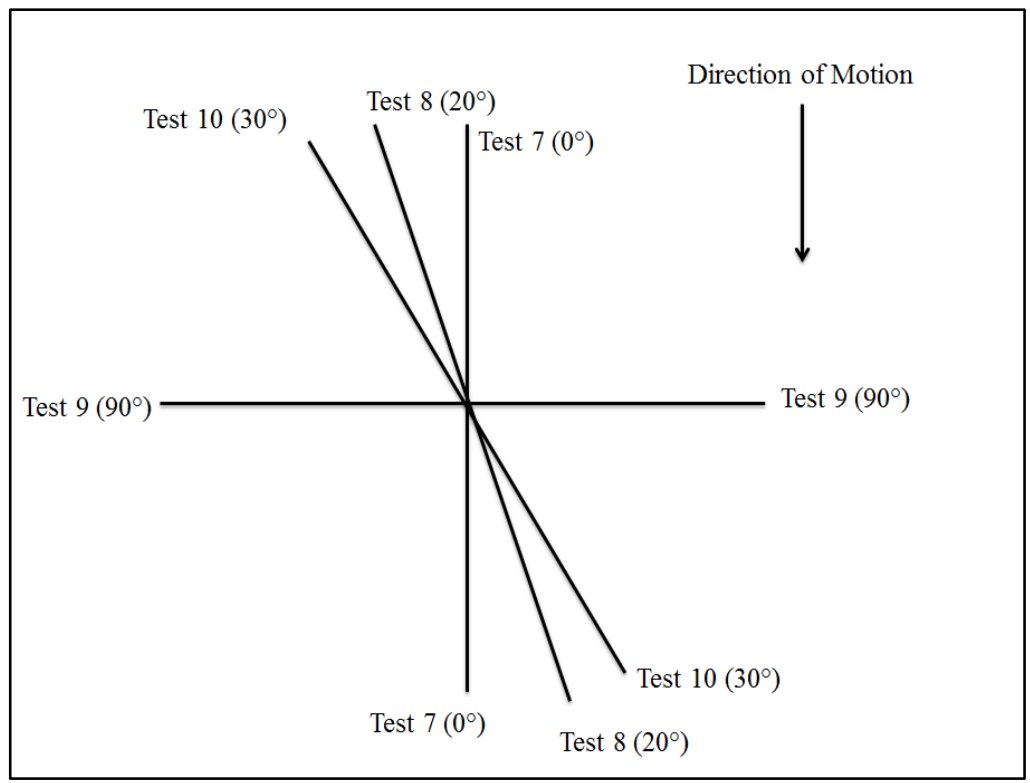

Figure 4-2 - Pipe orientation of deep tests (Tests 7-10, H/D=4) 


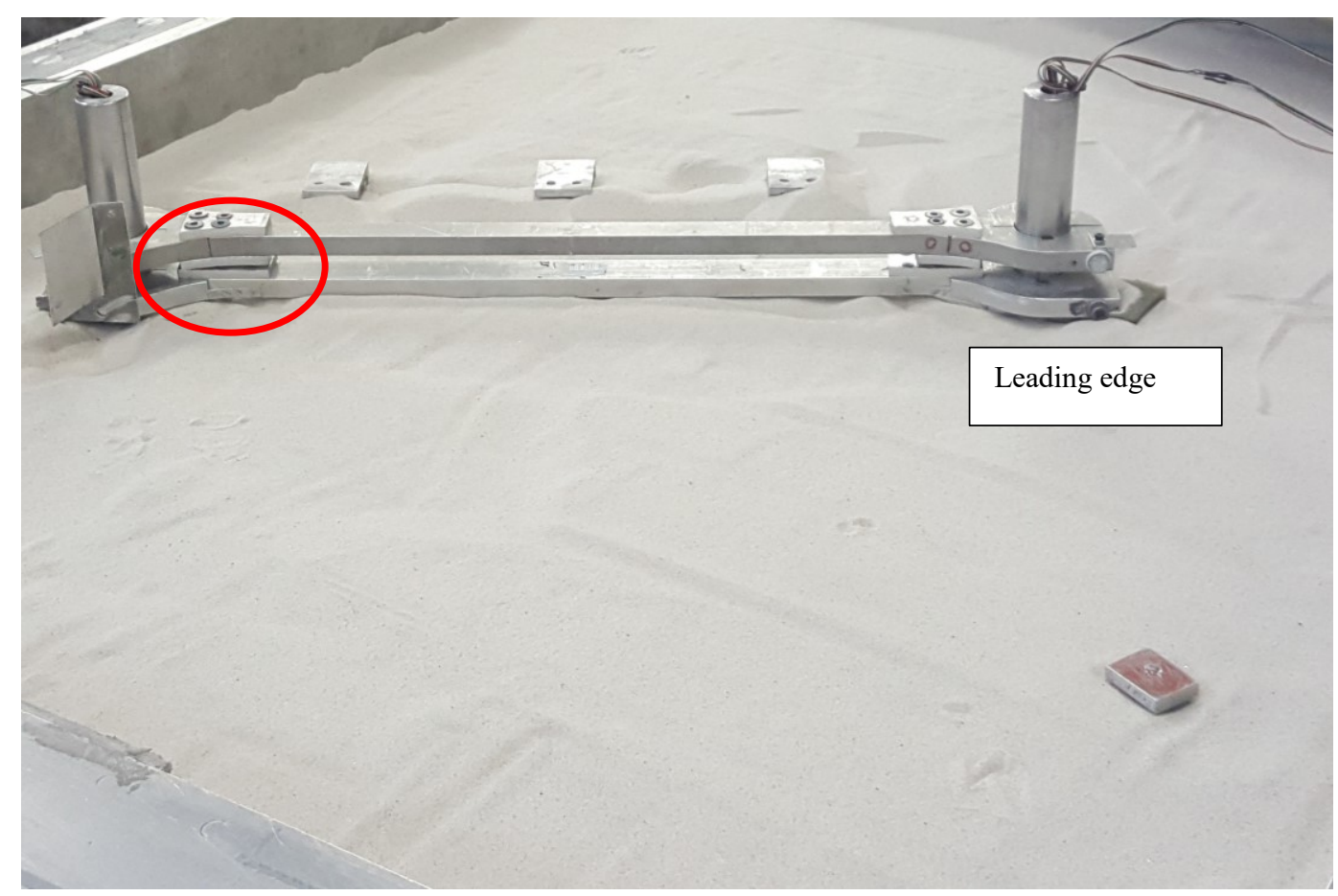

(a) Before Test $10\left(\mathrm{H} / \mathrm{D}=4,30^{\circ}\right)$

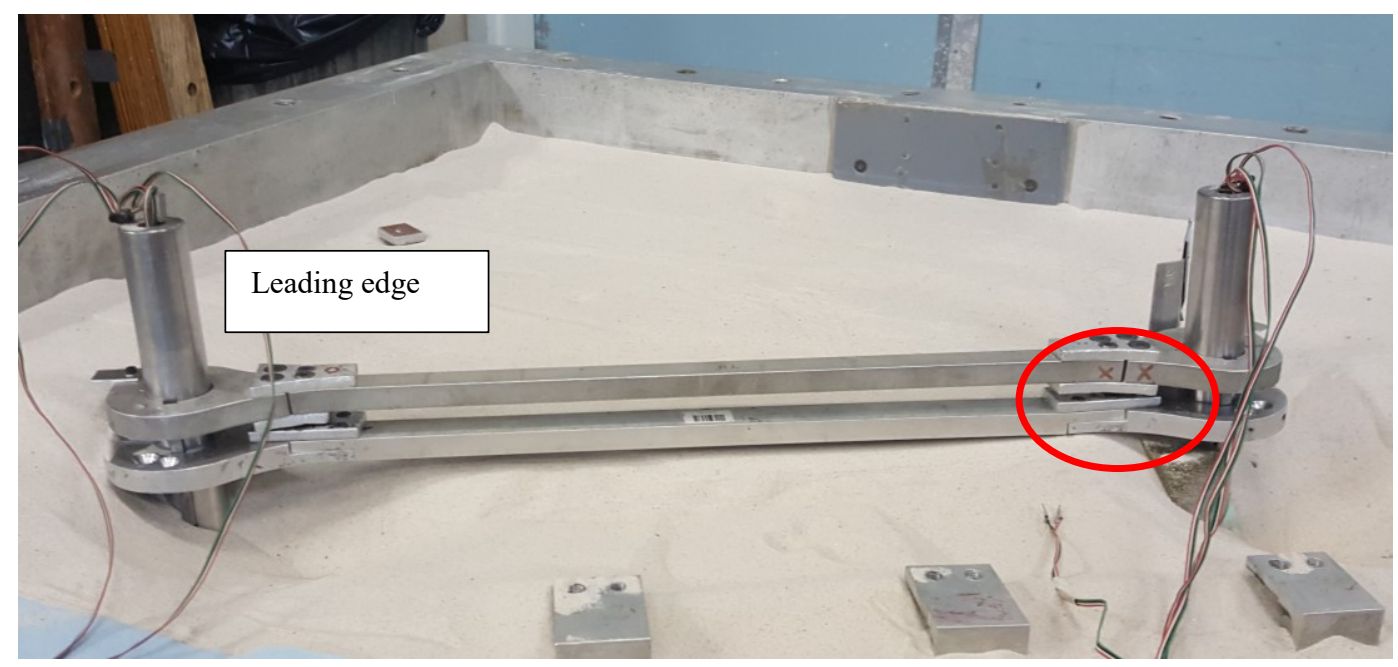

(b) After Test $10\left(\mathrm{H} / \mathrm{D}=4,30^{\circ}\right)$

Figure 4-3 - Bending of the double dog-bone set-up before and after Test 10

$$
\left(\mathrm{H} / \mathrm{D}=4,30^{\circ}\right)
$$




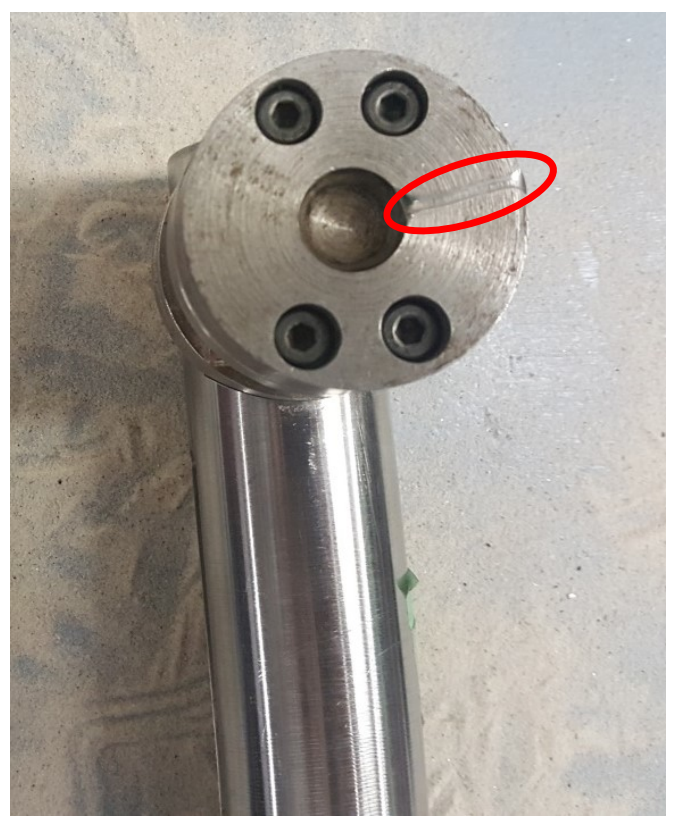

Damage cause by ball earing is circled in red

Figure 4-4 - Load cell A after model pipe was pulled out from between stanchions (Test $9,90^{\circ}, \mathrm{H} / \mathrm{D}=4$ )

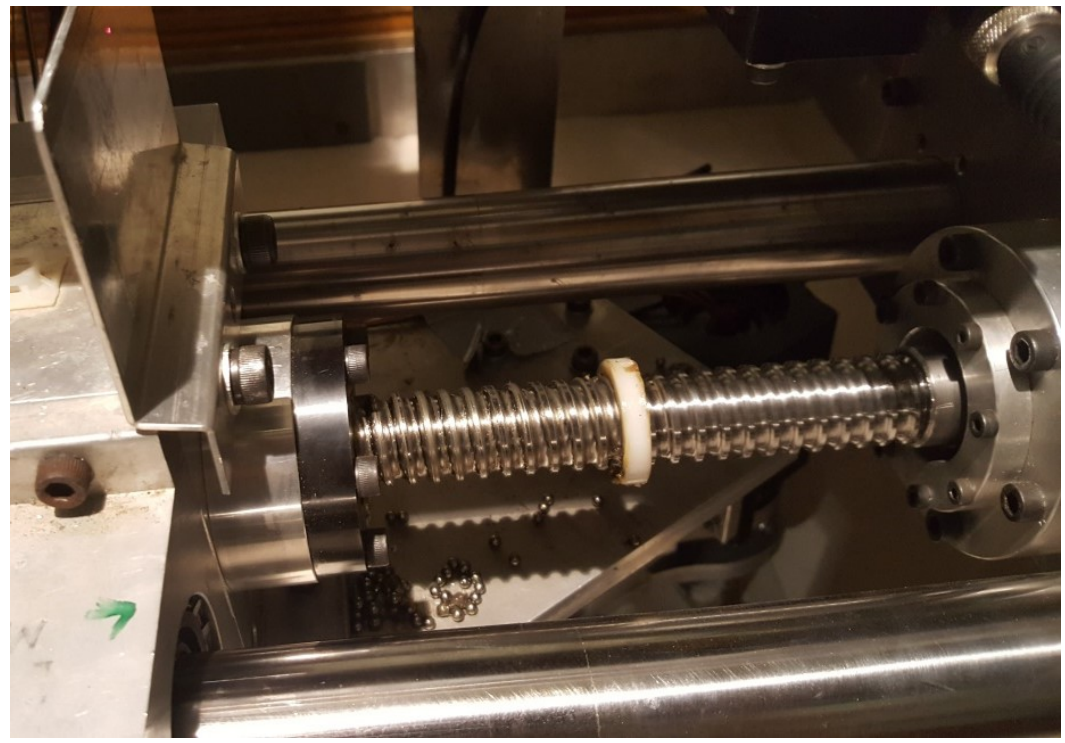

Figure 4-5 - Motor seal failure after final test (Test 10, 30, $\mathrm{H} / \mathrm{D}=4$ ) 


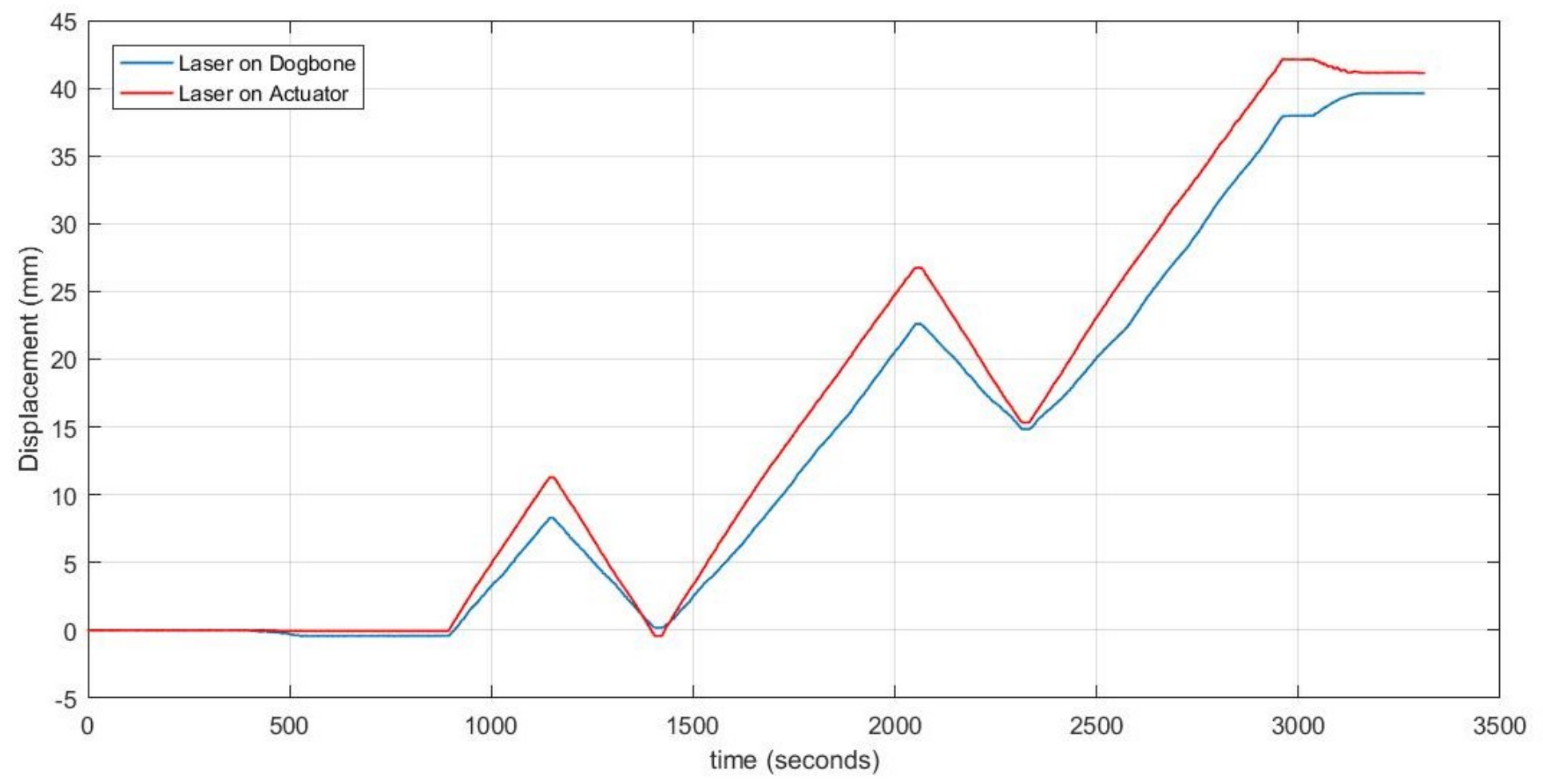

Figure 4-6 - Laser displacement as measured on the dog bone and actuator as a function of true time (Test $4,90^{\circ}, \mathrm{H} / \mathrm{D}=2$, no foam) 


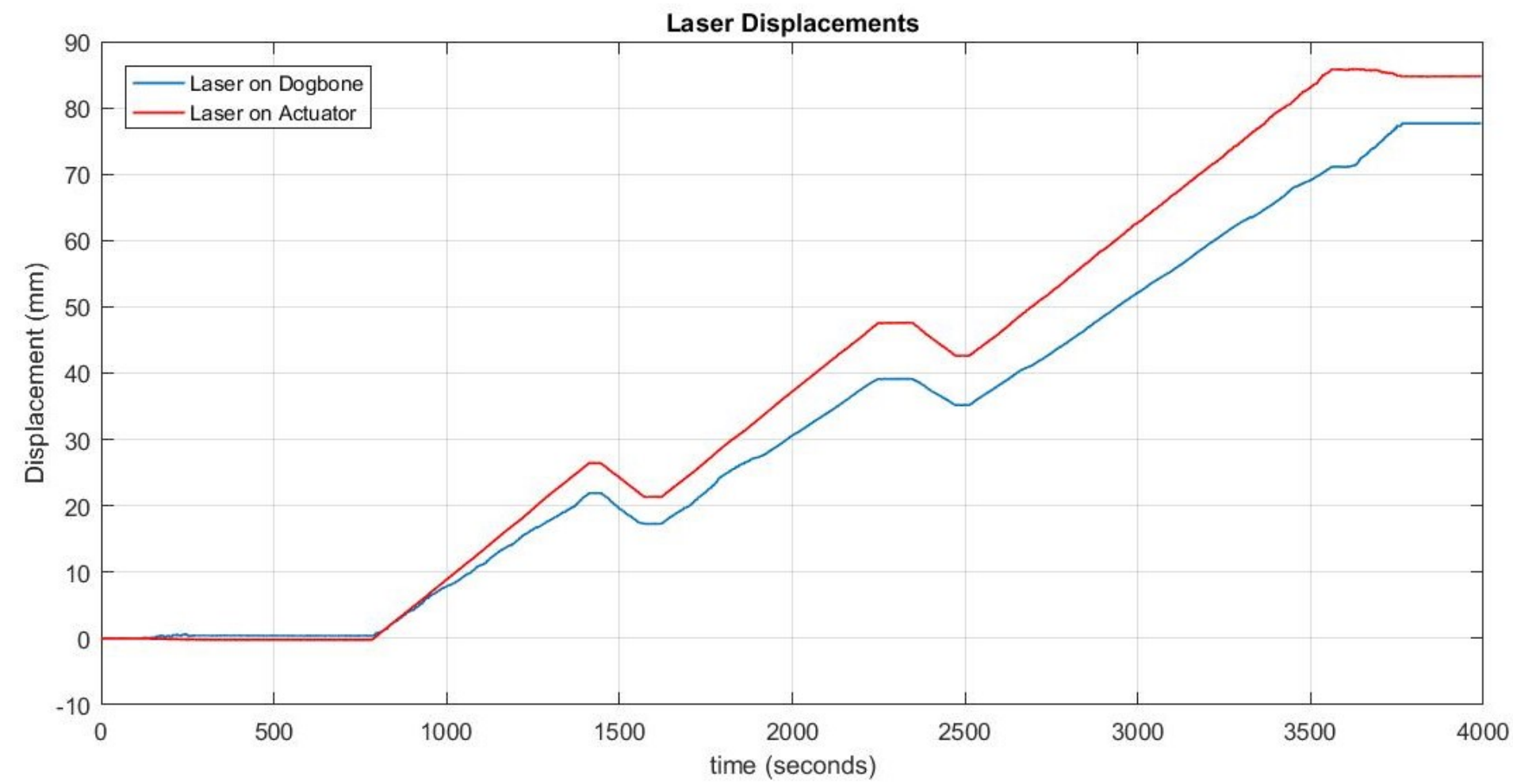

Figure 4-7 - Laser displacement as measured on the dog bone and actuator as a function of true time $\left(\mathrm{Test} 10,30^{\circ}, \mathrm{H} / \mathrm{D}=4\right)$ 


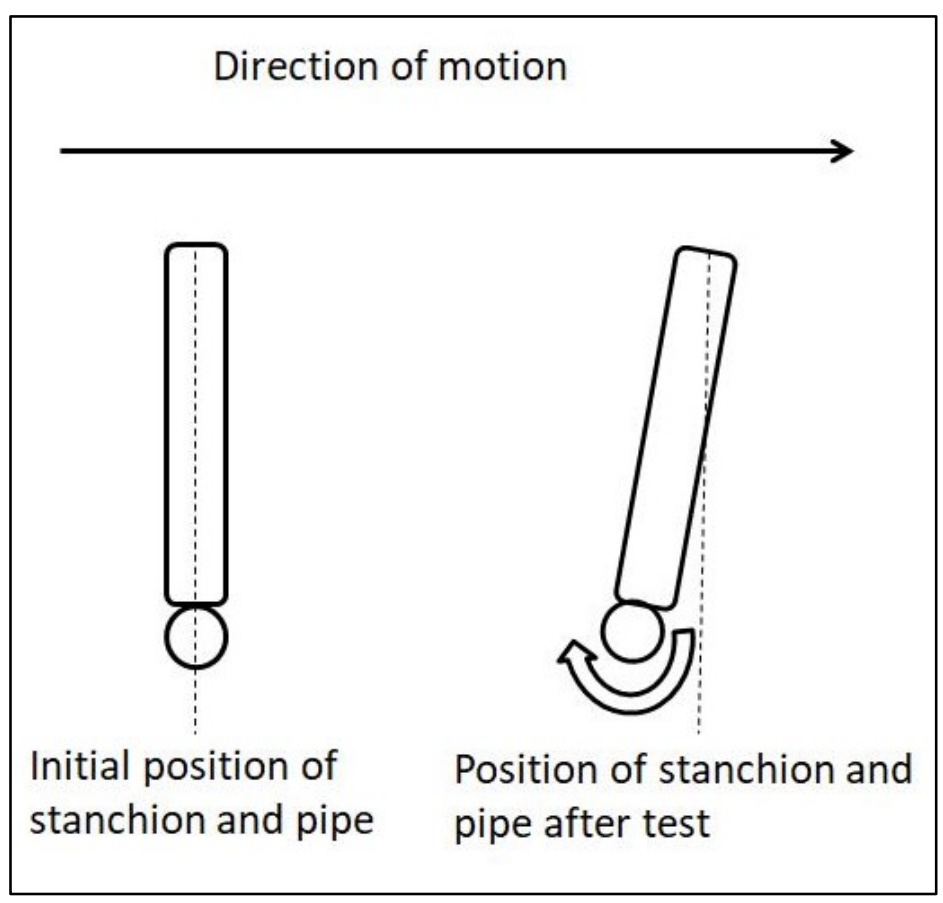

Figure 4-8 - Schematic of idealized pipeline lag during mobilization 

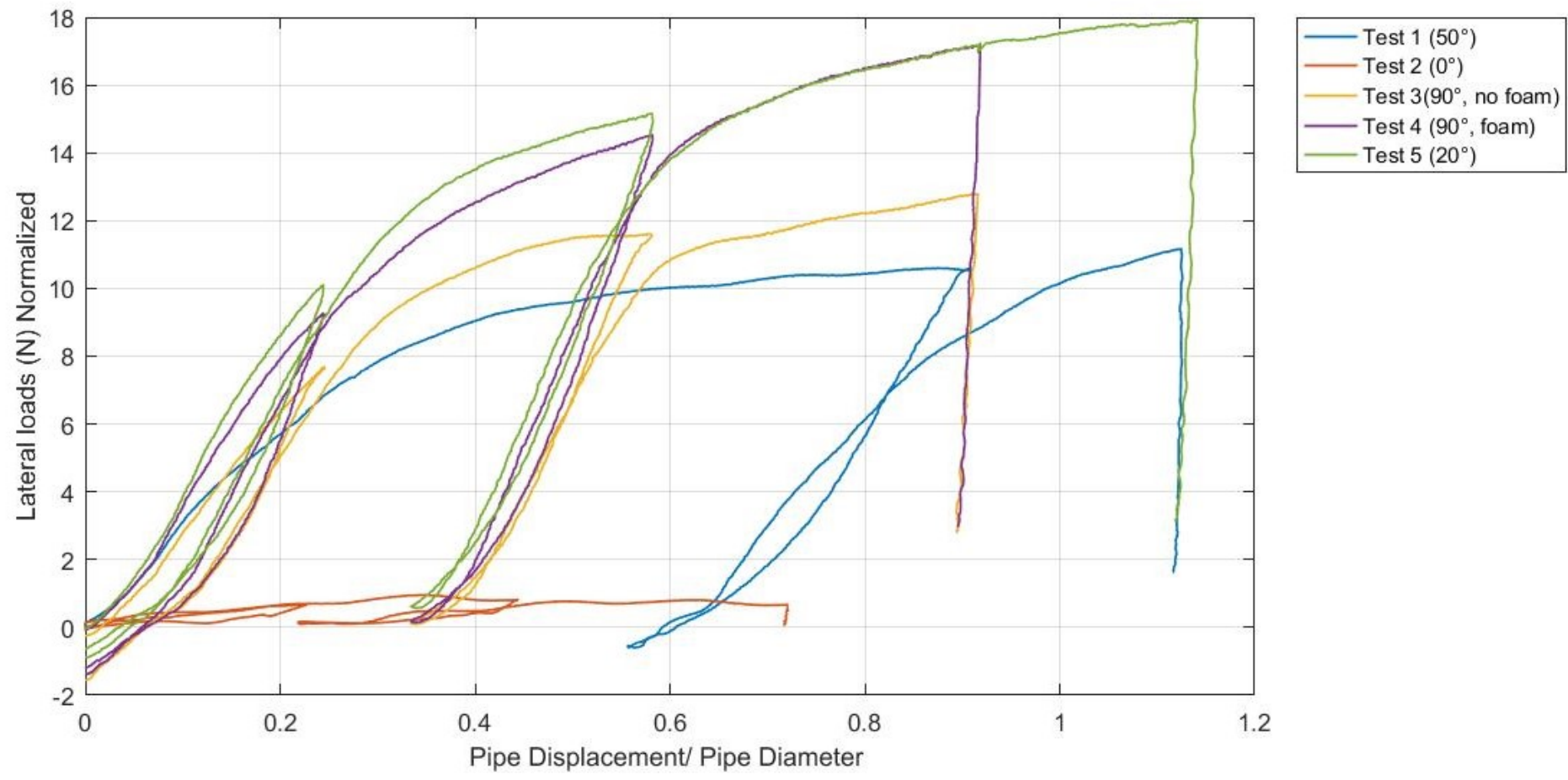

Figure 4-9 - Lateral Loads (normalized) as a function of corrected pipe movement (shallow tests) 


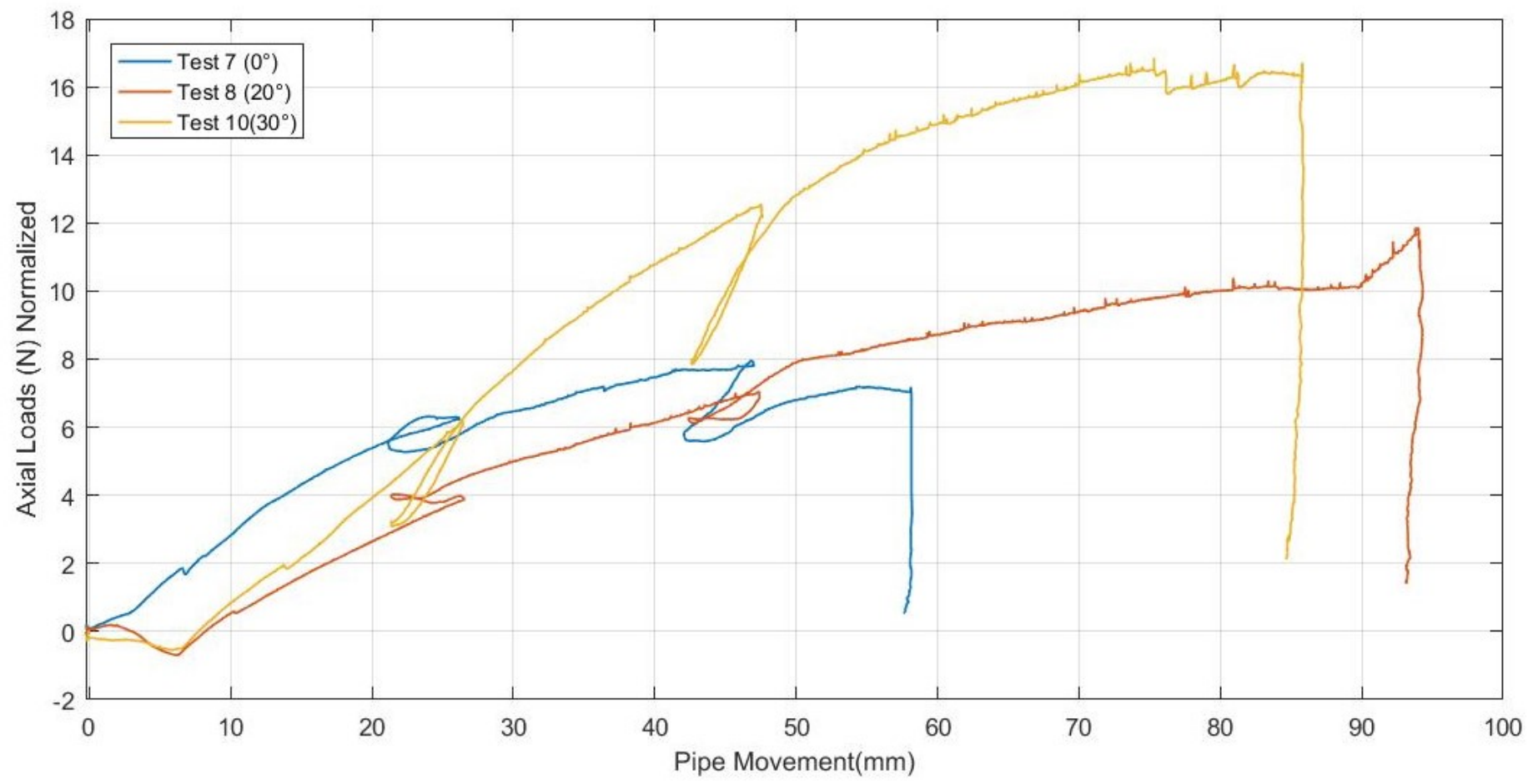

Figure 4-10 - Normalize axial loads as a function of corrected pipe movement (deep tests) 


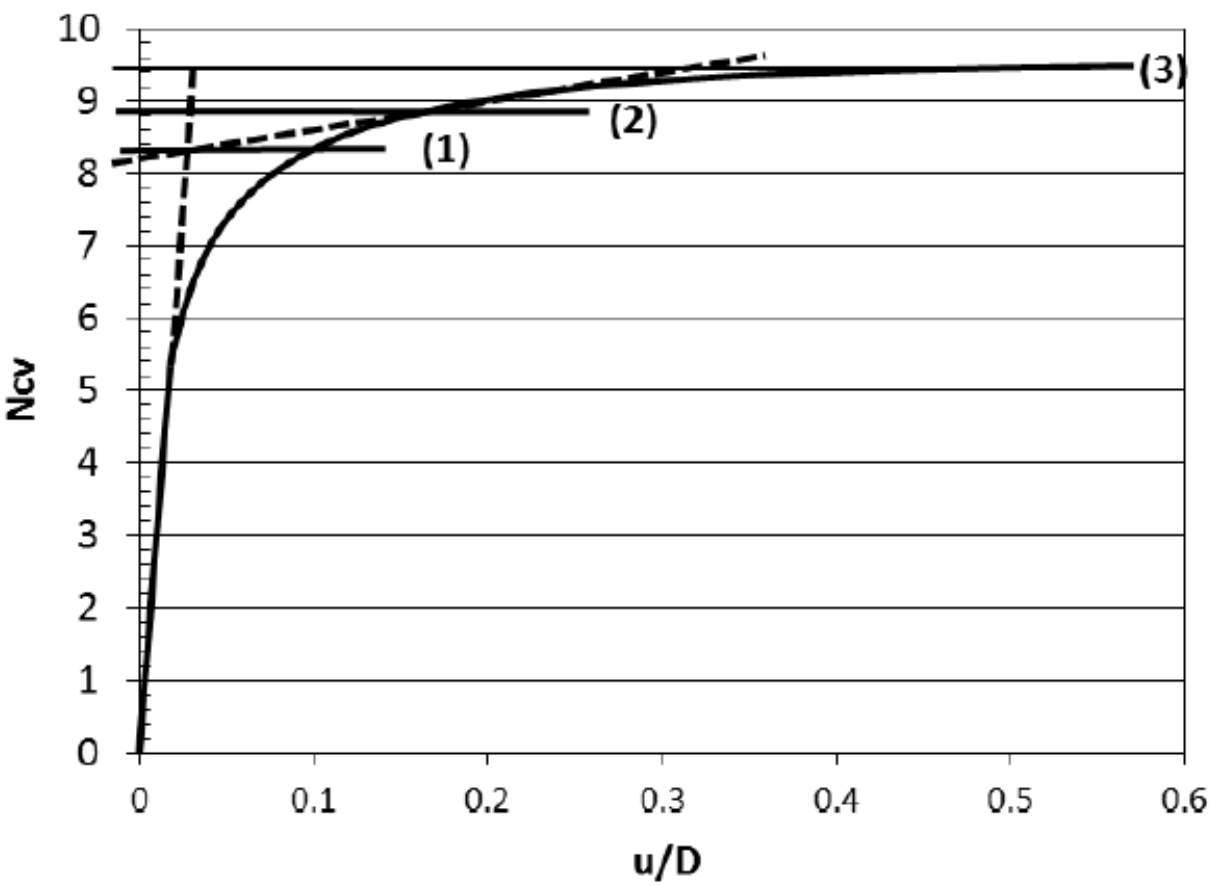

Figure 4-11 - Schematic illustration of peak load determination (Pike et al. 2011, from Debnath, 2016) 


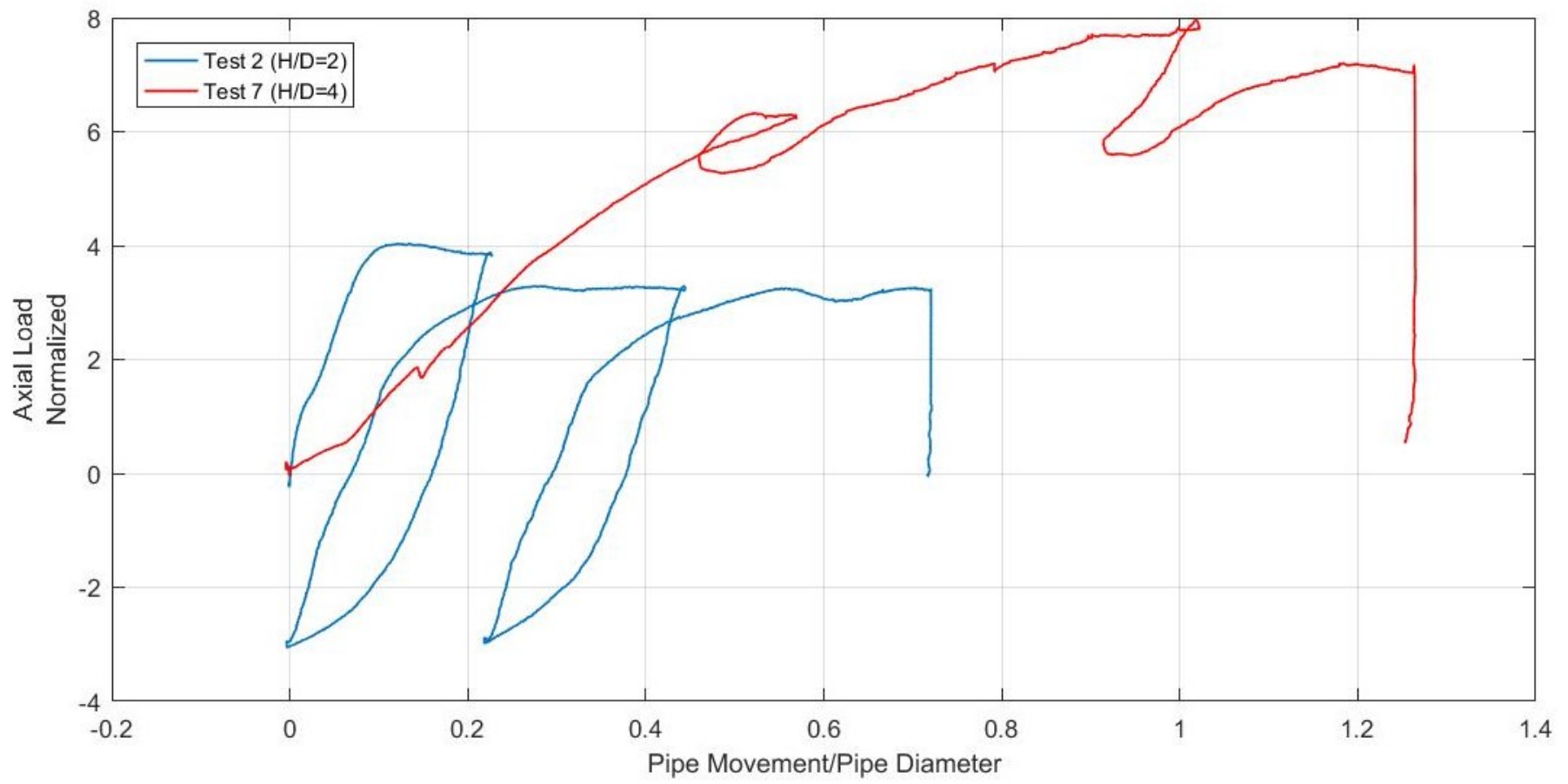

Figure 4-12 - Results of pure axial tests as a function of pipe diameter (Test $2-H / D=2$, Test $7-H / D=4$ ) 


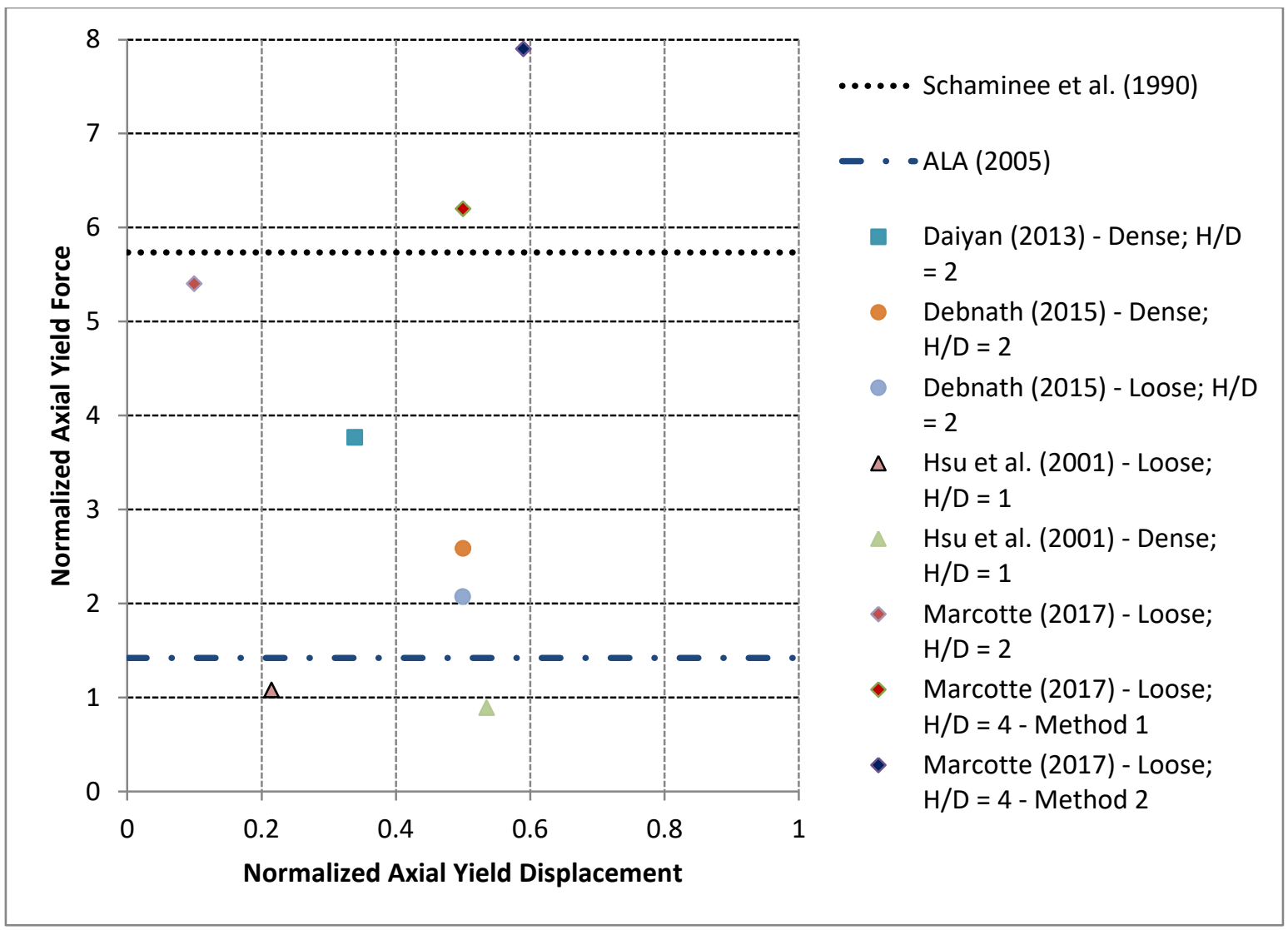

Figure 4-13 - Comparison of axial test results to existing data (variation to Kenny et al., 2015) 


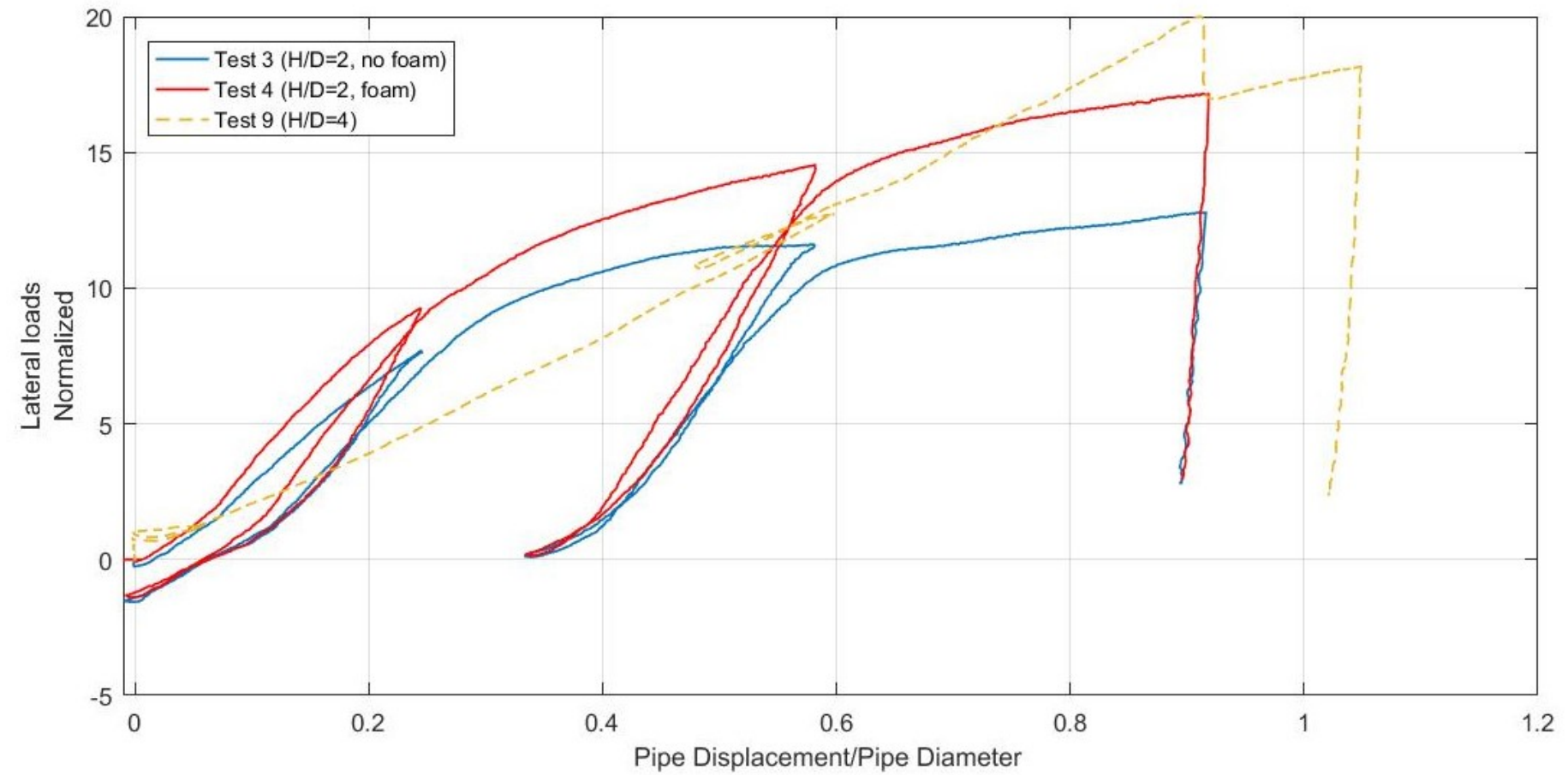

Figure 4-14 - Results of the pure lateral tests as a function of pipe mobilization (Test $2-\mathrm{H} / \mathrm{D}=2-$ no foam, Test $3-\mathrm{H} / \mathrm{D}=2-$ foam, Test $9-\mathrm{H} / \mathrm{D}=4$ ) 


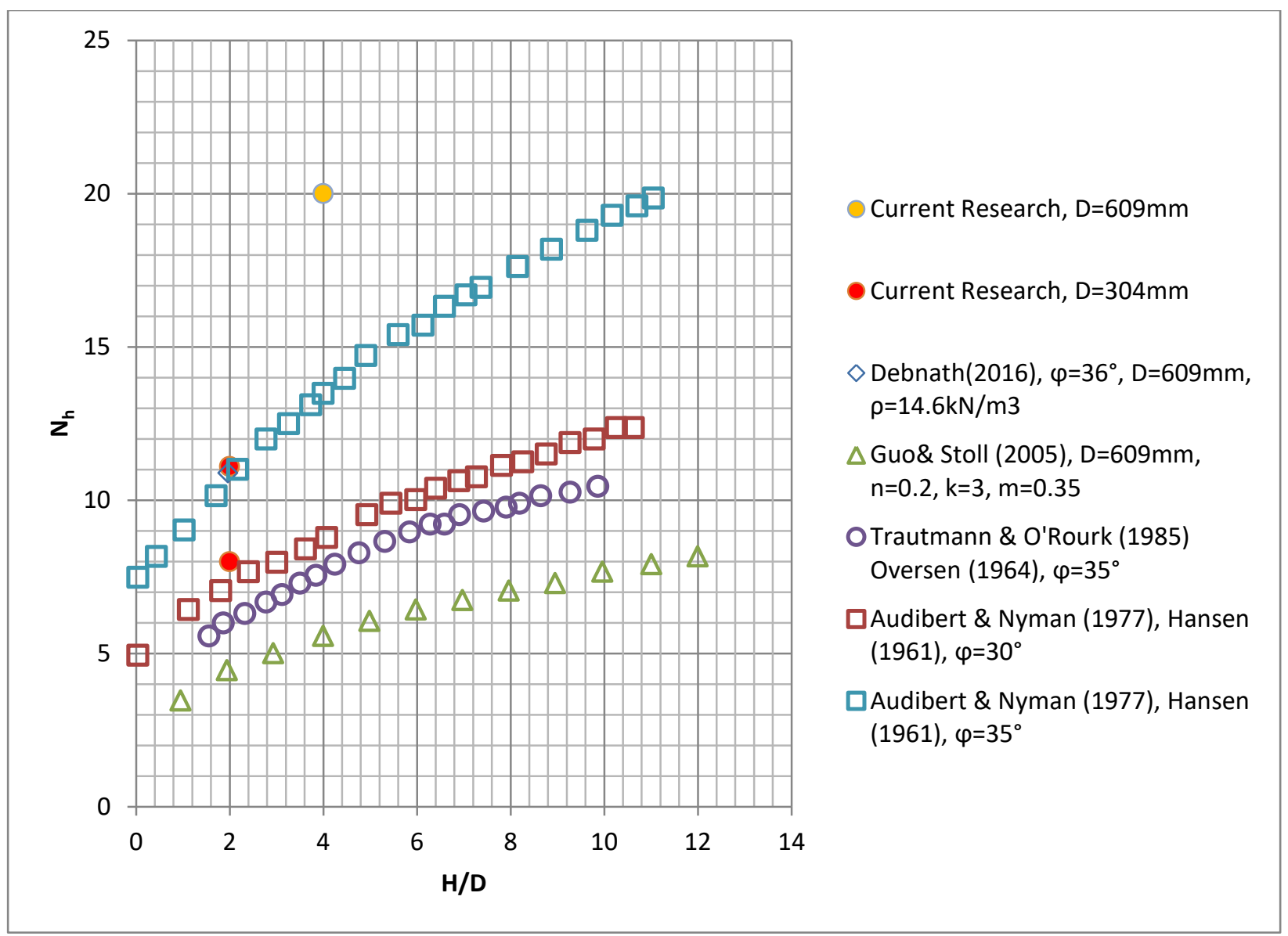

Figure 4-15 - Comparison of lateral test results in loose sands (variation on Kenny et al., 2015) 


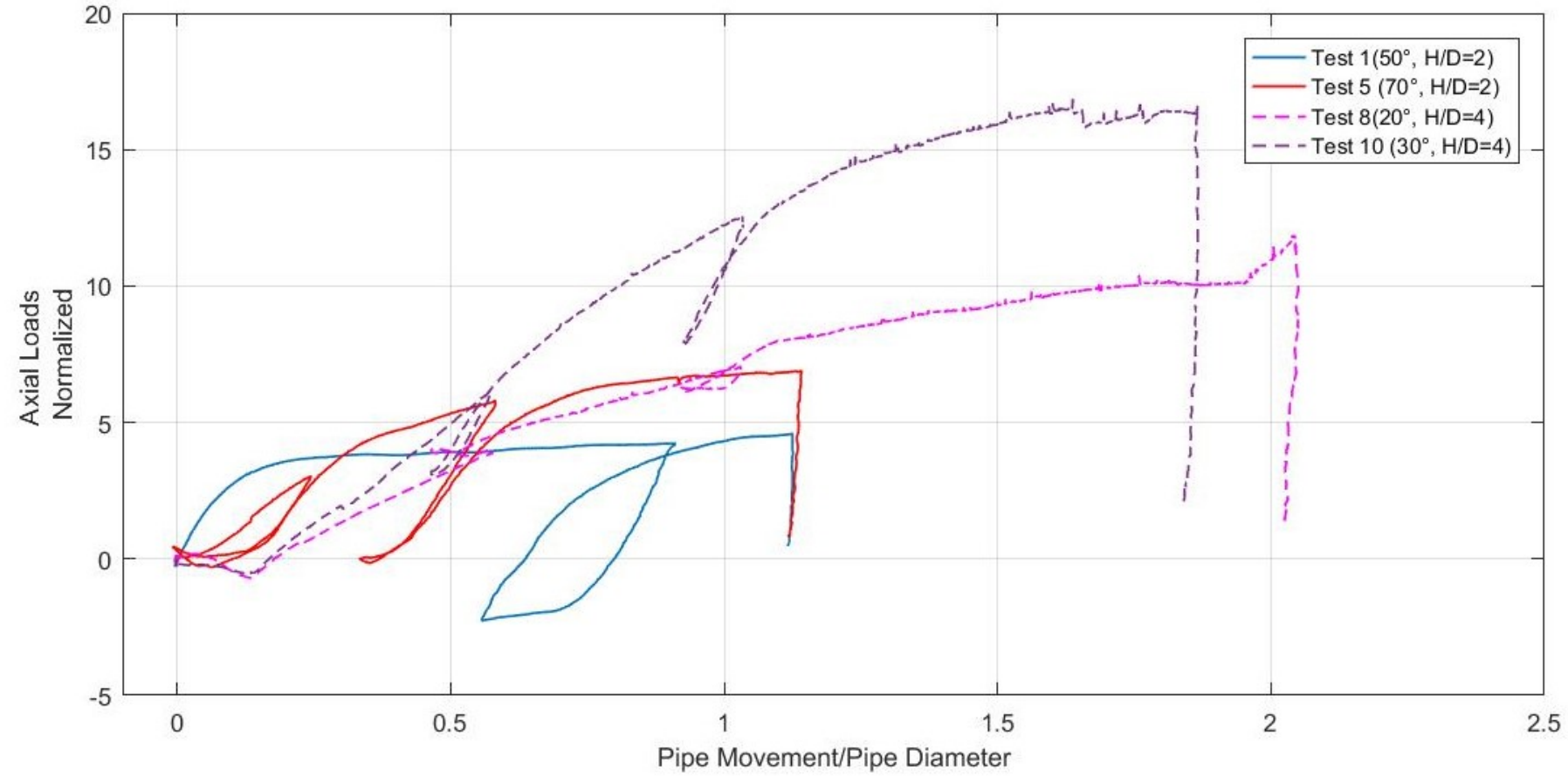

Figure 4-16 - Normalized axial load as a function of pipe displacement for oblique tests $\left(50^{\circ}-\mathrm{H} / \mathrm{D}=2,70^{\circ}-\mathrm{H} / \mathrm{D}=2,20^{\circ}-\mathrm{H} / \mathrm{D}=4,30^{\circ}-\mathrm{H} / \mathrm{D}=4\right)$ 


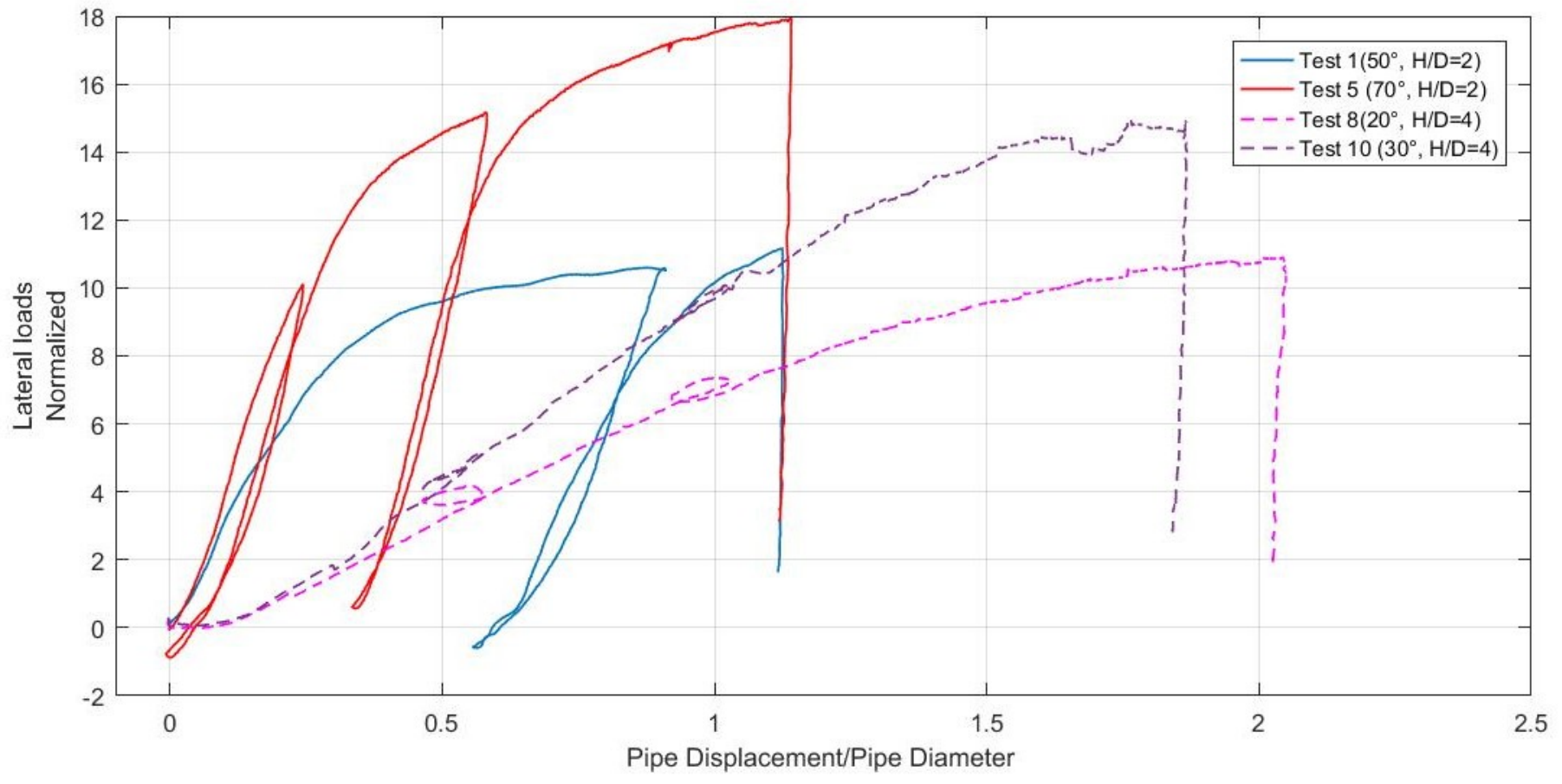

Figure 4-17 - Normalized lateral load as a function of the true pipe displacement for oblique tests $\left(50^{\circ}-\mathrm{H} / \mathrm{D}=2,70^{\circ}-\mathrm{H} / \mathrm{D}=2,20^{\circ}-\mathrm{H} / \mathrm{D}=4,30^{\circ}-\mathrm{H} / \mathrm{D}=4\right)$ 


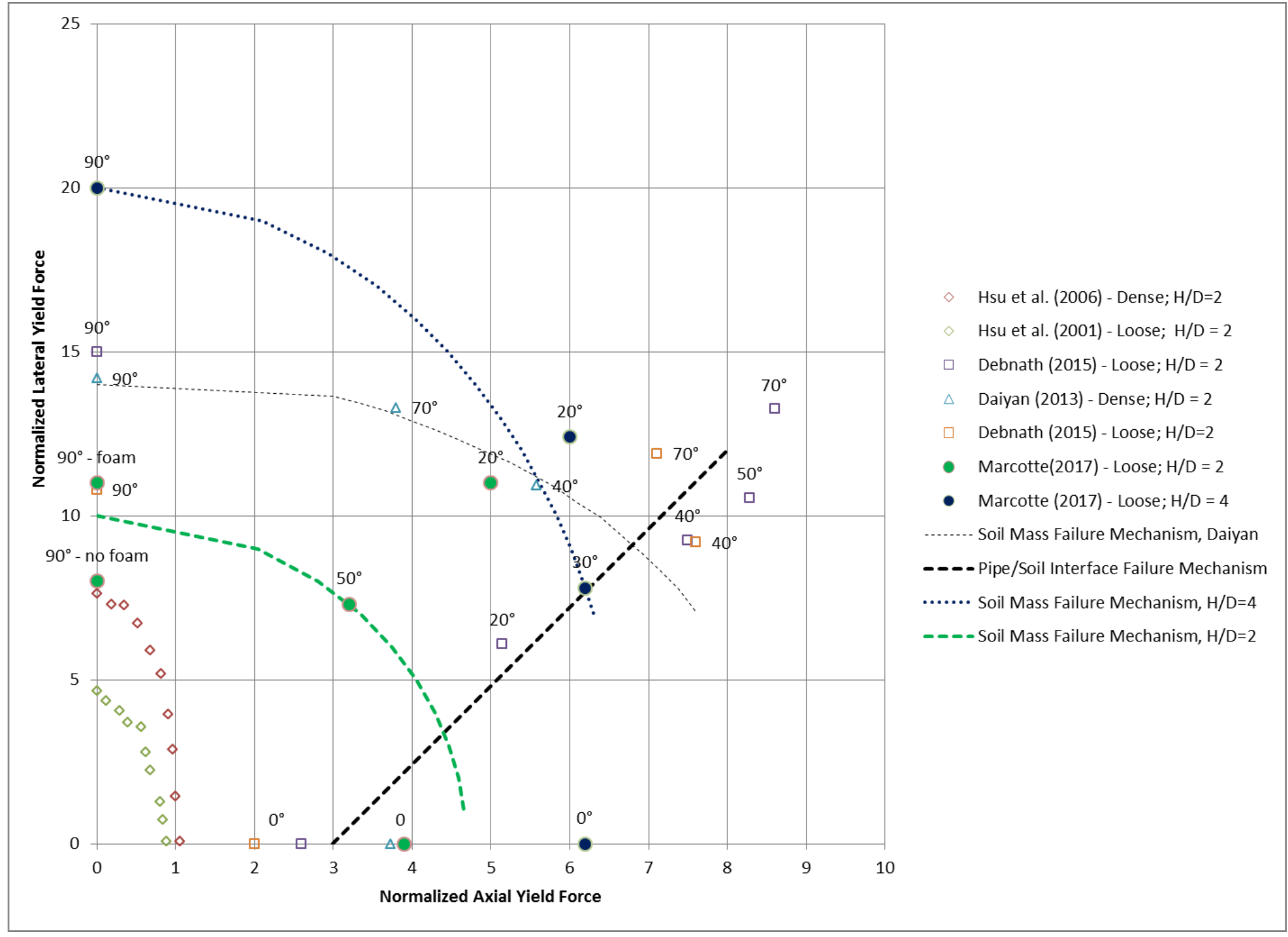

Figure 4-18 - Comparison of axial and lateral load results (variation on Kenny et al., 2015) 


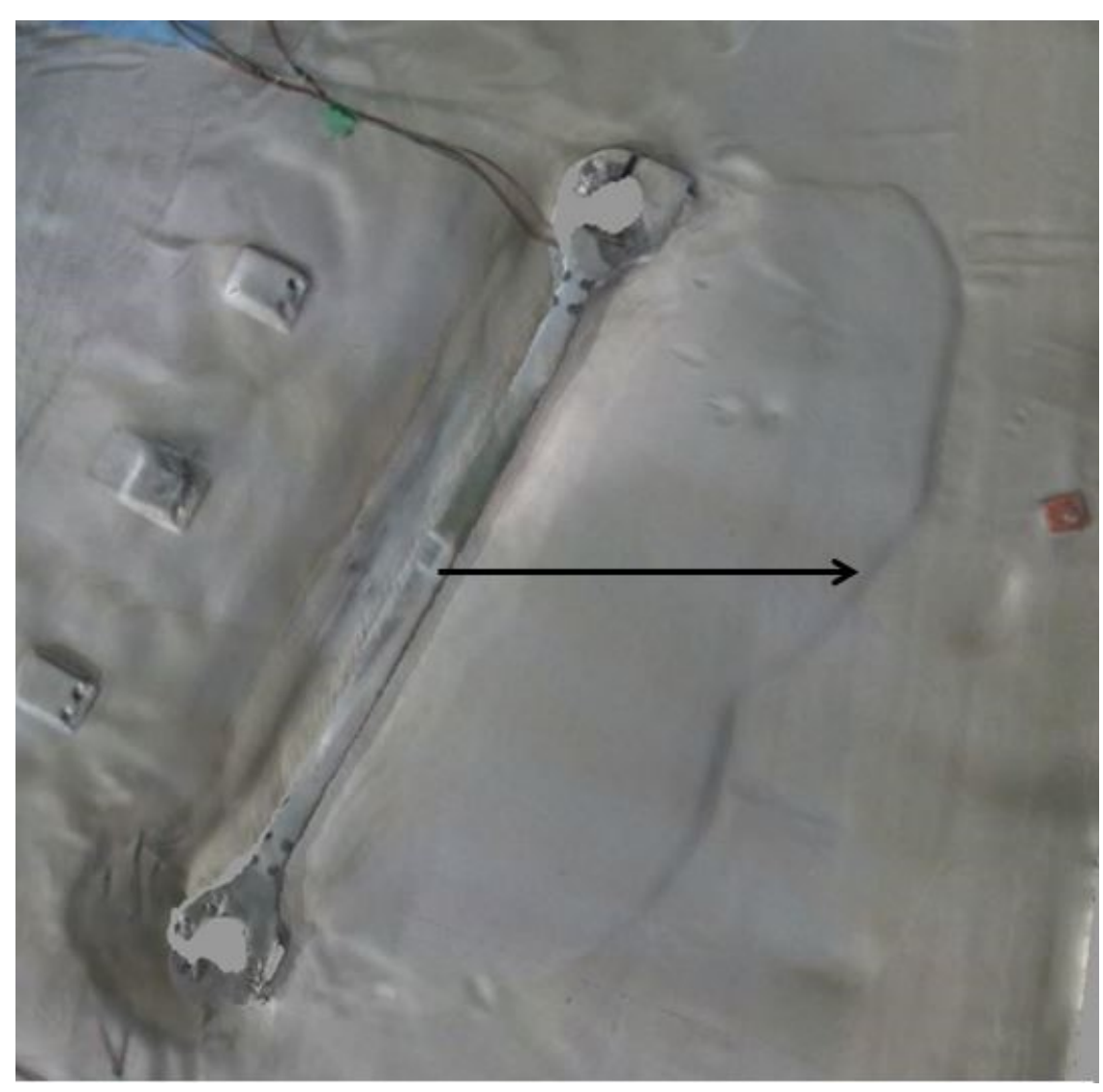

Figure 4-19 - Test $5\left(20^{\circ}, \mathrm{H} / \mathrm{D}=2\right)$ post-test scan 


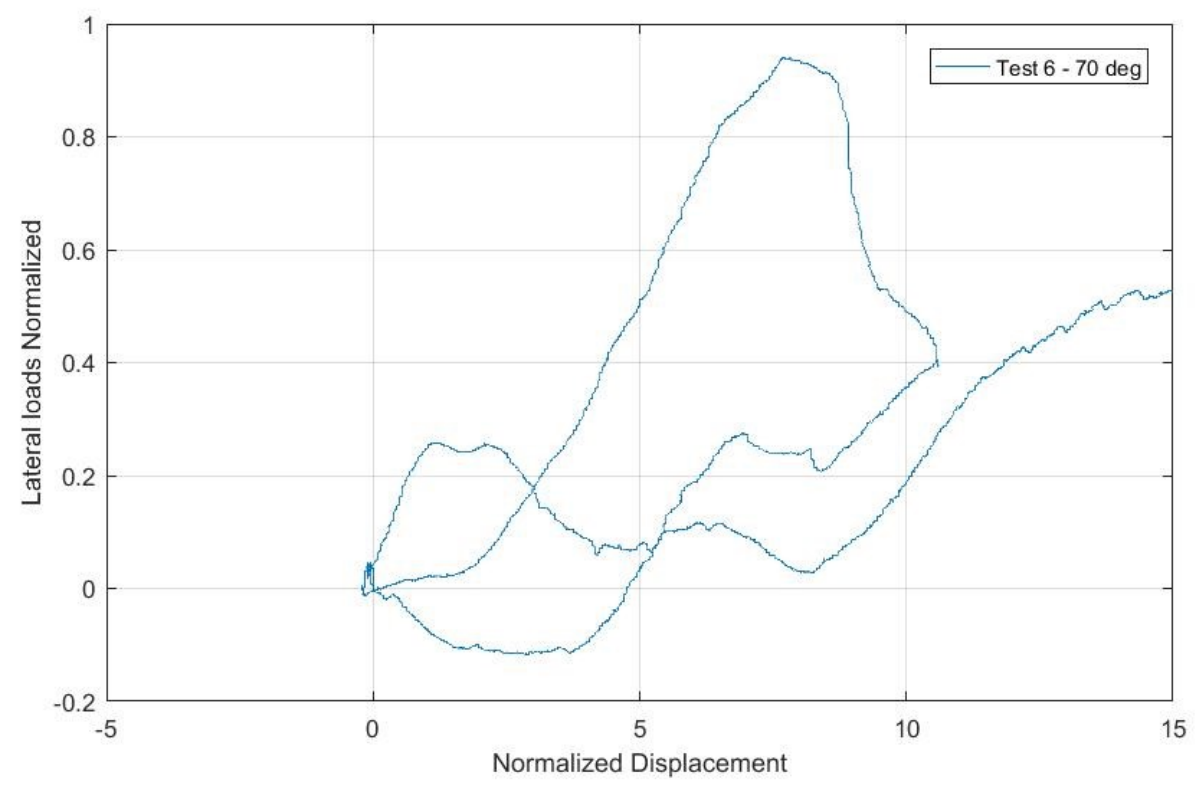

Figure 4-20 - Normalized lateral load as a function of pipe displacement (Test $6,70^{\circ}, \mathrm{H} / \mathrm{D}=2$ )

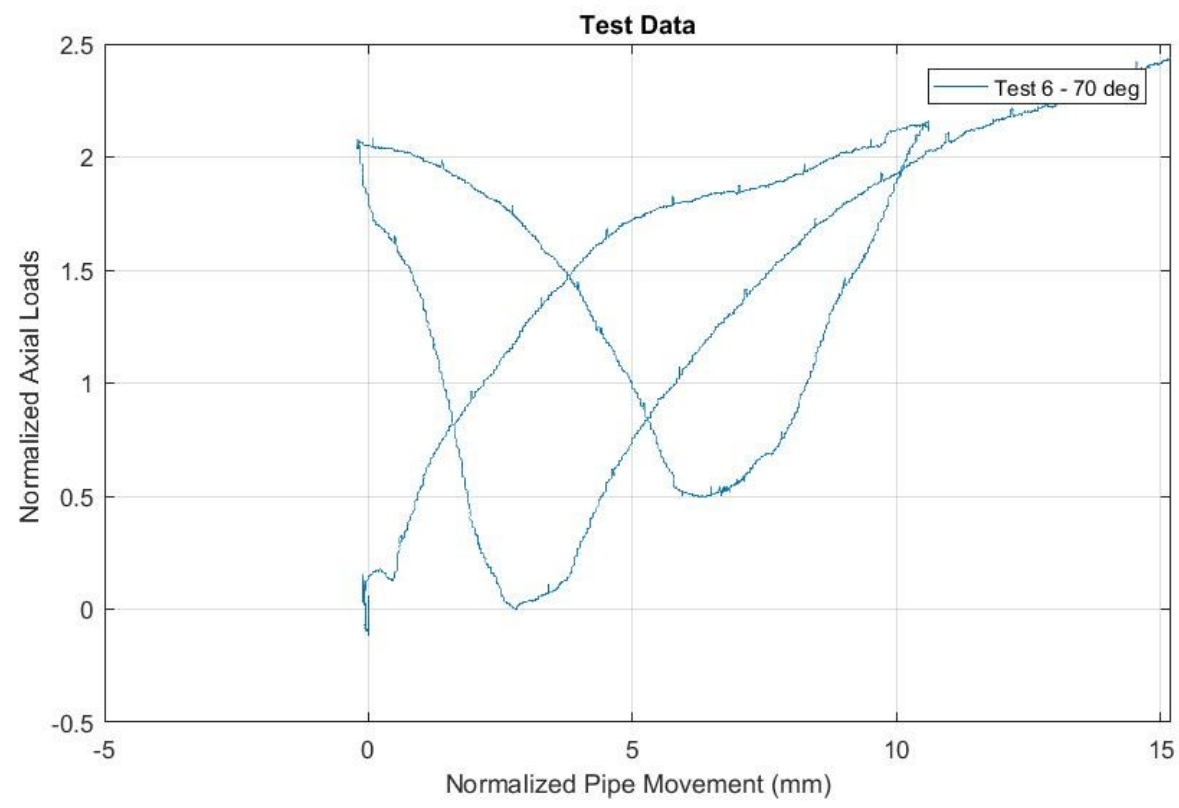

Figure 4-21 - Normalized axial loads as a function of pipe displacement (Test $6,70^{\circ}, \mathrm{H} / \mathrm{D}=2$ ) 


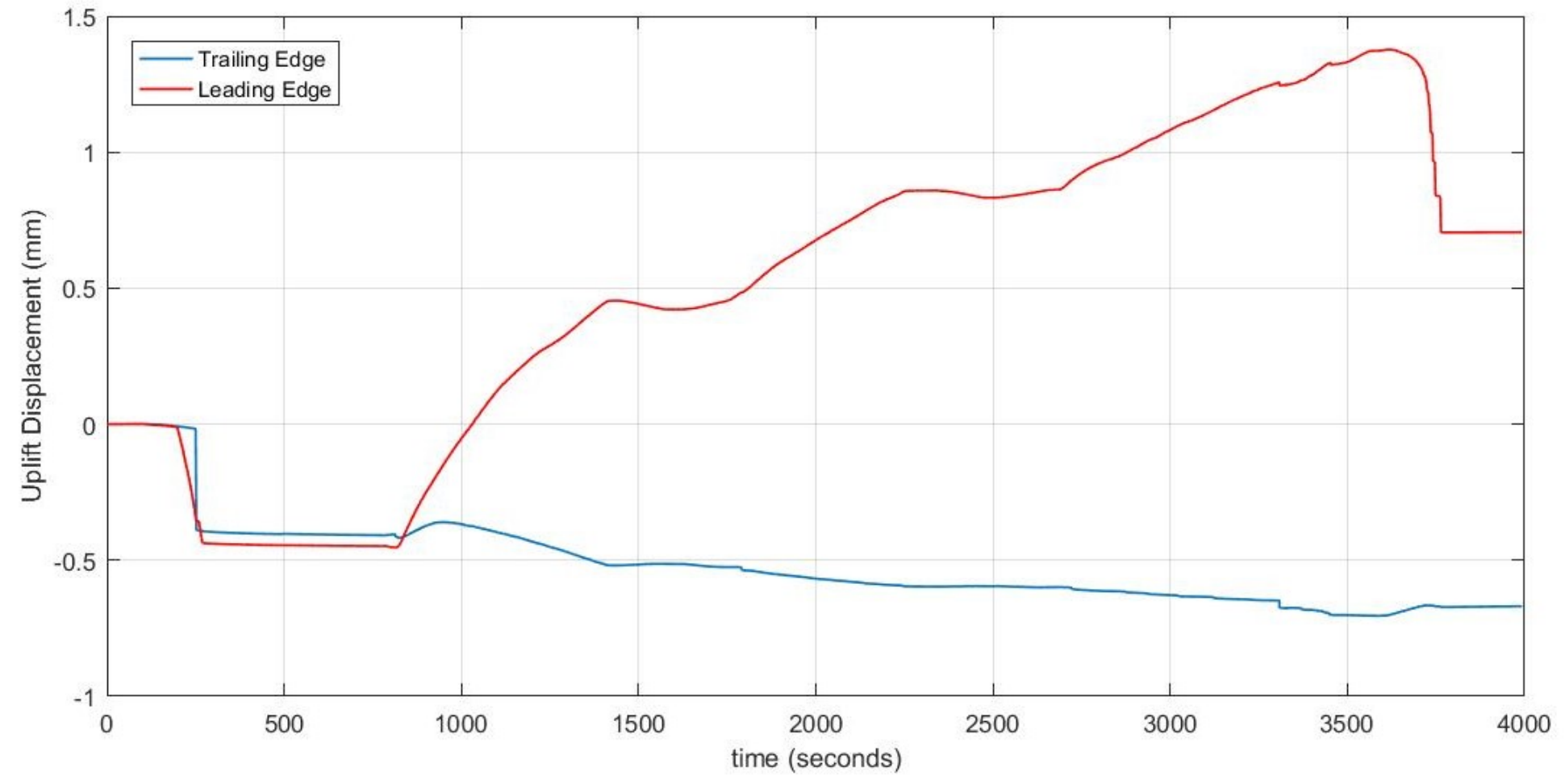

Figure 4-22 - Uplift displacement of leading and trailing edge of dogbone (Test 4, 90, $\mathrm{H} / \mathrm{D}=2$ ) 


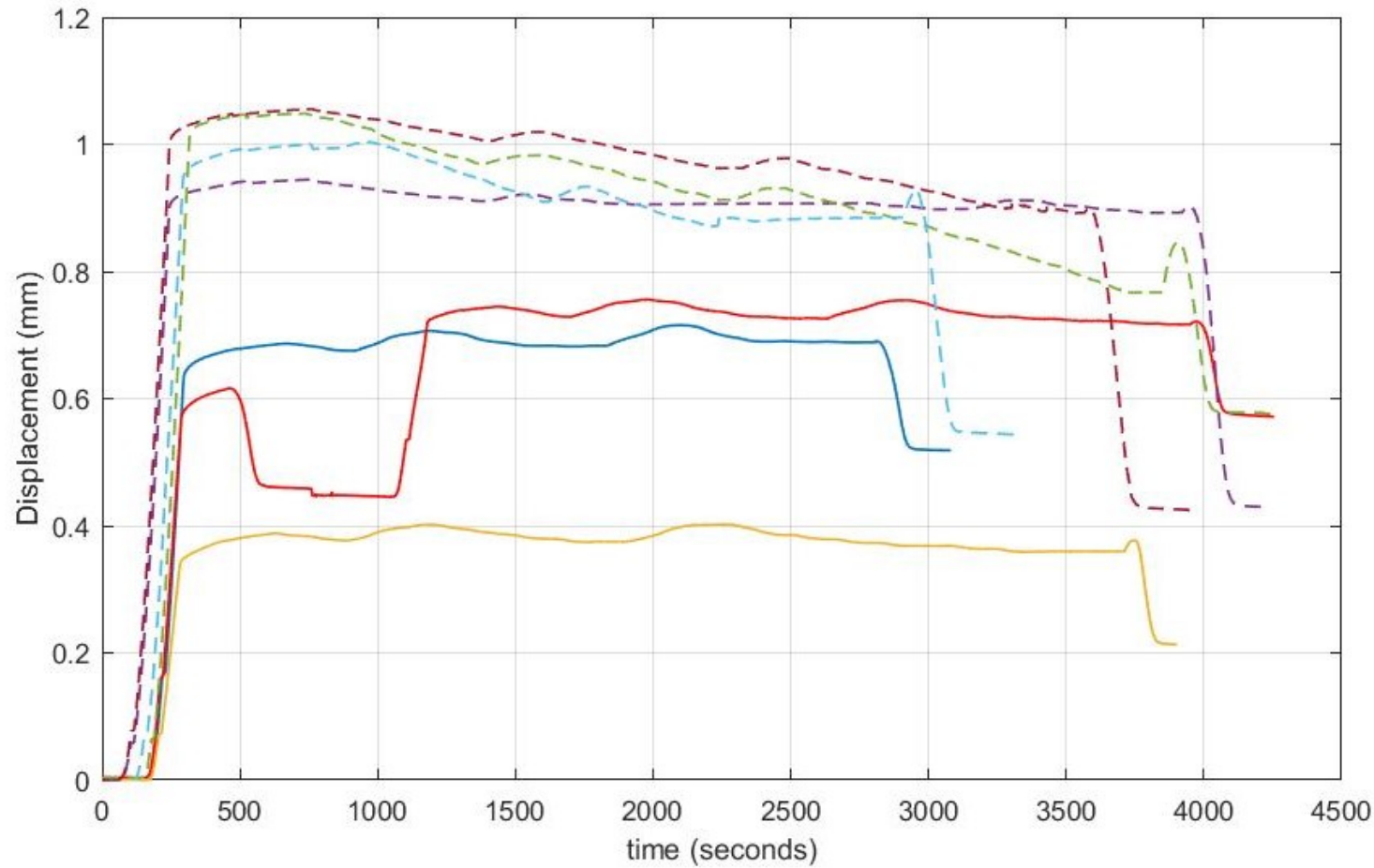

Test $3\left(90^{\circ}\right.$, no foam, $\left.\mathrm{H} / \mathrm{D}=2\right)$

Test $5\left(20^{\circ}, \mathrm{H} / \mathrm{D}=2\right)$

- Test $6\left(70^{\circ}, \mathrm{H} / \mathrm{D}=2\right)$

- - Test $7\left(0^{\circ}, \mathrm{H} / \mathrm{D}=4\right)$

- Test $8\left(20^{\circ}, \mathrm{H} / \mathrm{D}=4\right)$

- Test $9\left(90^{\circ}, \mathrm{H} / \mathrm{D}=4\right)$

- - Test $10\left(30^{\circ}, \mathrm{H} / \mathrm{D}=4\right)$

Figure 4-23 - Soil Settlement as a function of time for Test 3, 5, 6, 7, 8, 9, and 10. 


\section{Summary and Conclusions}

A series of ten reduced-scale tests were completed at different attack angles in loose silica sand with a friction angle of $29^{\circ}$. All ten tests were conducted using a similar testing procedure with respect to the test bed preparation, instrumentation type, number and placement, and treatment of boundary conditions using the acoustic foam. The pipe was cyclically loaded during testing to confirm the elastic behaviour of the soil and consistency of the test bed condiotion. The purpose of the research was to measure the soil yield load and yield displacement response and determine the failure envelope.

Six tests were completed at an H/D ratio of 2 and were considered the shallow tests. The tests were completed at the following angles: $0^{\circ}, 20^{\circ}, 50^{\circ}, 70^{\circ}$, and two tests at $90^{\circ}$. One of the $90^{\circ}$ tests was completed without the acoustic foam in front of the stanchions to determine the effects of the foam during testing. The ultimate lateral and axial loads determined during testing were similar to the results from the previous centrifuge and finite element research (Daiyan, 2013, Debnath, 2015), which were greater than measurements obtained during full-scale physical modelling (Hsu, 2010). In comparison with previous research, the mobilization distances at yield loads from this research were much closer to the mobilization distances proposed by the ALA guidelines (2005). This was particularly evident when comparing the mobilization distances developed for the $90^{\circ}$ test using the acoustic foam, which was consistent with the ALA guidelines, with the same test without using the foam inserts.

A series of five tests were also completed at a spring line burial depth of $4 \mathrm{D}$, which were considered the deep tests. These tests were completed at the following angles: $0^{\circ}, 20^{\circ}, 30^{\circ}$, and $90^{\circ}$. During testing, the increased loads due to the deeper burial depth during all five tests caused 
additional bending of the dog bone pieces and a rotation of the pipe assembly. The measured yield loads and mobilization distances were greater than the ALA guideline predictions (2005). The discrepancy was attributed to mechanisms developed in the test frame during the test including pipe lag and pipe assembly rotation, which may have reached up to $0.2 \mathrm{D}$ deflection magnitude. The lag was caused by insufficient stiffness of the test frame and was affected by the increased resistance of the additional weight of the soil above the pipe. This mechanism resulted in the failure of the test assembly and load cell. Before further deep tests can be conducted, the pipe assembly would require improvements to ensure that additional errors are not introduced to the results by the rotation of the pipe assembly.

\subsection{Future Research and Recommendations}

This research is part of a larger body of studies on pipe/soil interaction and provides complementary evidence supporting and extending the database on oblique pipe/soil interaction events. To help improve the knowledge base, it is recommended that additional research be conducted to further confirm the assumptions and results from this research.

\subsubsection{Future Reduced Scale Test}

Before additional reduce scaled tests are conducted, the following improvements to the reduced scale testing methodology are proposed:

- Reinforcement of the pipe assembly and frame, especially for the deep tests. This reinforcement would help minimize the rotation of the stanchions during mobilization and minimize the error caused by the pipe movement lag during testing. A possible option is to include a tensioned rod connecting the two load cells to ensure that the model pipe is not pulled from between the stanchions. Before this option could be used, the 
effect of the rod on the end bearing conditions would need to be modelled as the load cell would no longer be held in place with a pinned connection.

- Reduction of the weight of the pipe assembly by using a lighter composite material especially if the assembly is reinforced to ensure that the weight is consistent with a real pipe during testing.

- Introduction of additional instrumentation along the pipe and pipe assembly itself to provide additional information during testing. Strain gauges could be added along the pipe length and the stanchions, which would help quantify the bending that is occurring during testing. A load cell may also be added to the top of the stanchions to measure the loads on the stanchions during testing.

- Refinement of the loading/ mobilization pattern. A smaller amplitude of motion during loading and unloading would minimize the effect of ratcheting and may provide more accurate results for uplift modelling.

- Confirmation of the expected loads using numerical modeling before the reduce scale tests are completed. This would help minimize the possibility of bending of the pipe assembly during testing and failure of the motor due to the applied moments. For this research, the expectant loads were calculated based on the ALA guidelines (2005) and a safety factor of 1.5 was applied to ensure that the motor would have the capacity to mobilize the pipe.

Future reduce scaled tests should also be conducted with different variables including burial depths, saturation levels, and soil properties. Other possible tests may include additional tests 
with an H/D of 4 but different densities and/or internal friction angle of sand and tests in cohesive soils.

\subsubsection{Soil Property and Characteristics}

As additional tests are conducted with different types of cohesionless soils, the soil characterization process should be refined for the reduced scale tests. Sieve analysis should be conducted before and after the testing to confirm and quantify the changes to the gradation of the soil caused by the testing procedure.

Triaxial tests, as opposed to simple shear tests, are recommended to determine the internal friction of the soil. For this research, the shear tests were used due to the availability of the equipment at the time of testing.

\subsubsection{Verification Testing}

Full-scale tests should be conducted with the same testing parameters as this research to provide a comparison to this data set. The results of the full-scale tests conducted by Hsu (2010) do not match the results of the reduced scale tests with similar parameters from Daiyan (2013) or the practice guidelines. Since the previous reduced-scale tests, the methodology has been refined and has shown results closer to the expected results.

\subsubsection{Finite Element Modeling}

A model using similar parameters as this research should be conducted to confirm if the results are consistent with the finite element model proposed by Daiyan (2013). The previous research by Daiyan was conducted at shallow depth using dense sands so these new testing parameters can be used to validate his model. 
It is also recommended that the effect of the stanchions be modelled to help estimate the amount of rotation and bending of the stanchions during testing. It may also help quantify the pipe lag which occurred during the deep tests. During modelling, different resistances could be modelled in front of the stanchions to help determine which material would be the most effective at minimizing the effect of the stanchions on the end bearing conditions.

\subsubsection{Integration of Results}

Once a sufficient amount of data is available including results from reduce-scaled tests, fullscale tests, and numerical models, the results should be compared to help improve the existing ALA guidelines and best-practice procedures. These improvements would include a more accurate way to estimate the ultimate yield loads and displacements and will allow for a more accurate model of multi-directional loaded pipelines. Updated failure envelopes should also be developed based on the soil type and pipeline dimensions to allow for user-friendly design tables or graphs for use in industry. 


\section{Bibliography}

Abdoun, Tarek (2011). Centrifuge physical modeling \& scaling laws. RPI/UCD NEES

Centrifuge Research and Training Workshop 2011.

American Lifeline Alliance (2001). Guidelines for the design of buried steel pipe, American

Lifeline Alliance (ALA), Federal Emergency Management Agency (FEMA), Washington, D.C.

ALA 2005. Guidelines for the design of buried steel pipes. American Lifelines Alliance, 76p.

ASCE (1984). Guidelines for the seismic design of oil and gas pipeline systems. American Society of Civil Engineers, Committee on gas and liquid fuel lifelines, Technical Council on Life line Earthquake Engineering, ASCE, NewYork.

ASTM D3080 / D3080M-11, Standard Test Method for Direct Shear Test of Soils Under Consolidated Drained Conditions, ASTM International, West Conshohocken, PA, 2011

Audibert, J. M. E. and Nyman, K. J. (1977). Soil restraint against horizontal motion of pipes. Journal of Geotechnical Engineering Division, ASCE, 103(10), 111 9-11 42.

Balachowski, L. 2007. Size Effect in Centrifuge Cone Penetration Tests. Hydro-Engineering and Environmental Mechanics. Vol 54 No. 3 pp. 191-181

Bolton, M. D., Gui, M.W., Garnier, J., Corte, J.F., Bagge, G., Laue,J., and Renzi, R. 1999. Centrifuge Cone Penetration Tests in Sand. Geotechnique 49, No. 4 : 543 - 552

Burnett, A. 2015. Investigation of full scale horizontal pipe/soil interaction and large strain behaviour of sand. M.A.Sc. Thesis, Queen's University, 118p. 
Craig, W.H. 1995. Geotechnical centrifuge: Past, present and future. Geotechnical Centrifuge Technology, pp.1-18.

Cheuk, C. Y., White, D. J ., Bolton, M. D. (2008). Uplift mechanisms of pipes buried in sand. Journal of Geotechnical and Geoenvironmental Engineering, ASCE, 134(2).

Cocchetti, G., Prisco, C., Galli, A. and Nova, R. (2009a). Soil-pipeline interaction along unstable slopes: a coupled three-dimensional approach. Part I : Theoretical formulation. Canadian Geotechnical Journal, 46 (11 ): 1289-1304.

Cocchetti, G., Prisco, C., and Galli, A. (2009b). Soil-pipeline interaction along unstable slopes: a coupled three-dimensional approach. Part 2: Numerical analysis. Canadian Geotechnical Journal, 46 (11): 1305-1321. Canadian Geotechnical Society. 2006.

Daiyan, N. 2013. Investigating Soil/Pipeline Interaction During Oblique Relative Movements. PhD Thesis, Memorial University of Newfoundland, 204p.

Daiyan, N., Kenny, S., Phillips, R. and Popescu, R. 2011. Investigating pipe/soil interaction under axial/lateral relative movements in sand. Can. Geotech. J., 48(11): 1683-1695.

Daiyan, N., Kenny, S., Phillips, R. and Popescu, R. 2010. Numerical investigation of oblique pipe/soil interaction in sand. Proc., IPC2010-31644:6p

Debnath, P. 2015. Centrifuge modeling of oblique pipe/soil interaction in dense and loose sand. M.Eng. (Thesis), Memorial University of Newfoundland, 120p.

El Hmadi, K., O’Rourke, J. 1988. Soil Spring for Buried Pipeline Axial Motion. J. Geotech. Enrg. 114(11) 1335-1339 
Garnier, J., Gaudin, C., Springman, S.M., et al. 2007. Catalogue of scaling laws and similitude questions in geotechnical centrifuge modelling. Int. J. Phy. Mod. Geo., 7(3):1-23.

Gaudin, C., Randolph, M. and White, D. 2016. Centrifuge Modelling in Geotechnics. CRC Press, ISBN 9780415522243, 544p.

Guo, P. (2005). Numerical modeling of pipe-soil interaction under oblique loading. Journal of Geotechnical and Geoenvironmental Engineering, ASCE, 131 (2), pp. 260-268.

Guo. P. and Stolle. D. F. (2005). Lateral pipe-soil interaction in sand with reference to scale effect. Journal of Geotechnical and Geoenvironmental Engineering, ASCE, 131 (3): 338349.

Hansen, J.B. (196 1). The ultimate resistance of rigid piles against transversal forces. Bulletin 12, Danish geotechnical institute, Copenhagen, Denmark, pp.S-9.

Hodder, M. S. and Cassidy, M. J. (20 I 0). A plasticity model for predicting the vertical and lateral behavior of pipelines in clay soils. Geotechnique, 60, o. 4, pp. 247-263.

Horvath, J. S. Colasanti. R.J 2011. New Hybrid Subgrade Model for Soil-Structure Interaction Analysis: Foundation and Geosynthetics Applications. GeoFrontiers2011, ASCE.

Horvath, J. S. (2002). Soil-structure interaction research project; basic SSI concepts and applications overview. Report No. CGT-2002-2, Manhattan Coil., Bronx, NY.

Honegger, D. G. (1999). Field measurements of axial soil friction forces on buried pipelines. Proceedings of the Fifth U.S. Conference on Lifeline Earthquake Engineering, Technical 
Council on Lifeline Earthquake Engineering, Monograph No. 16, American Society of Civil Engineers.

Honegger. D. G., Hart, J. D., Phillips, R., Popelar. C. and Gailning, R. W. (201 0). Recent PRCI guidelines for pipelines exposed to landslide and ground subsidence hazards. Proceedings of IPC201 0, International Pipeline Conference, Calgary.

Honegger, D. G. and Nyman, J. (2004). Guidelines for the seismic design and assessment of natural gas and liquid hydrocarbon pipelines. Pipeline Research Council International, Inc., No.L5 1927.

Hsu, T.W., Chen, Y.J. and Hung, W.C.2006. Soil restraint to oblique movement of buried pipes in dense sand." J. Transp. Eng. 132(2):175-181.

Hsu, T.W., Chen, Y.J. and Hung, W.C. 2001. Soil friction restraint of oblique pipelines in loose sand. J. Transp. Eng. 127(1):82-87.

Jacky, J. (1944). The coefficient of earth pressure at rest. Journal of the society of Hungrian Architects and Engineers, Budapest, Hungry, pp. 355-358.

Jardine, R. J., and Overy, R. F. (1996). Axial capacity of offshore piles driven in dense sand. Proceedings Offshore International Conference, Houston, Texas, USA., pp. 161-180.

Karimian, S. A. (2006). Response of buried steel pipelines subjected to longitudinal and transverse ground movement. PhD Thesis, The University of British Colombia. 
Kennedy, R. P. , Chow, A. W., and Williamson, R. A. ( 1977). Fault movement effects on buried oil pipelines, Journal of the Transportation Engineering Division, ASCE, vol. 103, pp. 6 17-633.

Kenny, S., Jukes, P. 2015. Pipeline/Soil Interaction Modeling in Support of Pipeline Engineering Design and Integrity. John Wiley and Sons

Kenny, S. Pike, K., Debnath, P., and Hawlader, B. 2015. Integrated Framework in Support of Pipeline Engineering Design for Geohazards. Geo Quebec 2015

Knut. S. 2016. Characteristic soil strength for axial pile capacity and its estimation with confidence for offshore applications. Structural Safety Vol 63 pg. 81-89

Lam, S.Y., Ng. C.W.W., Leung C.F, Chan, S.H. 2009. Centrifuge and Numerical Modeling of Axial Load Effects on Piles in Consolidating Ground. Canadian Geotechnical Journal 46.1

Liu, Q.B, Lehane, B.M. 2012. The influence of particle shape on the (centrifuge) cone penetration test (CPT) end resistance in uniformly graded granular soils. Géotechnique: Vol.62 Issue 11, pp. 973-984

Mackenzie, T. R. (1955). Strength of deadman anchors in clay. MSc. Thesis, Princeton University, USA.

Maddock, D.V. 1981. The Development of a Transducer to Measure the Effective Soil Stresses and the Pore Water Pressure Acting on the Surface of a Driven Steel Pile. Cambridge University 
Merifield, R. S. and Sloan, S. W. (2006). The ultimate pullout capacity of anchors in frictional soils. Canadian Geotechnical Journal, 43, pp. 852-868.

Merifield, R. S., Sloan, S. W. and Yu, H. S. (2001). Stability of plate anchors in undrained clay. Geotechnique 51, No.2, pp. 14 1-153.

Meyerhof, G. G. (1955). Influence of roughness of base and groundwater conditions on the ultimate bearing capacity of foundations. Geotechnique, Vol. 5, pp. 227-242.

National Research Canada. 2016. 10 Key Facts on Canada's National Resources. NRC

Ng, P. C. F. (1994). Behavior of buried pipelines subjected to external loading. PhD Thesis, University of Sheffield, England.

Ng, C. W. W., and Springman, S. M. (1994). Uplift resistance of buried pipelines in granular materials. Centrifuge 94, Leung, Lee and Tan, eds., pp. 753-758.

Ng, C.W.W. (2014) The state of the art centrifuge modeling of geotechnical problems at HKUST. Journal of Zhejiange University. Vol 15 Issue 1. Pp1-21.

Nobahar, A., Kenny, S. and Phillips, R. (2007). Buried pipelines subject to sub gouge deformations. International Journal of Geomechanics, 7(3).

Nobahar, A., Popescu, R., and Konuk, 1. (2000). Estimating progressive mobilization of soil strength. Proceedings 53rct Canadian Geotechnical Conference, Montreal, Que., 15-18 Oct. 2000. Edited by D. Leboeuf Bi Tech Publishers Ltd., Richmond, B.C.

Nyman, K.J. (1984). Soil response against oblique motion of pipes. Journal of Transportation Engineering, 11 0(2), pp. 190-202. 
O'Rourke, T.D. (1989). Seismic design considerations for buried pipelines. Annals of the New York academy of sciences, ISSN 0077-8923, Vol. 558, pp. 324-346.

O' Rourke, T.D., Turner, J.E., Jeon, S-S., Stewart, H.E, Wang, Y. and Shi, P. (2005). Soilstructure interaction under extreme loading conditions, The 13th Spencer J. Buchanan Lecture.

Ovesen, N. K. (1964). Anchor slab calculation methods and model tests. Danish Geotechnical Institute, Copenhagen, Denmark, Bulletin 16, 40p.

Paulin, M. J., Phillips, R., Clark, J. I., Trigg, A., \& Konuk, I. 1998. Full-scale investigation into pipeline/soil interaction. Proc., CGS:241-248.

Phillips, R., Nobahar, A., and Zhou, J.2004a. Combined axial and lateral pipe-soil interaction relationships. Proc., IPC-0144:5p.

Phillips, R., Nobahar, A., and Zhou, J.2004b. trench effects on pipe-soil interaction. Proc., IPC0141:7p

Pike, K., Kenny, S., (2011) Advancement of CEL procedures to analyze large deformation pipeline /soil interaction events, Proceedings of Offshore Technology Conference, Houston, Texas, USA, May 2011.

Pike, K.P. and Kenny, S.P. 2012a. Lateral-axial pipe/soil interaction events: Numerical modeling trends and technical issues. Proc., IPC-90055:6p.

Rossiter, C. and Kenny, S. 2012. Evaluation of lateral-vertical pipe/soil interaction in clay. Proc., OTC-23735:13p. 
Rowe, R. K. (1978). Soil structure interaction analysis and its application to the prediction of anchor behaviour. PhD thesis, University of Sydney, Sydney, Australia.

Rowe, R. K., and Davis, E. H. (1982a). The behaviour of anchor plates in clay. Geotechnique, 32(1), pp. 9-23.

Rowe, R. K., and Davis, E. H. (1982b). The behavior of anchor plates in sand. Geotechnique, 32(1), pp. 25-4 1 .

Schaminee, P. E. L., Zorn, N. F., \&Schotman, G. J. M. 1990. Soil response for pipeline upheaval buckling analyses: Full-scale laboratory tests and modeling. Proc., OTC-6486:563-572.

Sherif. M. A., Fang, Y. S. and Sherif, R. I. (1984). $K^{\prime \prime}$ and $K_{0}$ behind rotating and on yielding walls. ASCE Journal of Geotechnical Engineering, 110, pp. 41-56.

Stroud, M. A. (1971). Sand under low stress levels in simple shear apparatus. PhD thesis, Cambridge University, Cambridge, UK.

Taylor, R. N. (1995). Geotechnical centrifuge technology. Blackie academic \& professional, London, 296p.

Trautmarm, C. H. (1983). Behavior of pipe in dry sand under lateral and uplift loading. PhD thesis, Cornell University, Ithaca, New York.

Trautmann, C. H. and O' Rourke, T. D. (1985). Lateral force-displacement response of buried pipe. Journal of Geotechnical Engineering, ASCE, 111 (9), pp. 1077-1 092.

Wantland. G. P., O'Neil, M. B., Coelogyne, E. H. and Reese, L. C. (1982). Pipeline lateral stability in soft clay. Journal of Petroleum Technology, 34(1), pp. 217-220. 
Wijewickreme, D., Karimian, A., Honegger, D.G. (2005). Effectiveness of some methods of reducing axial soil loads on buried pipelines subjected to ground movements. Proceedings of the 58th Canadian Geotechnical Conference, Saskatoon

Wijewickreme, D., Karimian, H. and Honegger, D. (2009). Response of buried steel pipelines subjected to relative axial soil movement. Canadian Geotechnical Journal, 46, pp. 735752.

Winkler, E. (1867). Die Lehre Von Elastizitat und Festigkeit (Teachings on Elasticity and Stiffness). Prague, Czechoslovakia, 182p.

Zhang, Y. (2004). Characterization of the Compressive and Fracture Behaviors, as well as the Residual Tensile Strength of a Polyurethane Foam. Master of Science Thesis, Oklahoma State University 
Appendix A - Soil Properties 


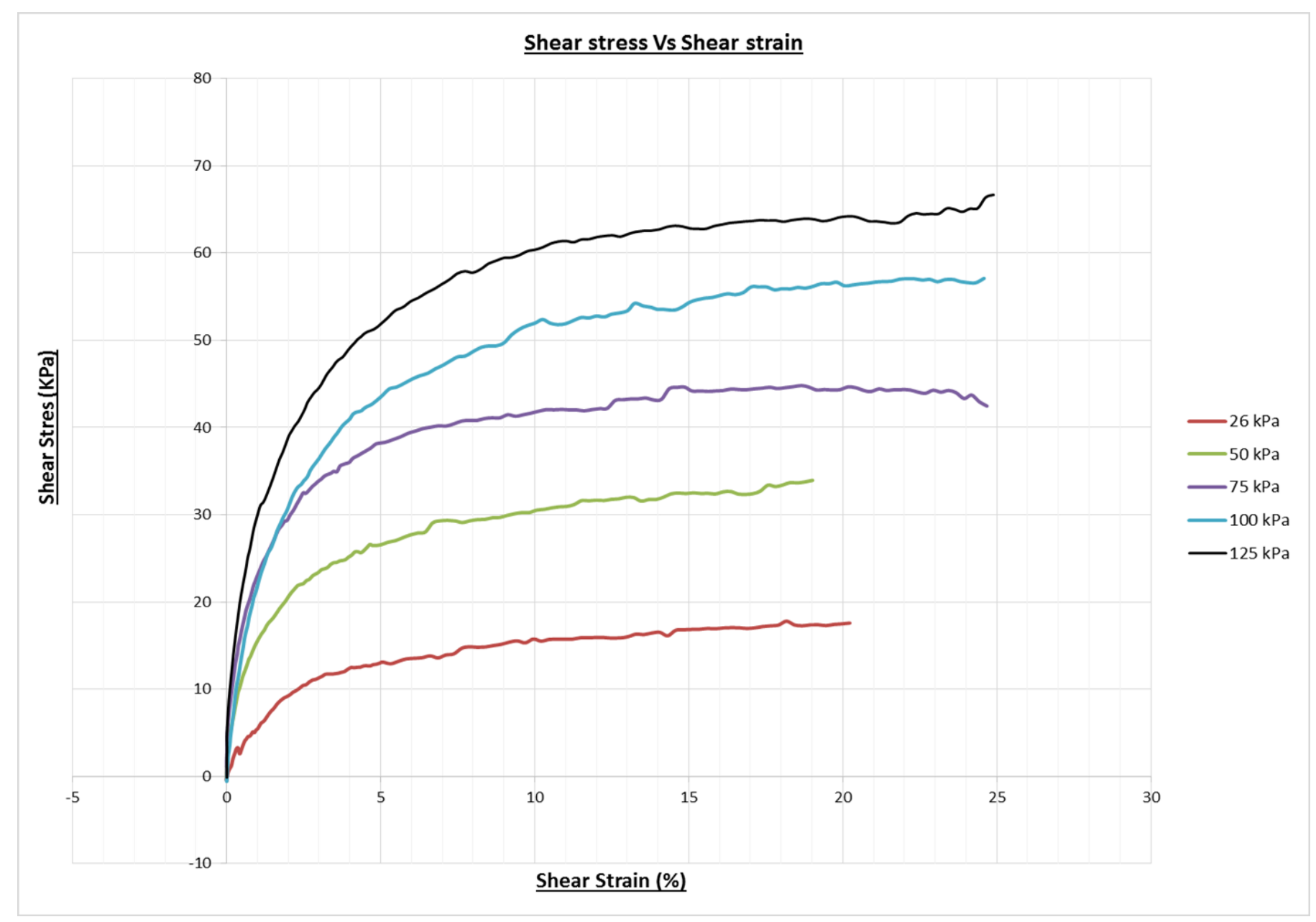

Figure A- 1- Shear Test Results of Silica Sand used in testing 


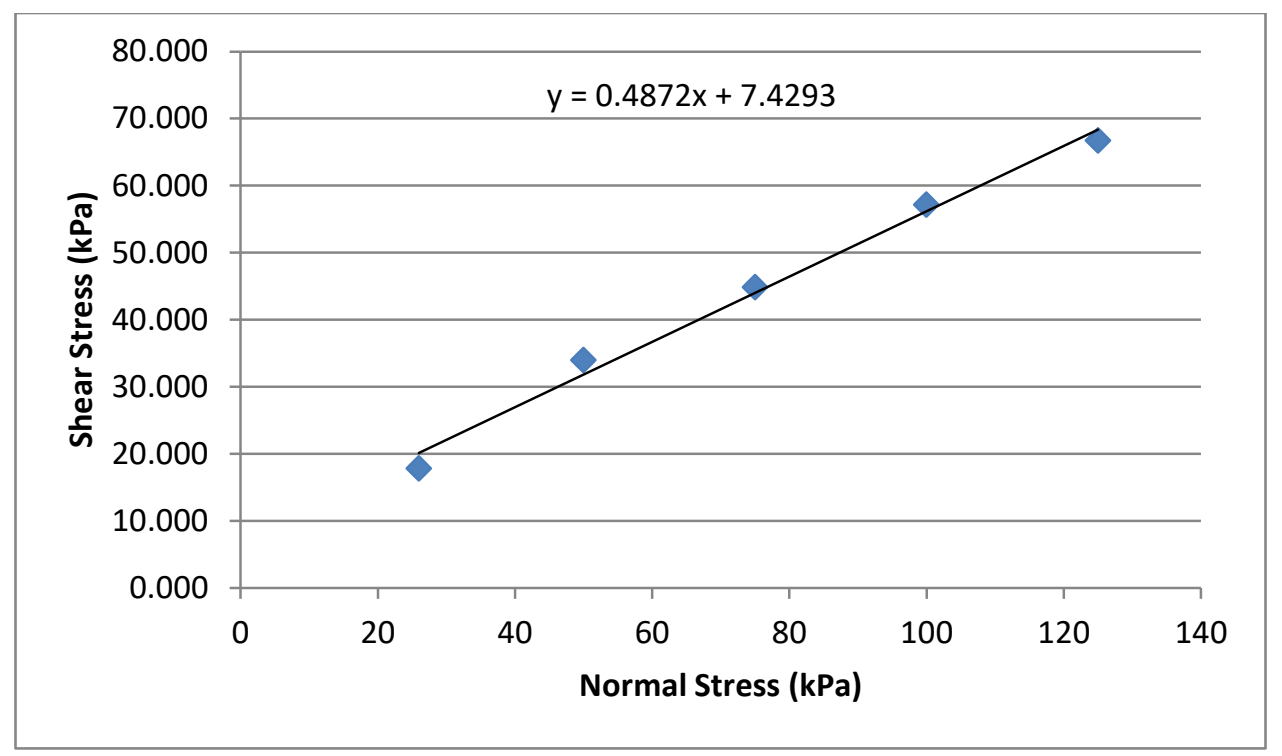

Figure A- 2 - Normal stress as a function of shear stress

Table A- 1 - Sieve test results for silica sand used in testing

\begin{tabular}{|r|r|r|r|r|r|r|}
\hline & \multicolumn{2}{|c|}{ Test 1 } & \multicolumn{2}{c|}{ Test 2 } & \multicolumn{2}{c|}{ Test 3 } \\
\hline $\begin{array}{r}\text { Sieve Size } \\
(\mathrm{mm})\end{array}$ & Weight(g) & \%Passing & Weight(g) & \%Passing & Weight(g) & \%Passing \\
\hline Initial Weight & 1497.4 & & 1946.8 & & 985.7 & \\
\hline 2.36 & 0.2 & $100 \%$ & 0 & $100 \%$ & 0 & $100 \%$ \\
\hline 1 & 0.2 & $100 \%$ & 0 & $100 \%$ & 0 & $100 \%$ \\
\hline 1.18 & 0.2 & $100 \%$ & 0 & $100 \%$ & 0 & $100 \%$ \\
\hline 0.25 & 434.2 & $71 \%$ & 998.2 & $49 \%$ & 298.7 & $70 \%$ \\
\hline 0.15 & 1070.4 & $29 \%$ & 1644.1 & $16 \%$ & 684.5 & $31 \%$ \\
\hline 0.075 & 1464.6 & $2 \%$ & 1934.7 & $1 \%$ & 964.2 & $2 \%$ \\
\hline 0 & 1493.3 & $0 \%$ & 1946.6 & $0 \%$ & 985.2 & $0 \%$ \\
\hline Difference & -4.1 & & -0.2 & & -0.5 & \\
\hline
\end{tabular}


Appendix B - Instrument Calibration 
Table B - 1 - Calibration Matrix for Load Cell A

\section{CALIBRATION MATRIX}

\begin{tabular}{|c|c|c|c|c|c|c|c|}
\hline \multirow[b]{2}{*}{ Load/Force } & \multirow[b]{2}{*}{ Axial } & \multirow[b]{2}{*}{ Low lat } & \multirow[b]{2}{*}{ High lat } & \multicolumn{3}{|c|}{$\begin{array}{l}\mathrm{mV} \text { matrix, normalised by } \\
\text { load }\end{array}$} & \multirow[b]{4}{*}{ Lat } \\
\hline & & & & Axial & Low lat & $\begin{array}{l}\text { High } \\
\text { lat }\end{array}$ & \\
\hline & \multirow[b]{2}{*}{0} & \multirow[b]{2}{*}{1} & \multirow[b]{2}{*}{1} & \multirow[b]{2}{*}{$5.68 \mathrm{E}-05$} & $-4.05 E-$ & $-4.02 \mathrm{E}-$ & \\
\hline Lateral & & & & & $\begin{array}{r}03 \\
-8.52 E-\end{array}$ & $\begin{array}{r}03 \\
-2.06 \mathrm{E}-\end{array}$ & \\
\hline Axial & 1 & 0 & 0 & $\begin{array}{c}3.85 \mathrm{E}-03 \\
-9.34 \mathrm{E}-\end{array}$ & 04 & $\begin{array}{r}03 \\
1.76 \mathrm{E}-\end{array}$ & \multirow{2}{*}{$\begin{array}{l}\text { Axial } 1 \\
\text { Axial } 2\end{array}$} \\
\hline dAxial & 0 & -0.152 & 0.224 & 04 & $7.68 \mathrm{E}-04$ & 03 & \\
\hline Cal kg/mV & Lat & Ax1 & $A \times 2$ & \multicolumn{3}{|c|}{ Inverse $\mathrm{mV}(\mathrm{kg} / \mathrm{mV})$} & \\
\hline Lateral & -245.94 & 7.09 & 14.28 & 7.4 & 368.2 & 447.7 & \\
\hline Axial & 7.42 & 368.16 & 447.69 & -443.4 & -334.3 & 1405.0 & \\
\hline dAxial & 111.72 & 127.29 & 531.50 & 197.5 & 341.4 & 1419.2 & \\
\hline \multirow[t]{5}{*}{ Inv Cal } & & & & & & & \\
\hline & $\begin{array}{r}-4.04 \mathrm{E}- \\
03\end{array}$ & $5.68 \mathrm{E}-05$ & $6.06 \mathrm{E}-05$ & 17618.4 & -247.2 & -248.6 & \\
\hline & $-1.34 \mathrm{E}-$ & & $-3.21 \mathrm{E}-$ & & & & \\
\hline & 03 & $\begin{array}{r}3.85 \mathrm{E}-03 \\
-9.34 \mathrm{E}-\end{array}$ & 03 & 259.7 & -1173.1 & -485.8 & \\
\hline & $1.17 \mathrm{E}-03$ & 04 & 2.64E-03 & -1070.4 & 1301.9 & 568.3 & \\
\hline & & & & \multicolumn{4}{|c|}{$\begin{array}{l}\text { Predicted combined load outputs } \\
\text { (check) }\end{array}$} \\
\hline
\end{tabular}


Table B - 2 - Calibration Matrix Load Cell B

\section{CALIBRATION MATRIX}

\begin{tabular}{|c|c|c|c|c|c|c|c|}
\hline \multirow[b]{2}{*}{ Load/Force } & \multirow[b]{2}{*}{ Axial } & \multirow[b]{2}{*}{ Low lat } & \multirow[b]{2}{*}{ High lat } & \multicolumn{3}{|c|}{ mV matrix, normalised by load } & \multirow[b]{3}{*}{ Lat } \\
\hline & & & & Axial & Low lat & High lat & \\
\hline Lateral & 0 & 1 & 1 & $3.62 \mathrm{E}-05$ & $-3.71 E-03$ & $\begin{array}{r}-3.60 \mathrm{E}- \\
03 \\
1.73 \mathrm{E}-\end{array}$ & \\
\hline Axial & 1 & \multirow[b]{2}{*}{-0.152} & 0 & $-1.00 \mathrm{E}-03$ & $8.20 \mathrm{E}-04$ & $\begin{array}{r}03 \\
-1.92 \mathrm{E}-\end{array}$ & \multirow{2}{*}{$\begin{array}{l}\text { Axial } 1 \\
\text { Axial } 2\end{array}$} \\
\hline dAxial & 0 & & 0.224 & $-9.73 E-04$ & $-7.05 \mathrm{E}-04$ & 03 & \\
\hline Cal kg/mV & Lat & $A \times 1$ & $A \times 2$ & \multicolumn{2}{|c|}{ Inverse $\mathrm{mV}(\mathrm{kg} / \mathrm{mV})$} & & \\
\hline Lateral & -263.75 & 8.63 & -18.69 & -43.7 & -575.2 & -438.3 & \\
\hline Axial & -43.71 & -575.22 & -438.34 & -452.3 & -447.9 & 443.4 & \\
\hline dAxial & 111.06 & 170.36 & -170.93 & 188.5 & 456.6 & -462.1 & \\
\hline \multirow[t]{5}{*}{ Inv Cal } & & & & & & & \\
\hline & $-3.67 \mathrm{E}-03$ & $3.62 \mathrm{E}-05$ & $3.08 \mathrm{E}-04$ & 27599.0 & -269.2 & -277.9 & \\
\hline & 1.19E-03 & $-1.00 \mathrm{E}-03$ & 2.43E-03 & -1000.2 & 1219.8 & 576.4 & \\
\hline & $-1.20 \mathrm{E}-03$ & $-9.73 E-04$ & $-3.22 \mathrm{E}-03$ & -1027.8 & -1417.6 & -521.4 & \\
\hline & & & & \multicolumn{4}{|c|}{ Predicted combined load outputs (check) } \\
\hline
\end{tabular}




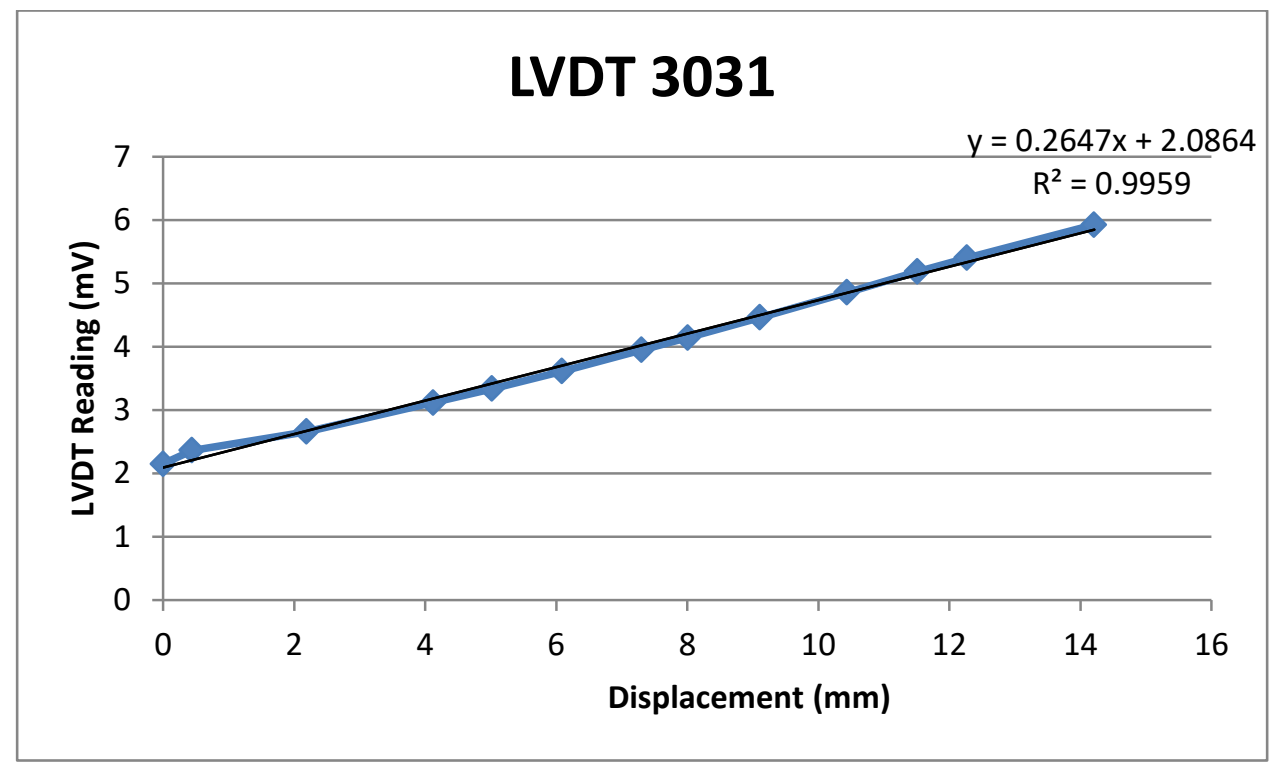

Figure B- 1 - LVDT 3031 Calibration

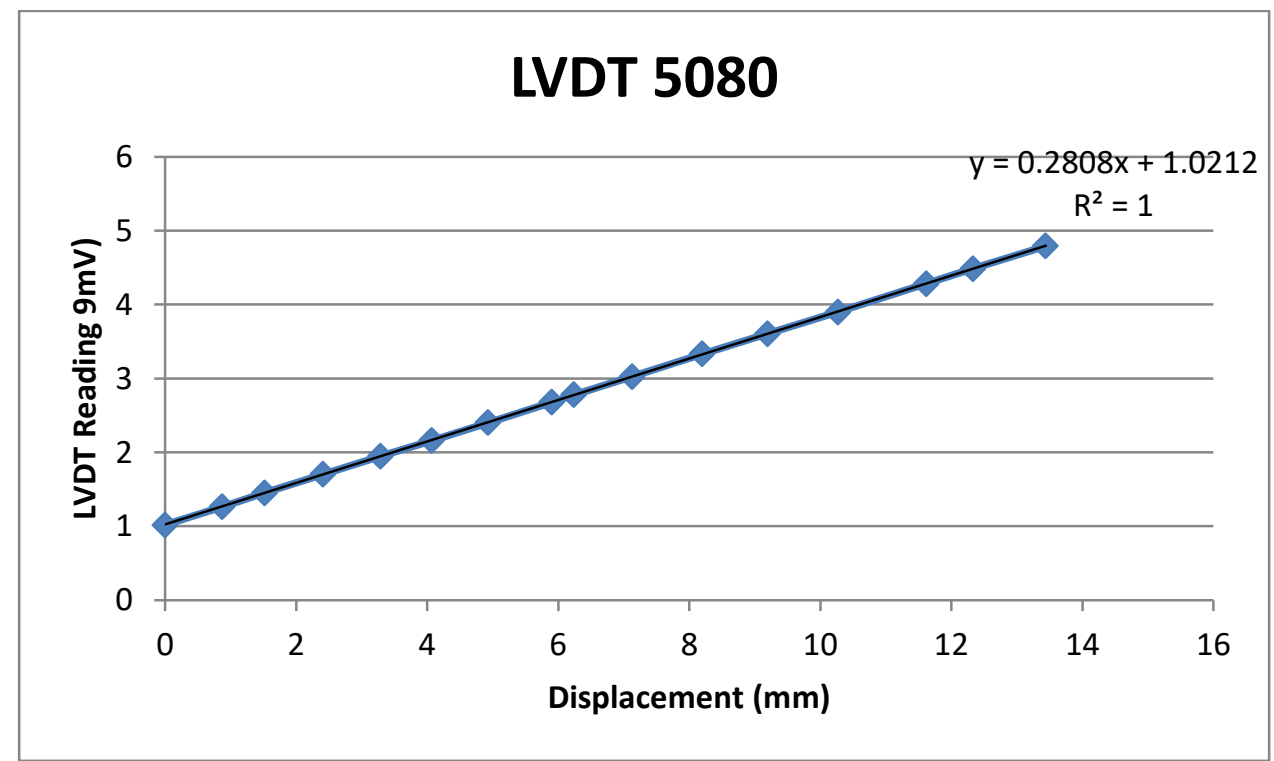

Figure B- 2 - LVDT 5080 Calibration 
Appendix C - Raw Test Data 


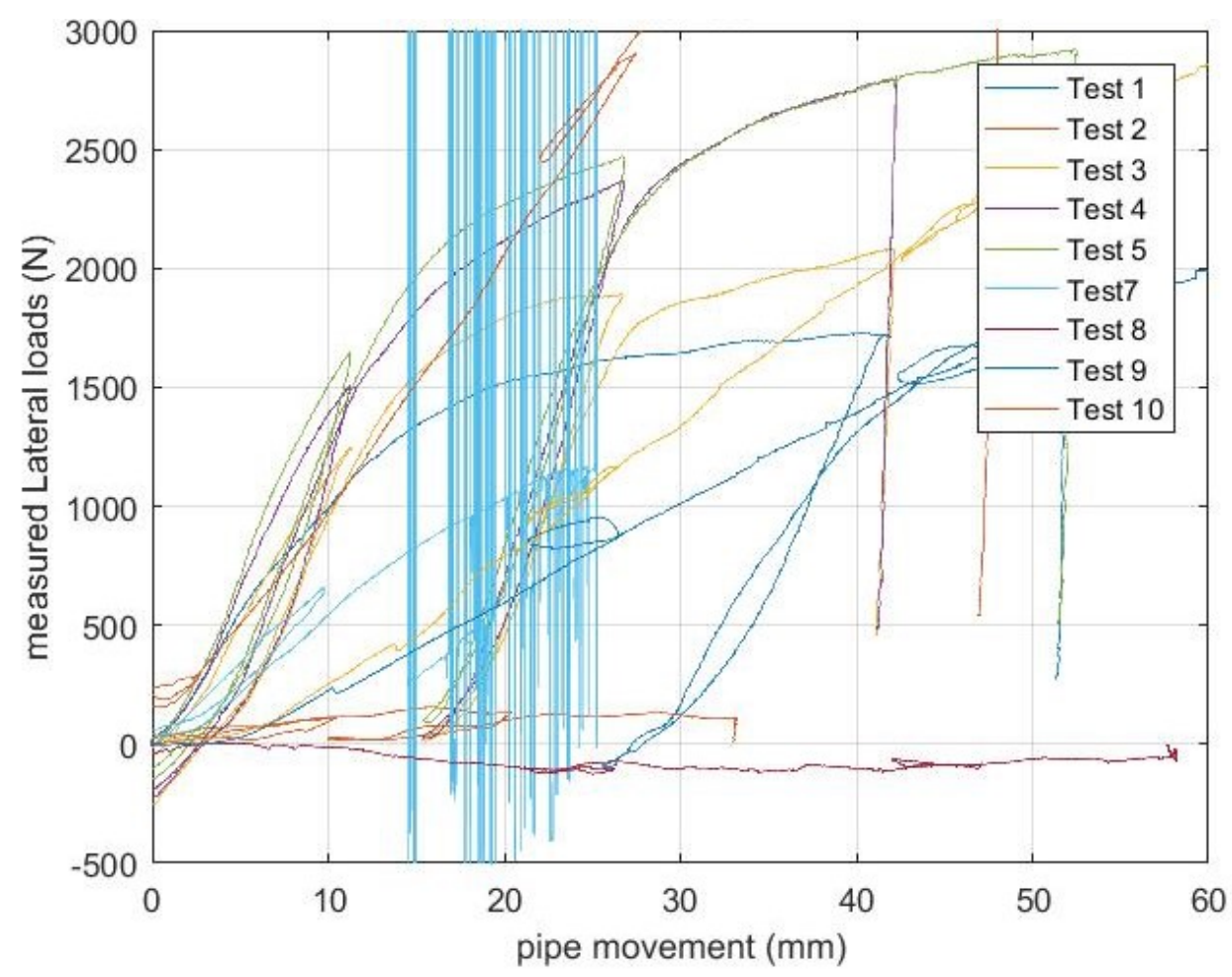

Figure C- 1 - Unprocessed lateral load $(\mathrm{N})$ as a function of true pipe displacement $(\mathrm{mm})$ for all ten reduced scaled tests. 


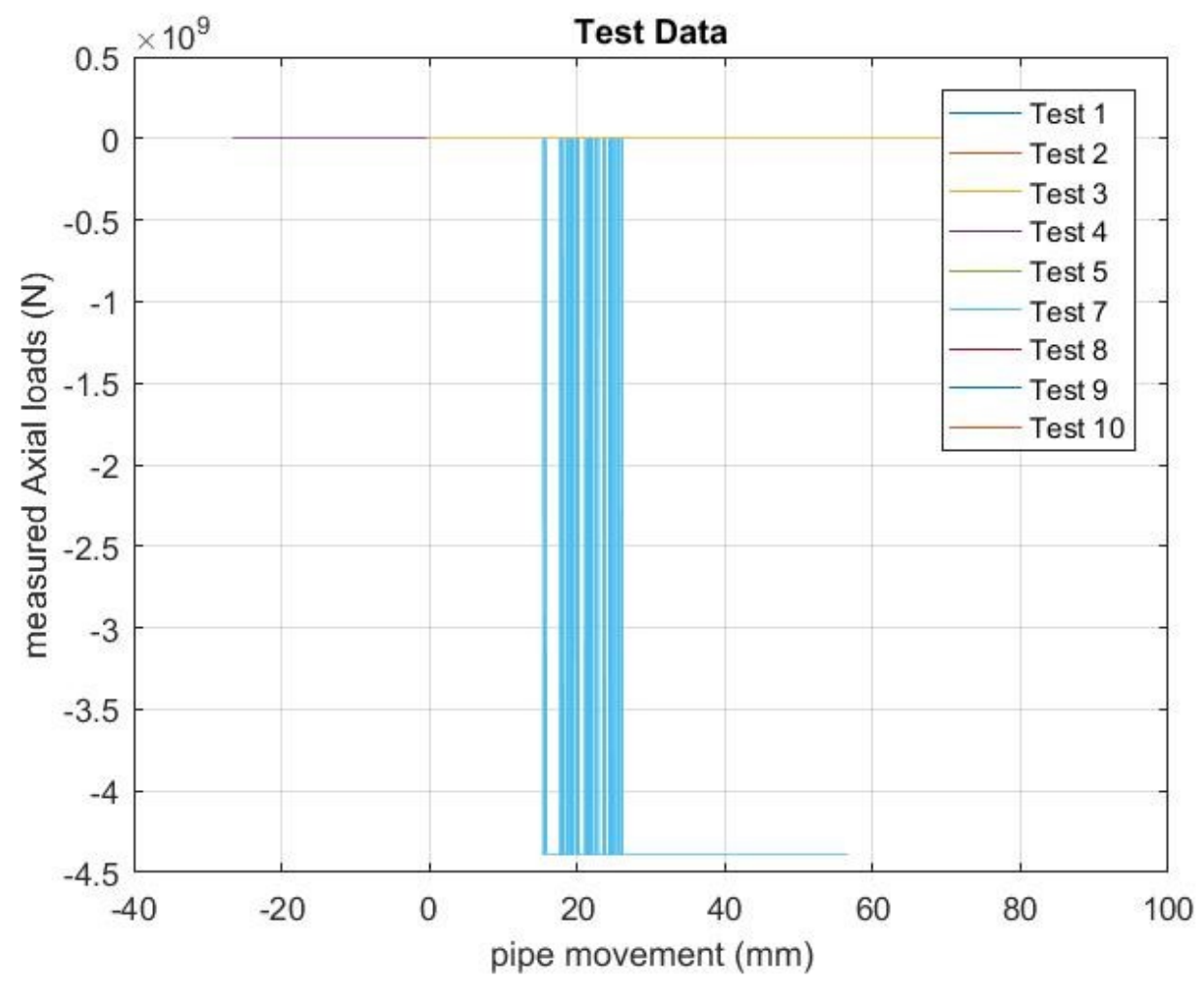

Figure C- 2 - Unprocessed axial load $(\mathrm{N})$ as a function of true pipe movement $(\mathrm{mm})$ for all ten reduced scaled tests. 


\section{Appendix D - Test Scans}




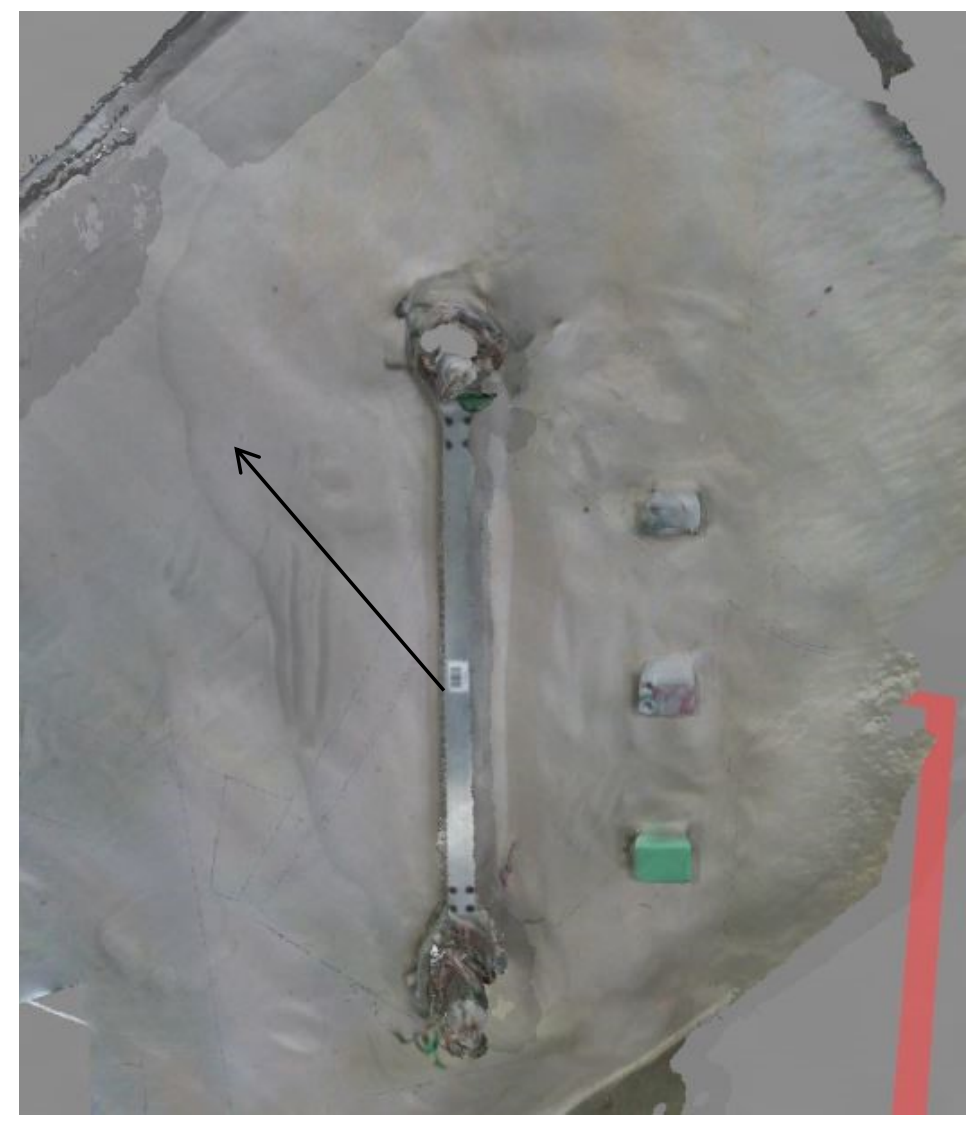

Figure D- 3- Post-test scan Test $1\left(50^{\circ}, \mathrm{H} / \mathrm{D}=2 \mathrm{D}, 6.5 \mathrm{~g}\right)$.

Arrow shows direction of movement 


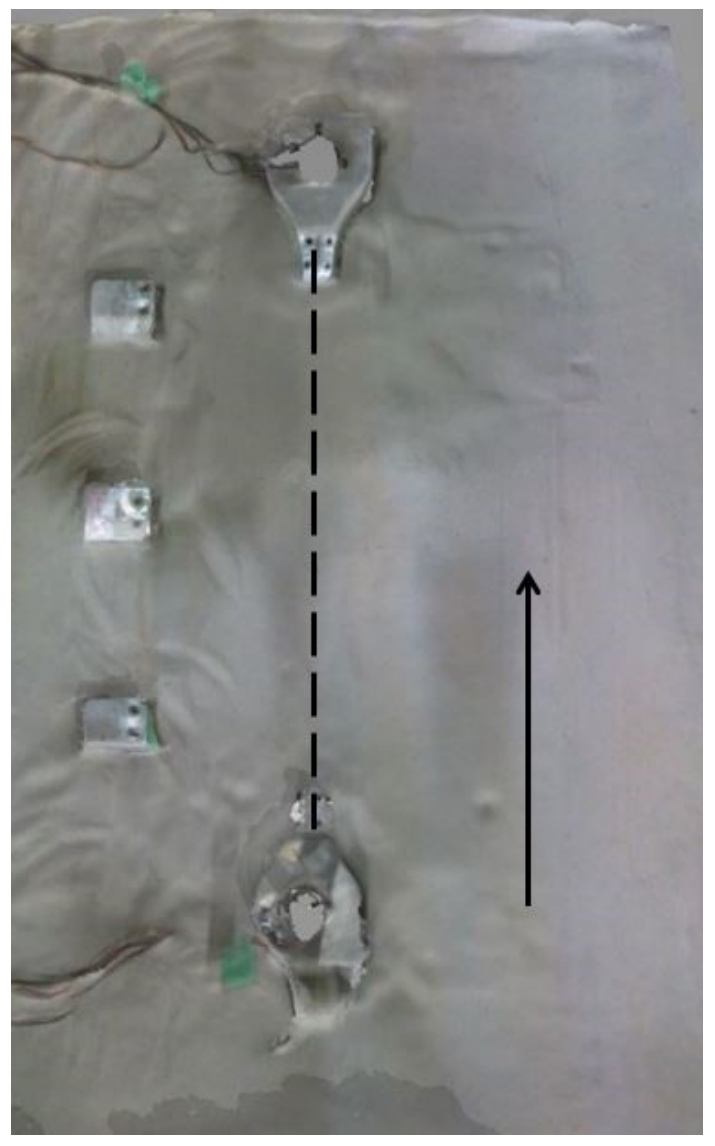

Figure D- 4 - Post-test scan Test $2\left(0^{\circ}, \mathrm{H} / \mathrm{D}=2,6.5 \mathrm{~g}\right)$

The arrow shows the direction of movement, and the dashed line shows pipe alignment. 

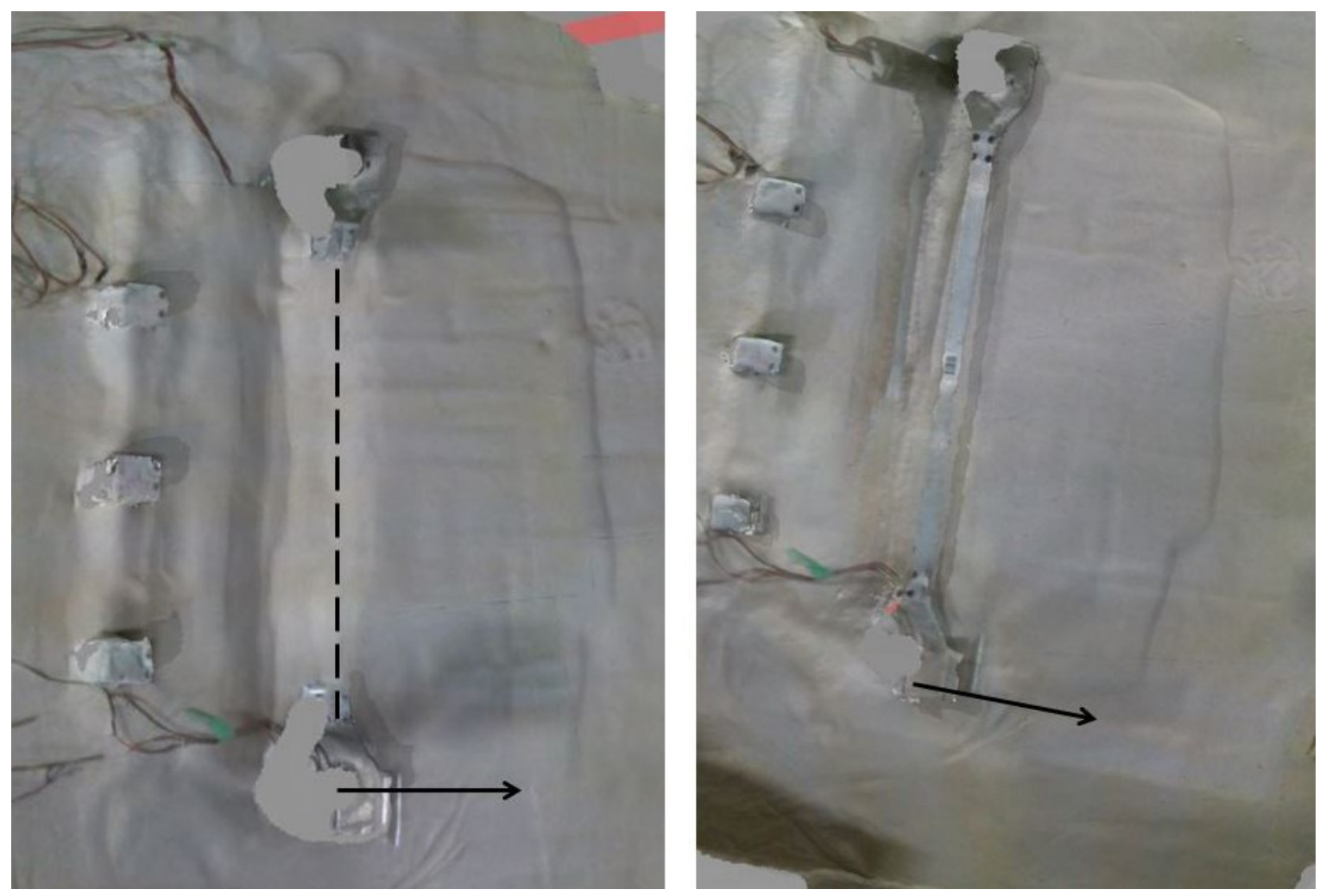

Figure D- 5 - Post-test scan of test $3\left(90^{\circ}, \mathrm{H} / \mathrm{D}=2\right.$, no foam, $\left.6.5 \mathrm{~g}\right)$ without dog bone and with dog bone

The arrow shows the direction of movement and the dashed line shows pipe alignment. 


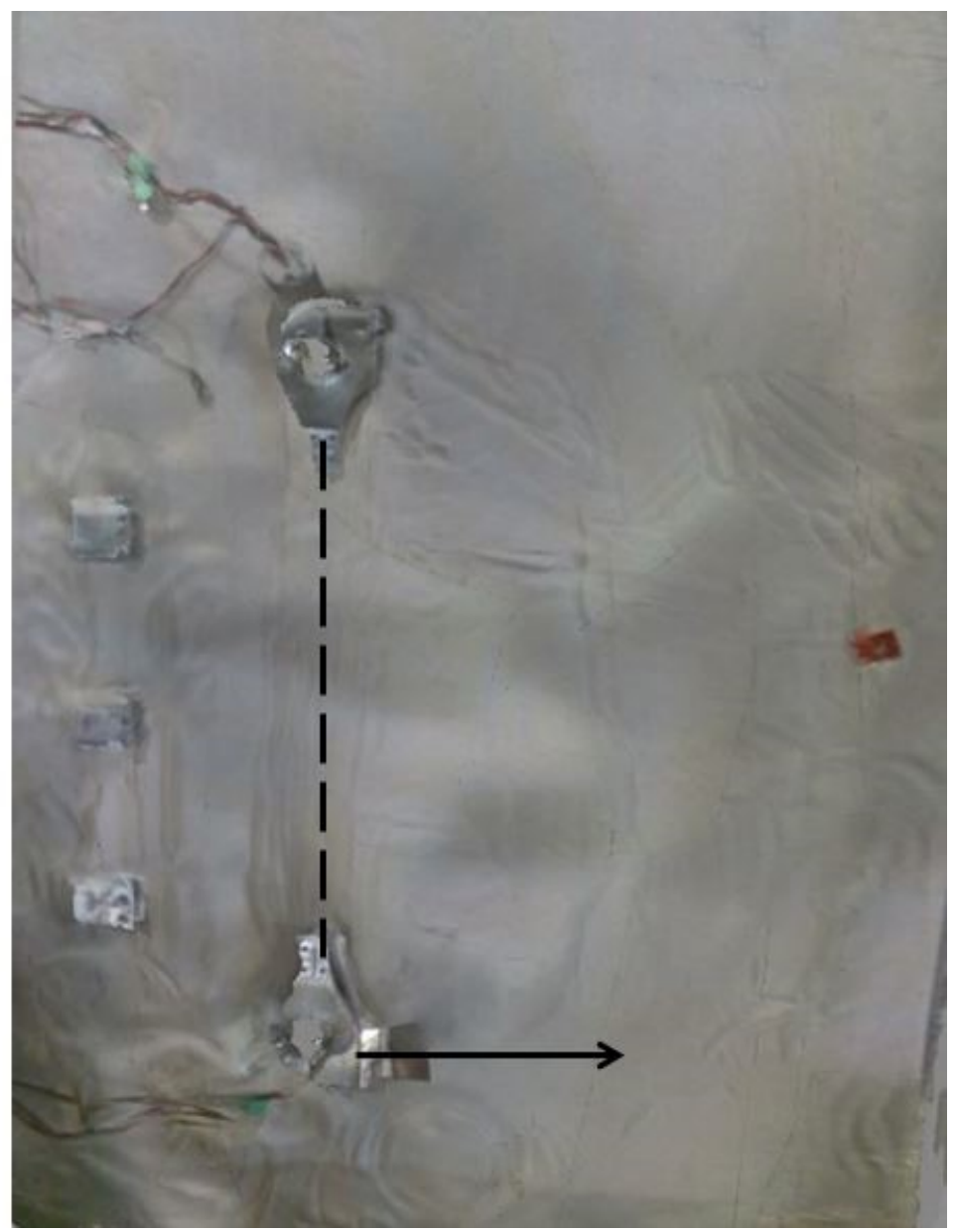

Figure D- 6 - Post-test scan of Test $4\left(90^{\circ}, \mathrm{H} / \mathrm{D}=2\right.$, with foam, $\left.6.5 \mathrm{~g}\right)$

The arrow shows the direction of motion. The dashed line shows pipe alignment. 


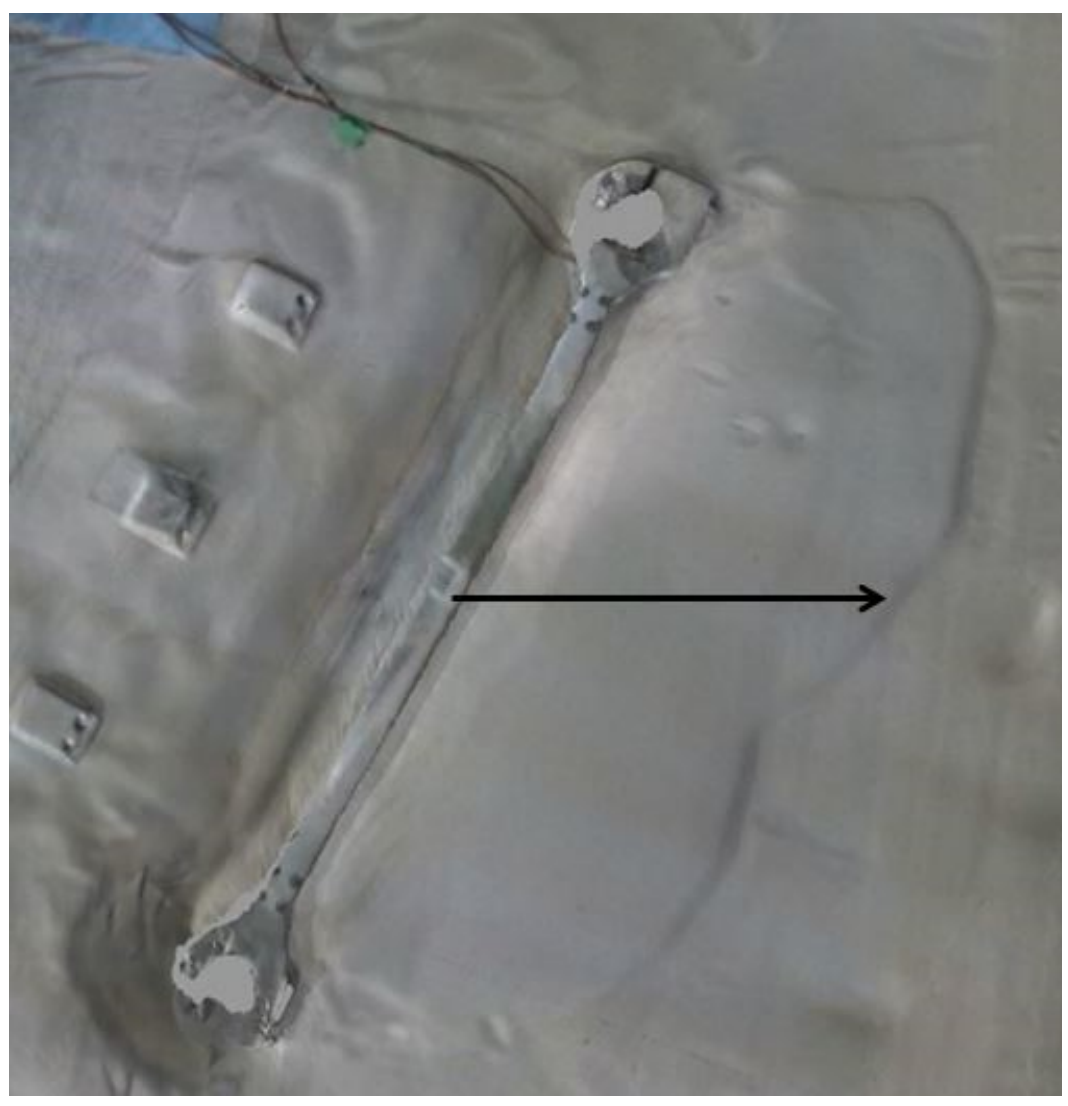

Figure D- 7 - Post-test scan of Test $5\left(20^{\circ}, \mathrm{H} / \mathrm{D}=2,6.5 \mathrm{~g}\right)$

The arrow shows direction of movement 


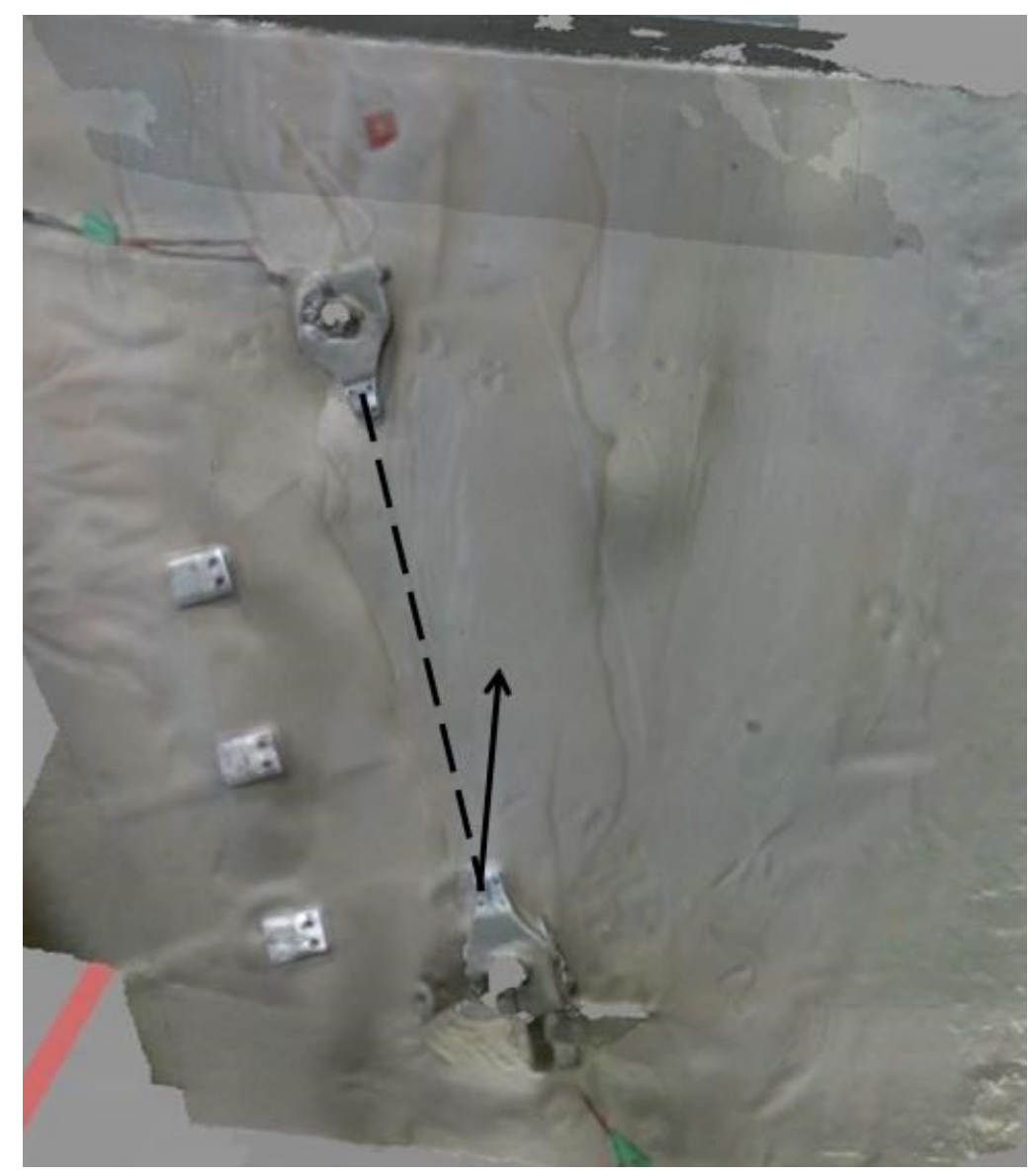

Figure D- 8 - Post-test scan of Test $6\left(70^{\circ}, \mathrm{H} / \mathrm{D}=4,6.5 \mathrm{~g}\right)$

The arrow show direction of movement. The dashed line shows pipe alignment. 

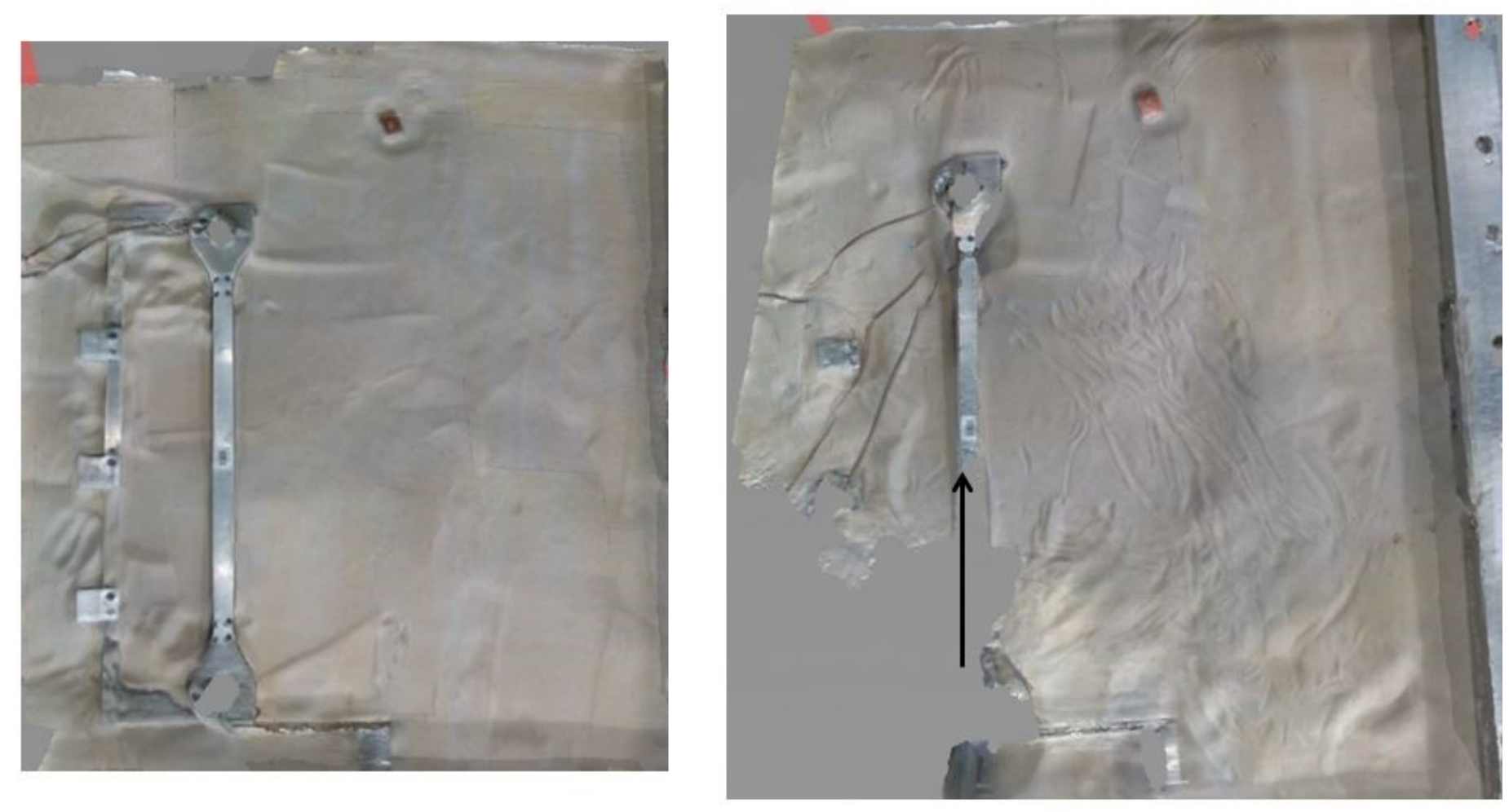

Figure D- 9 - Pre-test (right) and post-test (left) scans for Test $7\left(0^{\circ}, \mathrm{H} / \mathrm{D}=4,13.25 \mathrm{~g}\right)$ The arrow shows the direction of movement. 

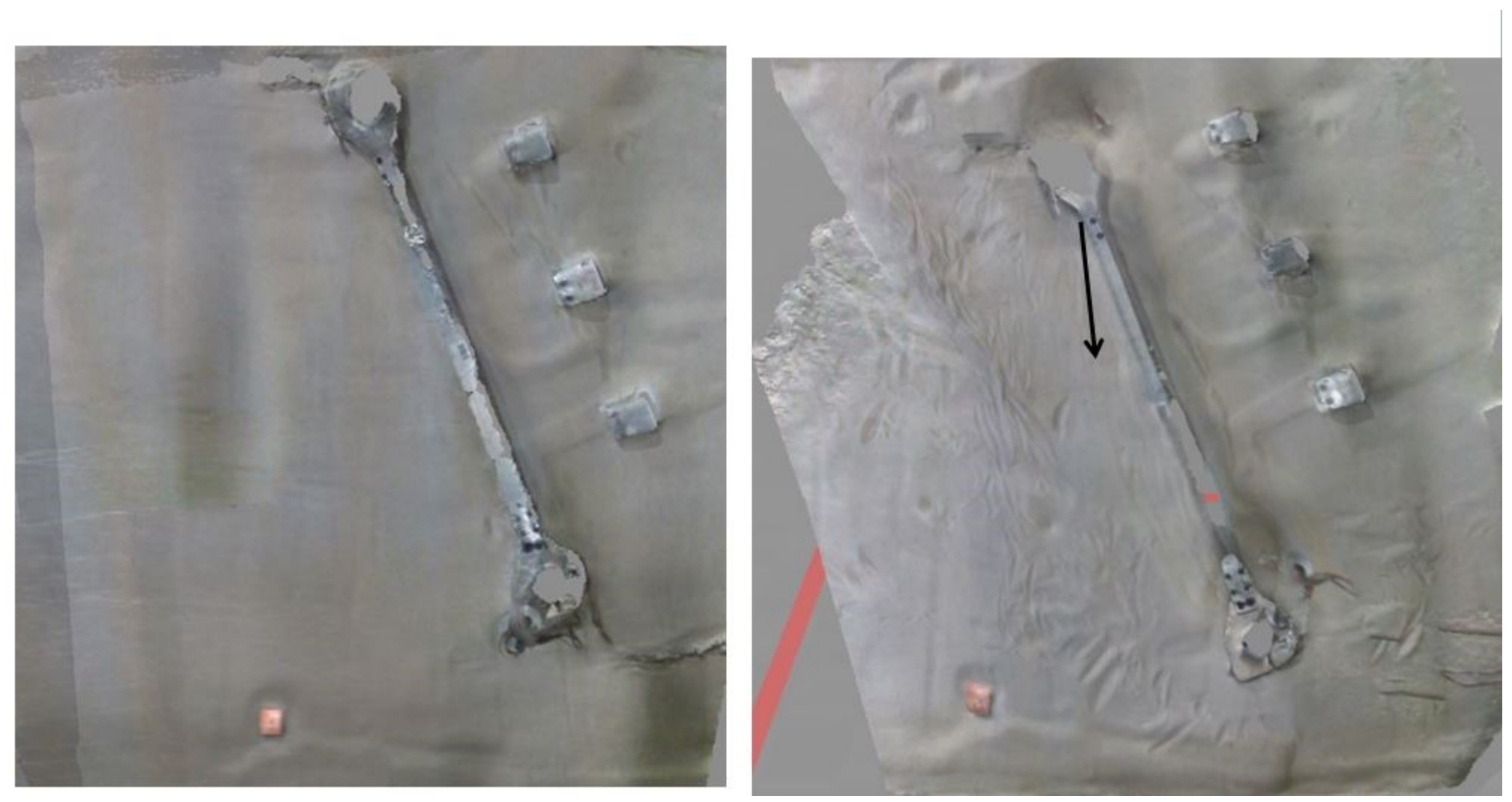

Figure D- 10 - Pre-test (right) and Post-test (left) scans of Test $8\left(20^{\circ}, H / D=4,13.25 \mathrm{~g}\right)$ The arrow shows the direction of movement. 

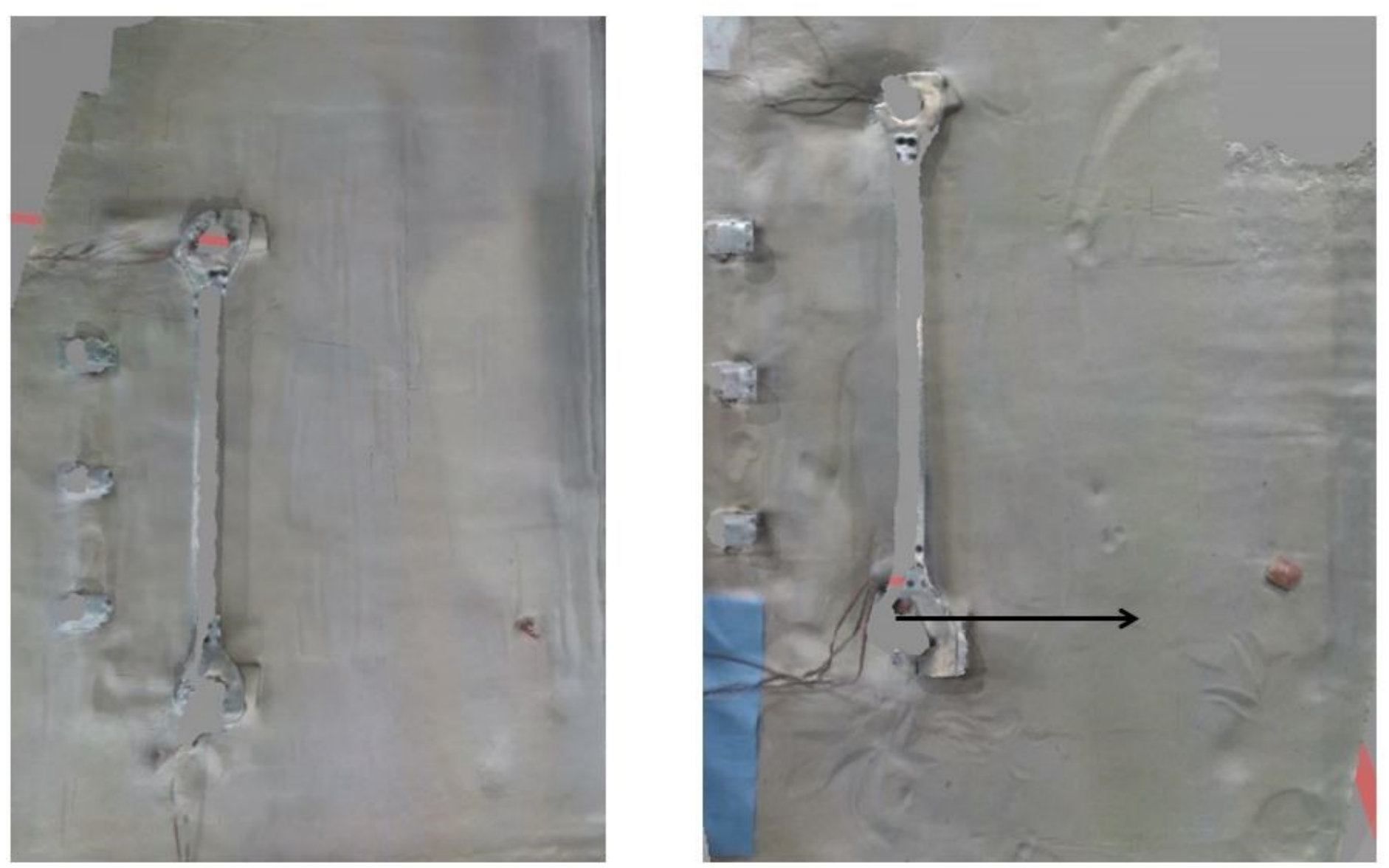

Figure D- 11 - Pre-test (right) and Post-test (left) scans of test $9\left(90^{\circ}, \mathrm{H} / \mathrm{D}=4,13.25 \mathrm{~g}\right)$ Arrow shows direction of movement 

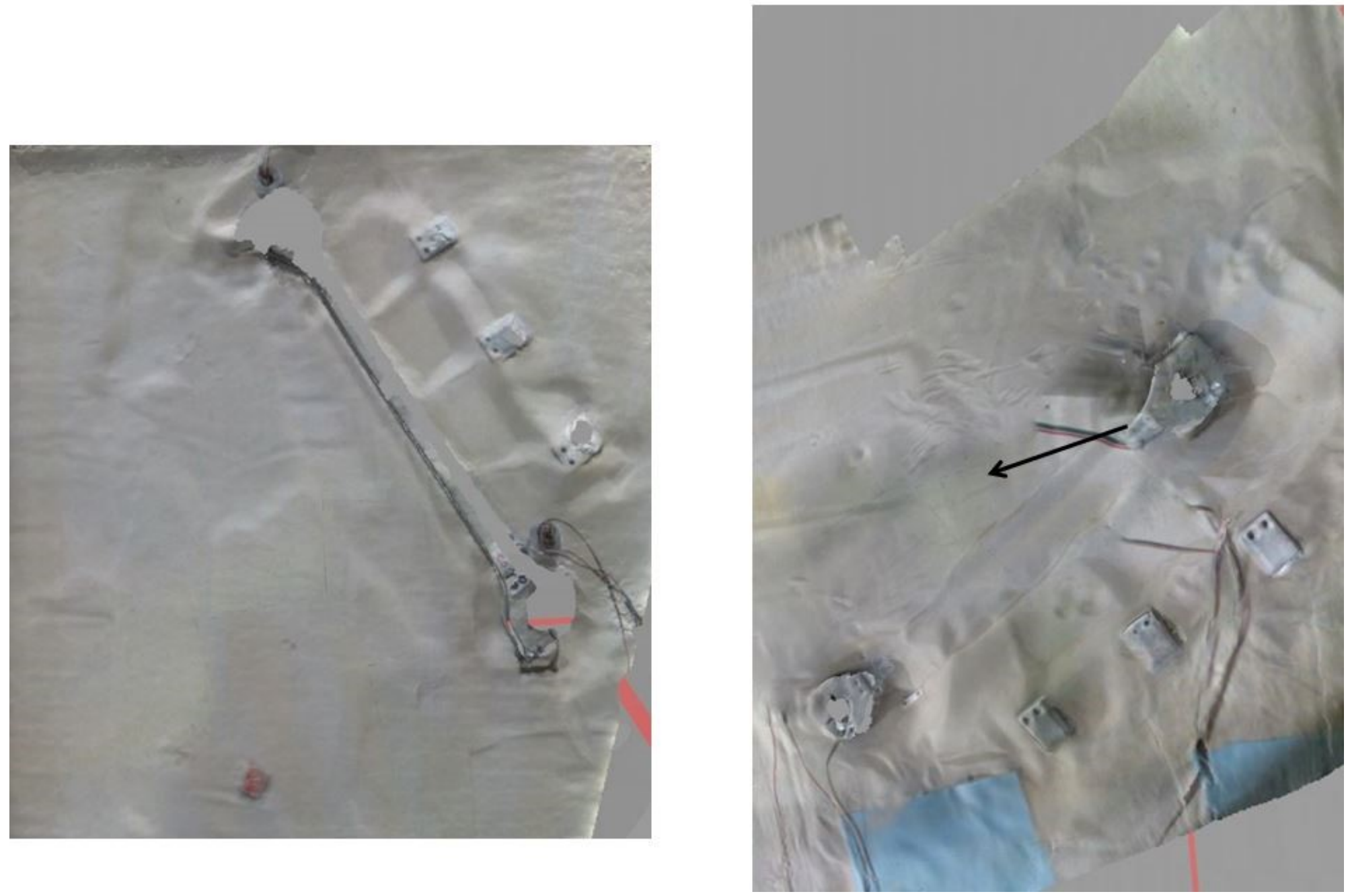

Figure D- 12 - Pre-test (right) and Post-test scan of test $10\left(30^{\circ}, \mathrm{H} / \mathrm{D}=4,13.25 \mathrm{~g}\right)$ The arrow shows the direction of movement. 
Appendix E - Geo-Ottawa 2017 Paper 


\title{
Centrifuge Modeling of Lateral-Axial Oblique Loading on Buried Pipelines in Cohesionless Soil
}

\author{
G. Marcotte, S. Kenny, S. Sivathayalan \\ Department. of Civil and Environmental Engineering, Carleton University, Ottawa, \\ Ontario
}

\begin{abstract}
Pipelines may be subject to oblique loading conditions due to relative ground motion associated with geohazards including ground subsidence, slope stability, frost heave and fault movement. Conventional guidelines for engineering stress analysis of pipe/soil interaction employ a series of orthogonal, independent springs, within structural based finite element modelling procedures, to represent soil reaction loads. This formulation cannot account for load effects during oblique pipe/soil interaction events. A series of reduced scale physical tests to investigate oblique load effects, in the lateral-axial plane, on a buried pipe in cohesionless soil were conducted in the C-CORE geotechnical centrifuge facility.
\end{abstract}

A $46 \mathrm{~mm}$ diameter pipe was buried with a spring line cover depth of 2, and 4 pipe diameters was subject to an acceleration field of $6.25 \mathrm{~g}$ and $13.25 \mathrm{~g}$, respectively. The shallow pipe modeled a $304 \mathrm{~mm}$ pipeline and was tested at angles of $0,20,50,70$, and 90 degrees within lateral axial plane. The deeper pipe modeled a $609.5 \mathrm{~mm}$ pipeline and was tested at angles of $0,20,30$ and 90 degrees. The imposed relative pipe/soil motion was sufficient to extend beyond peak loading conditions. A biaxial load cell measured the soil reaction loads relative to the pipe longitudinal and transverse horizontal (i.e. lateral bearing) axis. Failure surfaces for the yield load and mobilization distances were established and compared with other physical tests and numerical simulations of oblique loading events. Observations on potential scale effects in the centrifuge tests and guidance on numerical models simulating oblique loading events are discussed.

\section{RÉSUMÉ}

Les pipelines peuvent être soumis à des conditions de chargement obliques en raison d'un mouvement relatif du sol associé à des risques géotechnique. Les risques peuvent inclure l'affaissement au sol, la stabilité de la pente, l'accélération du gel et le mouvement des failles. Les directives conventionnelles pour l'analyse de contraintes techniques de l'interaction entre les tuyaux et les sols utilisent une série de ressorts orthogonaux et indépendants, dans les procédures de modélisation des éléments finis basés sur les structures, pour représenter les charges de réaction des sols. Cette formulation ne peut pas tenir compte des effets de charge lors d'événements d'interaction obliques entre la pipe et le sol. Une série de tests physiques à échelle réduite pour étudier les effets de charge obliques, dans le plan axial latéral, sur un tuyau enterré dans un sol sans cohésion a été réalisé dans la centrale de centrifugation géotechnique C-CORE.

Un tuyau de $46 \mathrm{~mm}$ de diamètre a été enterré avec une profondeur de couverture de ligne de ressort de 2 et 4 diamètres de tuyaux et ont été soumis respectivement à un champ d'accélération de $6,25 \mathrm{~g}$ et 13,25 $\mathrm{g}$. La conduite moins profonde a modelé une canalisation de $304 \mathrm{~mm}$ et a été testée à des angles de 0, 20,50, 70 et 90 degrés dans le plan axial latéral. La conduite plus profonde a modelé un pipeline de $609,5 \mathrm{~mm}$ et a été testée à des angles de $0,20,30$ et 90 degrés. Le mouvement relatif des conduites / sols imposé était suffisant pour s'étendre au-delà des conditions de chargement maximales. Une cellule de charge biaxiale mesurait les charges de réaction du sol par rapport à l'axe longitudinal et horizontal transversal (c'est-à-dire le roulement latéral). Les surfaces de décharge pour la charge de rendement et les distances de mobilisation ont été établies et comparées à d'autres tests physiques et des simulations numériques d'événements de chargement obliques. Les observations sur les effets potentiels de l'échelle dans les tests de centrifugation et les conseils sur les modèles numériques simulant les événements de chargement obliques sont discutées 


\section{INTRODUCTION}

With an estimated $852,000 \mathrm{~km}$ of pipelines crisscrossing Canada, pipelines are one of the most effective methods to transport liquids and gases over long distances (NRCan, 2014). To minimize the effect and damage caused by external influences including weathering, traffic, snow, waves and currents, the majority of pipelines are buried.

Though burying pipelines offers additional protection, the buried pipelines can be subject to large deformations, stresses, and loads. These loads can be caused by various geotechnical hazards including subsidence, liquefaction, unstable slopes, and freeze/thaw settlement and can damage the pipelines. Damaged pipelines may not be able to meet the operation and serviceability required and in time may fail. A pipeline failure can cause extensive damage to the environment, the reputation of the company, and lost revenue to the company and supporting sectors. To help minimize the possibility of pipeline failures, a better understanding of the complex relationship between the pipeline and the surrounding soil needs to be achieved.

Current design guidelines for pipe-soil interaction, including those provided by the American Lifeline Association (ALA), are used as the basis to form engineering models. The models can then be used to analyze the stresses created during geotechnical events to determine the mechanical behaviour of the pipeline including if failure will occur. A typical model used is called the Winkler-type model and uses the following major assumptions:

- The pipeline is treated as a rigid structural element based on beam theory which takes into account internal pressure and thermal expansion.

- The soil response is modeled using springs elements. A distributed geotechnical load is shown by placing three springs along each unit length. Traditionally three springs are placed in mutually exclusive axis relative to the pipe cross-section. For this research, the three axes are stated as axial, lateral, and vertical directions.

- $\quad$ Each soil spring element is uncoupled and acts independently. Generally, bilinear or hyperbolic functions are used to determine the relationship between the soil yield load and the yield displacement.

These models, including the Winkler-type model, are fairly accurate for simple cases including straight pipelines buried at a shallow depth in homogenous noncohesive soils with loading along a single axis. In more complex situations, for example where the soil is not homogenous, there is a large expected deformation or when the loading/ pipeline deformation is along more than one axis; the models do not match the measured results from full-sized field tests, and centrifuge models (Rossiter, 2012).

The limitations and uncertainty of the existing models can be reduced by completing additional physical models to confirm the scaling laws and soil behaviour. Due to the cost and time required to complete full-scale model tests, a series of ten reducedscale centrifuge tests were completed at the C-Core testing facility is St. John's, Newfoundland. The tests included axial, lateral, and oblique tests. The angle of the pipe is measured off of the direction of motion of the pipe as shown below in Figure 1. This paper will discuss the results of those tests.

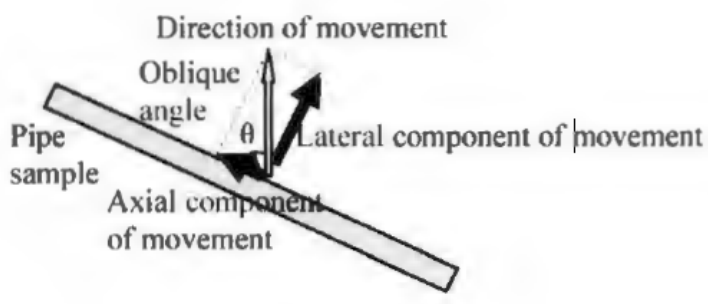

Figure 1 Axial-Lateral oblique angle (from Nasser, 2013)

\section{CENTRIFUGE MODEL}

During the fall of 2016, a series of ten reduced scale centrifuges tests were completed at the C-Core facility. These tests were completed to provide confirmation of the assumptions used within finite element models that have been proposed in previous research (Daiyan, 2013; Daiyan et al., 2011; Debnath, 2015; Burnett, 2015).

A rigid pipe was buried at a springline cover depth of 2 and 4 pipe diameters and was pulled through a prepared soil bed of loose cohesionless soil at various angles. The load-displacement response, pipe-soil response, soil failure mechanism, and strain localization are able to be examined during the tests. Loadcells, linear variable displacement transformers (LVDTs), lasers, and a cone penetration test (CPT) were used to monitor the pipe and soil's behaviour during the testing. The loadcells, LVDTS and lasers were all calibrated before testing began to ensure the accuracy of the readings.

Centrifuge modeling using scaling laws and the laws of similitude to reduce the size of the sample and time required to complete the physical modeling tests (e.g. Craig, 1995; Garnier et al., 2007; Gaudin et al., 2016). This is done by increasing the effects of gravitational acceleration subjected to the test bed and pipe assembly or payload. The scaling laws used for these tests are found in the table below. (Taylor, 1995)

\begin{tabular}{ll} 
Parameter & $\begin{array}{r}\text { (Prototyp } \\
\text { at }\end{array}$ \\
\hline Length & $1: 1 / \mathrm{N}$ \\
Stress & $1: 1$ \\
Strain & $1: 1$ \\
Density & $1: 1$ \\
Unit Weight & $1: \mathrm{N}$ \\
Force & $1: 1 / \mathrm{N}^{2}$
\end{tabular}


The sub-sections below will discuss the apparatus and testing methodology in more detail used for this set of centrifuge models.

\subsection{Testing Apparatus and Instrumentation}

The testing apparatus and instrumentation used for this series of reduced scaled models were similar to those used by Debnath and Daiyan. As shown in Figure 2 below, the pipe assembly included a $46 \mathrm{~mm}$ diameter hollow pipe (1) with two bi-axial loadcell $(2,3)$ which were used to measure the axial and lateral loads during the tests. Previous tests conducted by Daiyan used a $41 \mathrm{~mm}$ which was heavier (Daiyan, 2013). A slightly larger, lighter pipe was used in subsequent research to minimize any downward movement of the pipe during the acceleration of the payload during testing. The pipe was pulled through the prepared soil bed by vertical stanchions $(4,5)$ and braced horizontally by a 'dog bone' piece (6). For the last two tests, which were completed at a deeper burial depth and therefore subjected to a higher load, two dog bones were used to help stiffen the assembly and to keep the stanchion in place. The two dog bone assembly (6) is shown in Figure 3 below. Two pieces of crushable acoustic foam were placed in front of the stanchions according to the direction of motion of the pipe, to limit the effect of the stanchions during pipeline mobilization. The stanchions moved into the foam during testing.

During the preparation of the soil bed, the centrepiece of the dog bone was removed, and the back bracket (7) was used to hold the pipe in place and at the correct angle. This was to ensure that the dog bone did not affect the density of the sand above the pipe during the sand raining process. Once the soil bed preparation was completed, the centrepiece of the dog bone was screwed into place, and the bracket was removed for testing.

As shown in Figure 3 below, each stanchion was placed through an opening in the ball race $(7,8)$. The ball race acts as a sleeve for the stanchions and allows for vertical movement of the pipe assembly. The ball races are then attached to a guiding plate which is attached to the motorized carriage which is used to pull the pipe through the soil at an approximate speed of 1 $\mathrm{mm} / \mathrm{sec}$.

The instrumentation used to monitor the behaviour of the soil and of the pipeline included an LVDT at each end of the dog bone (9) to monitor the vertical displacement of the pipe assembly, an LVDT in the corner of the soil bed to determine the settlement of the soil due to the acceleration of the payload, a laser to measure the horizontal displacement of the motor carriage (12), and a laser to measure the horizontal displacement of the pipe assembly. A cone (13) for a cone penetration test was also completed once the prepared sample reached the required acceleration for the test and before the mobilization of the pipe started. The CPT tests were completed to confirm that the density of the soil bed remained similar for each test.

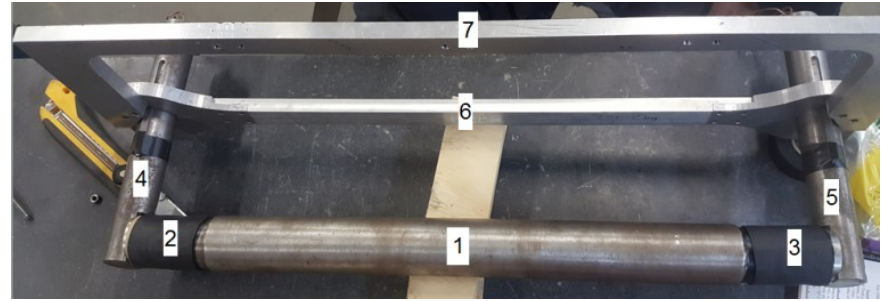

Figure 2 Pipe assembly (1) including biaxial load cell (2, $3)$, stanchions $(4,5)$, dog bone (6), and back bracket $(7)$.

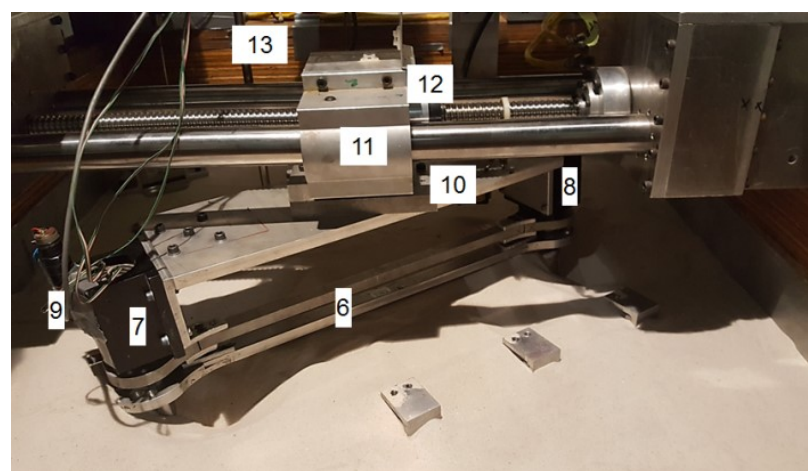

Figure 3 Major elements of the centrifuge test apparatus ('payload') including dog bone $(6)$, ball race $(7,8)$, LVDT (9), guiding plate (10), motorized carriage (11), laser (12), and cone (13).

\subsection{Testing Methodology and Parameters}

For all of the ten tests, a loose, dry test bed of finegrained silica sand was used. Sieve analysis and direct shear box tests were completed on samples of the sand to determine their properties. As shown below in Table 1 , the soil parameters used for these tests were similar to those used by Debnath for testing in loose sands (Kenny et al., 2015). All of the centrifuge tests completed by Daiyan were completed in dense, finegrained silica sand with similar soil parameters.

Direct shear tests were conducted by Marcotte (2017), and Debnath (2015). Triaxial tests were conducted by Daiyan to determine the soil parameters.

Table 1 Soil test bed parameters

\begin{tabular}{lllll}
\hline & \multicolumn{3}{c}{ Value } \\
\cline { 2 - 5 } Parameter & $\begin{array}{c}\text { Marcotte } \\
(2017)\end{array}$ & $\begin{array}{c}\text { Debnath } \\
(2015)\end{array}$ & $\begin{array}{l}\text { Daiyan } \\
(2013)\end{array}$ \\
\hline $\begin{array}{l}\text { Average particle size, } \\
(\mathrm{mm})\end{array}$ & $\mathrm{d}_{50}$ & 0.21 & 0.22 & $\mathrm{~N} / \mathrm{A}$ \\
Peak friction angle $\left({ }^{\circ}\right)$ & 38 & 40 & 47 \\
Average dry density $\left(\mathrm{kg} / \mathrm{m}^{3}\right)$ & 1455 & 1467 & $\begin{array}{l}1598 \\
(\text { dense) }\end{array}$ \\
Relative Density $(\%)$ & 32 & 33 & $\begin{array}{l}82 \\
(\text { dense) }\end{array}$ \\
\hline
\end{tabular}

For all ten of the completed tests, the sand was rained into the strongbox at a constant speed from a 
specified height. A bedding layer of $100 \mathrm{~mm}$ (2.4D) was used for each test to ensure the bottom of the strong box did not affect the results of the test. The initial and final location of the pipe was also never closer than 2.5 $D$ to ensure that the sides of the strong box did not affect the test results. By placing the pipe in this way, the pipe can be modeled as though it is a continuous layer of homogeneous soil.

Six tests were completed at a shallow burial depth of $2 \mathrm{D}$ at springline. This was the same depth that was modeled by Debnath and Daiyan. Daiyan and Debnath used an acceleration field of $12.3 \mathrm{~g}$ and $13.25 \mathrm{~g}$, respectively while these tests were modeled at $6.25 \mathrm{~g}$ (Kenny, 2015). The acceleration of $6.25 \mathrm{~g}$ with a $46 \mathrm{~mm}$ pipe corresponds to a pipeline that would be $304 \mathrm{~mm}$ in diameter if a full-scale test was conducted. The shallow pipe was modeled at the following angles: 0 (pure axial), $20,50,70$, and 90 (pure lateral) degrees within lateral axial plane. One shallow lateral test was completed with crushable foam in front of the leading stanchion, and one lateral test was completed without the crushable foam. The loadcell during the 20-degree test failed, and the axial and later yield loads were not determined.

Four tests were completed at springline burial depth of 4 pipe diameter and acceleration of $13.25 \mathrm{~g}$. This is the deepest that the pipe can be buried using the existing strong box. The deeper pipe modeled a 609.5 $\mathrm{mm}$ pipeline and was tested at angles of $0,20,30$ and 90 degrees. Crushable foam was placed in front of the stanchions for all four of the tests. Neither Daiyan nor Debnath had completed tests at this depth. The deeper burial depth allows for a higher confining pressure on the pipe and the data obtained will be used at a later date to confirm the scaling factors and finite element analysis previously proposed.

Table 2 Centrifuge strongbox and pipe model parameters

\begin{tabular}{|c|c|c|}
\hline \multirow{2}{*}{ Parameter } & \multicolumn{2}{|c|}{ Value } \\
\hline & Shallow Tests & Deep Tests \\
\hline Acceleration field, $\mathrm{g}$ & 6.25 & 13.25 \\
\hline Pipe diameter (mm) & \multicolumn{2}{|c|}{41} \\
\hline $\begin{array}{l}\text { Centrifuge strong box }(\mathrm{mm} \times \\
\mathrm{mm} \times \mathrm{mm})\end{array}$ & \multicolumn{2}{|c|}{$1180 \times 940 \times 400$} \\
\hline $\begin{array}{l}\text { Pipe length to diameter ratio, } \\
\text { L/D (\#) }\end{array}$ & \multicolumn{2}{|c|}{8} \\
\hline $\begin{array}{l}\text { Pipe burial depth at springline } \\
\text { to diameter ratio, } H / D(\#)\end{array}$ & \multicolumn{2}{|c|}{4} \\
\hline $\begin{array}{l}\text { Modeled pipeline diameter } \\
(\mathrm{mm})\end{array}$ & \multicolumn{2}{|r|}{609.5} \\
\hline
\end{tabular}

To help confirm the finite element models based on this series of tests, which will complete at a later date, the pipe was loaded and then unloaded several times. This cyclical loading will allow for better verification of the inputted soil properties by providing information on the elastic behaviour of the soil (Daiyan, 2013). During each test, the pipe was pulled forward for approximate 0.3 pipe diameter (0.3D) and then returned to its start position. The pipe was then moved to $0.6 \mathrm{D}$, returned to $0.3 \mathrm{D}$ and the mobilized to its full mobilization length. For the shallow tests, the pipe was mobilized a total of 1.0 to 1.2 pipe diameter. For the deep tests, the pipe was mobilized to a total of approximately $2.2 \mathrm{D}$. The total displacement distance was determined by comparing the results of the previous research of Daiyan and Debnath and the ALA guidelines. The ultimate yield displacement proposed in the ALA guidelines is $0.1 \mathrm{D}$ for cohesionless soils and $0.2 \mathrm{D}$ for cohesive soils (Kenny and Jukes, 2015). The research previously completed determined that the ultimate yield displacement required in centrifuge testing is closer to 1 to 1.1D. With the increased confining pressure on the pipe during the deep tests, it was assumed that an increase in the overall displacement of the pipe would be required since the ultimate yield displacement was expected to be higher. The total mobilization distance was measured using the motorized carriage and confirmed with the laser measurements from the guiding plate and from the dog bone.

It should be noted that the horizontal distance measured by both lasers did not match. This was caused by the resistance of the soil on the pipe which impeded the movement of the pipe and causes a rotation of the pipe assembly. Nasser (2013) proposed a displacement correction equation of:

$\mathrm{d}_{\text {pipe }}=\mathrm{d}_{\text {guiding plate }}-1.5\left(\mathrm{~d}_{\text {dog bone }}-\mathrm{d}_{\text {guiding plate }}\right)$

This equation was based on the results of a series of inair tests where lateral and axial loads were applied to the pipe to mimic the soil loads. The equation proposed by Nasser was deemed too conservative for the loose sand beds since the difference in horizontal measurements in the shallow tests did not exceed $5 \mathrm{~mm}$ and did not exceed $10 \mathrm{~mm}$ for the deep tests. A correction value of 1.1 for shallow tests and 1.25 for the deeper tests would be more accurate for the loose soil. A stiffer pipe assembly may minimize the requirements of a displacement correction equation since it would reduce the amount of rotation felt by the stanchions.

\section{TEST RESULTS}

The real lateral and axial loads were measured using a load cell on either side of the pipe. All of the load results were normalized to ensure that they can be accurately compared to existing results. The normalized load was defined as the real force per unit length divided by the unit weight of the soil, the springline burial depth, and the pipe diameter. The real mobilization distance was divided by the pipe diameter to provide a normalized horizontal mobilization

The subsections below will discuss the results of the testing completed during the fall of 2016 at the C-Core facility. The results will also be compared to existing data sets.

\subsection{Axial Pipe/Soil Interaction}


The axial test results from the deep, and the shallow tests were analyzed and compared to existing data including data from Daiyan (2013), Debnath (2015), and Hsu et al. (2001 and 2006).

The normalized axial yield force for the shallow test was $5.4 \mathrm{~N}$ with a normalized mobilization distance of $0.1 \mathrm{D}$. The normalized axial yield displacement matches the expected ALA values, but the yield force is substantially higher than specified by the ALA. As shown in the figure below, the axial yield force does fall within the range of Schaminee et al. proposed in 1990.

The normalized axial yield force for the deep test was calculated to be $23 \mathrm{~N}$ with a normalized yield displacement of $0.15 \mathrm{D}$. The yield displacement does fall within ALA's expected values, but the yield force is substantially higher than expected. This change in values may be due to errors in assumptions used while scaling the test and to the extra confining pressure caused by the additional soil above the pipe. The pipe assembly itself including the dog bone and guiding plate deflected during testing which may have decreased the accuracy of the readings.

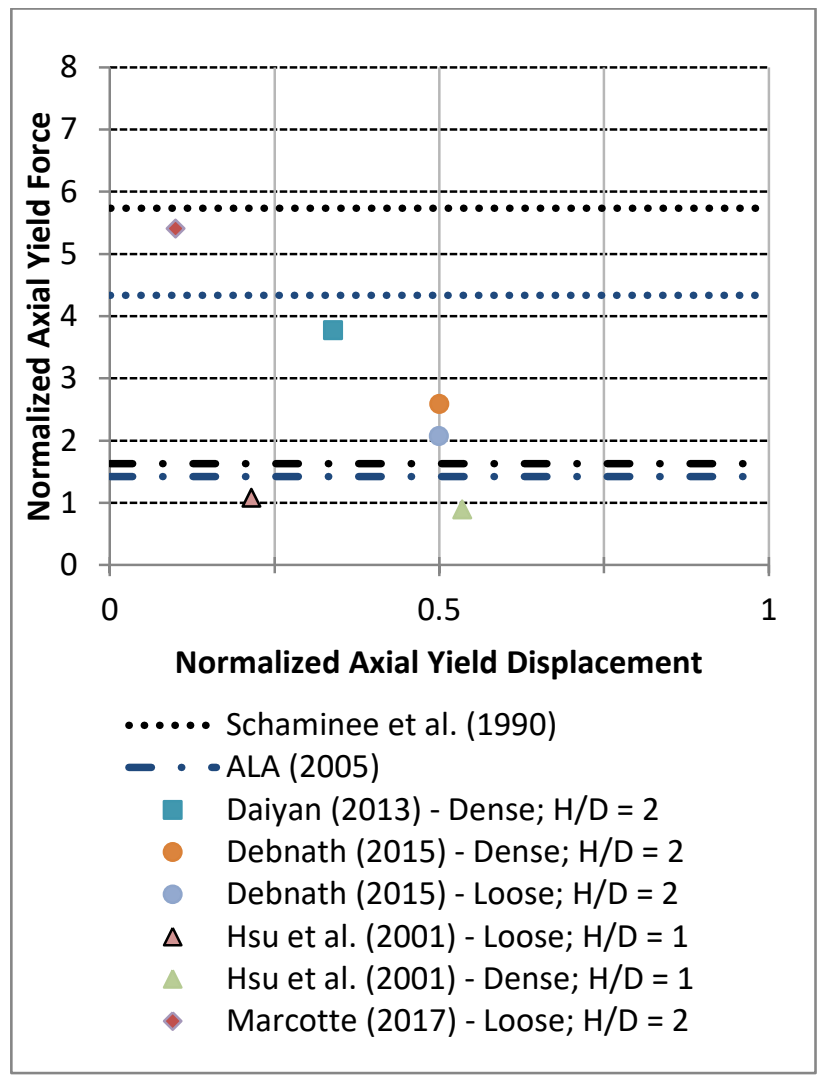

Figure 3 Normalized Axial Yield Displacement vs Axial Yield Force for Axial Pipe/Soil Interaction

\subsection{Oblique Pipe/Soil Interaction}

The axial and lateral loads during the oblique and lateral tests were also measured using load cells. During the 20 degree shallow test, the loadcells failed, and the axial and lateral yield forces were not determined. During the 30 degree deep test, the forces on the pipe assembly were too high, and the actuator was unable to mobilize the pipe to the required horizontal displacement. The yield forces were not able to be calculated for that test either.

The normalized axial and lateral yield forces for the shallow tests are similar to the previous reduced scaled results. Not all of the test results fall within the pipe/soil interface failure mechanism was determined by Daiyan (2013). The pipe/soil interface mechanism requires refinement if it is to match the existing test results. Two 90 degree test were completed at the shallow depth, one with crushable foam and one without crushable foam. The crushable foam reduced the lateral loads which indicated that the foam was able to reduce the effect of the stanchions on the loadcells.

All of the yield loads determined for the deep tests are higher than expected including the pure lateral and pure axial tests. This is most likely caused by the increased rotation of the pipe assembly during mobilization. The rotation created a rotational load or moment at the load cell which changes the boundary condition of the pipe.

As shown in the figure below, the testing results for both the shallow and deep tests are much larger than the results of the full-scale tests completed by Hsu et al. (2001 and 2006). The tests process, testing parameters, and procedures are similar for reduced and full-scale tests, but the soil/pipe behaviour do not match. The differences in results are most likely caused by the difference in boundary conditions and axial/lateral coupling behaviour between the full and reduced scale tests. There may also be an incorrect assumption made during the scaling of the centrifuge tests. The testing results for the shallow tests are similar to the results from previous finite element simulations that have been completed by other researchers including Daiyan, 2013; Daiyan et al., 2011; Phillips et al., 2004a; Pike and Kenny, 2012a, b). 


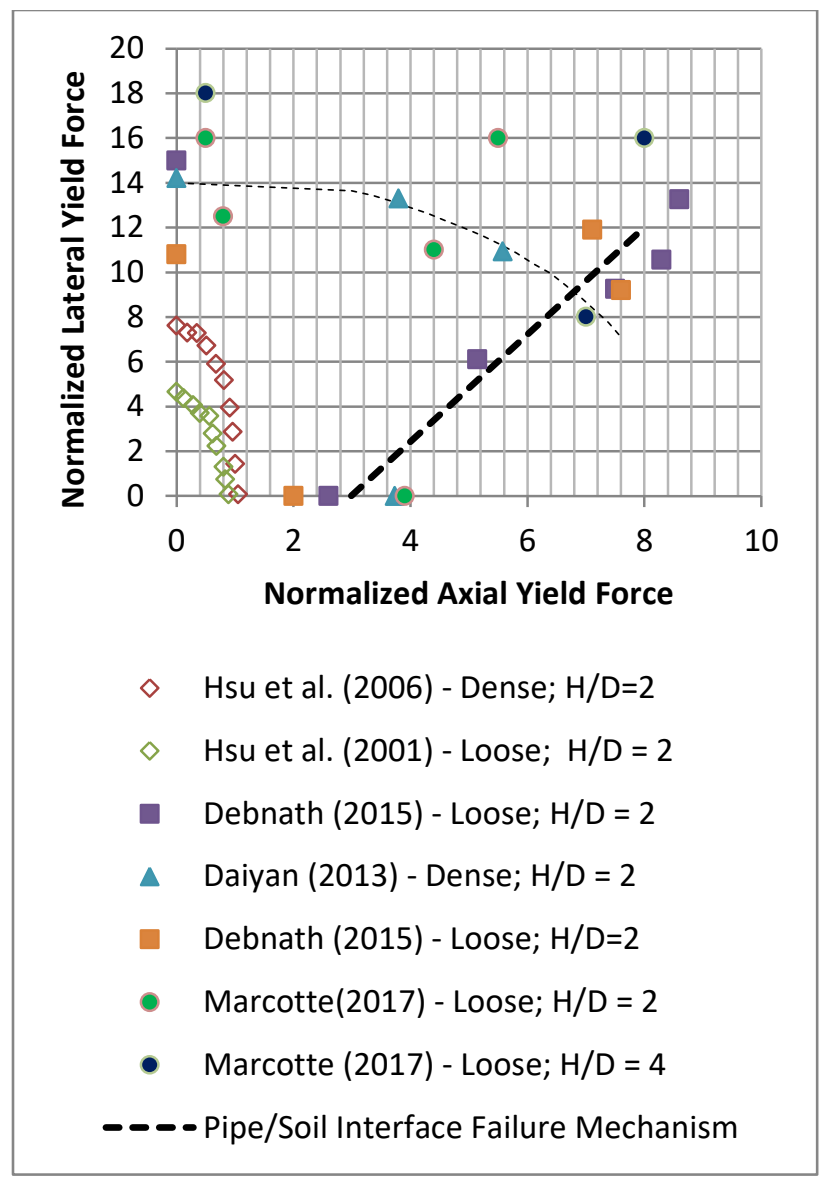

Figure 4 Normalized Axial Yield Force vs Normalized Lateral Yield Force

\section{FUTURE RESEARCH}

Additional research must be conducted to confirm further the assumptions made during previous finite element analysis and during previous research. The results of the full and reduced scale models still do not agree which means further research should be conducted to confirm that the correct boundary condition and scaling factors are being applied. The results from the ten tests completed this fall should also be compared to a finite element simulation to confirm that the testing procedures and parameters are accurate. The finite element simulations can also be used to confirm the axial-oblique loading coupling that seems to occur during oblique reduced-scale tests.

Future reduce scaled tests should also be conducted at different burial depths and speeds. These tests can be used to further validate the scaling laws and testing procedures. Before additional reduce scaled are conducted, the pipe assembly would require reinforcement to help minimize the rotation of the stanchions during mobilization.

\section{CONCLUSIONS}

A series of ten reduced-scale tests were completed to help confirm the assumptions used in previous research. The procedure and testing parameters used for the tests is discussed above. The shallow tests $(H / D=2)$ results were similar to the test results of previous reduced scale oblique tests that have been completed at the C-Core facility. The deep tests $(h / D=4)$ results were substantially higher than expected. The increase in measured loads during the deep tests was most likely caused by the rotation of the pipe assembly during loading. Further research should be conducted to confirm this and to further refine the pipeline guidelines.

\section{BIBLIOGRAPHY}

ALA 2005. Guidelines for the design of buried steel pipes. American Lifelines Alliance, 76p.

Burnett, A. 2015. Investigation of full-scale horizontal pipe-soil interaction and large strain behaviour of sand. M.A.Sc. Thesis, Queen'sUniversity, 118p.

Craig, W.H. 1995. Geotechnical centrifuge: Past, present and future. Geotechnical Centrifuge Technology, pp.1-18.

Daiyan, N. 2013. InvestigatingSoil/Pipeline Interaction During Oblique Relative Movements. PhD Thesis, MemorialUniversity of Newfoundland, 204p.

Daiyan, N., Kenny, S., Phillips, R. and Popescu, R. 2011. Investigating pipeline/soil interaction under axial/lateral relative movements in sand. Can. Geotech. J., 48(11): 1683-1695.

Daiyan, N., Kenny, S., Phillips, R. and Popescu, R. 2010. Numerical investigation of oblique pipeline/soil interaction in sand. Proc., IPC2010-31644:6p 
Debnath, P. 2015. Centrifuge modeling of oblique pipe/soil interaction in dense and loosesand.M.Eng. (Thesis), MemorialUniversity of Newfoundland, 120p. (in preparation)

Garnier, J., Gaudin, C., Springman, S.M., et al. 2007. Catalogue of scaling laws and similitude questiosn in geotechnical centrifuge modelling. Int. J. Phy. Mod. Geo., 7(3):1-23.

Gaudin, C., Randolph, M. and White, D. 2016. Centrifuge Modelling in Geotechnics. CRC Press, ISBN 9780415522243, 544p.

Hsu, T.W., Chen, Y.J. and Hung, W.C.2006. Soilrestraint to oblique movement of buried pipes in dense sand." J. Transp. Eng. 132(2):175-181.

Hsu, T.W., Chen, Y.J. and Hung, W.C. 2001. Soil friction restraint of oblique pipelines in loose sand. J. Transp. Eng. 127(1):82-87.

Kenny, S., Jukes, P. 2015. Pipeline/Soil Interaction Modeling in Support of Pipeline Engineering Design and Integrity. John Wiley and Sons

Kenny, S. Pike, K., Debnath, P., and Hawlader, B. 2015. Integrated Framework in Support of Pipeline Engineering Design for Geohazards. Geo Quebec2015 National Research Canada. 2016. 10 Key Facts on Canada's National Resources. NRC

Paulin, M. J., Phillips, R., Clark, J. I., Trigg, A., \&Konuk, I. 1998.Full-scale investigation into pipeline/soil interaction. Proc., CGS:241-248.

Phillips, R., Nobahar, A., and Zhou, J.2004a. Combined axial and lateral pipe-soil interaction relationships. Proc., IPC-0144:5p.

Phillips, R., Nobahar, A., and Zhou, J.2004b. trench effects on pipe-soil interaction. Proc., IPC-0141:7p.

Pike, K.P. and Kenny, S.P. 2012a. Lateral-axial pipe/soil interaction events: Numerical modeling trends and technical issues. Proc., IPC-90055:6p.

Rossiter, C. and Kenny, S. 2012. Evaluation of lateralvertical pipe/soil interaction in clay. Proc., OTC23735:13p.

Schaminee, P. E. L., Zorn, N. F., \&Schotman, G. J. M. 1990. Soil response for pipeline upheaval buckling analyses: Full-scale laboratory tests and modelling. Proc., OTC-6486:563-572. 